This is a post-peer-review, pre-copyedit version of an article published in: Archaeological and Anthropological Sciences

Arrighi, S., Marciani, G., Rossini, M., Pereira Santos, M. C., Fiorini, A., Martini, I., Aureli, D., Badino, F., Bortolini' E., Figus, C., Lugli, F., Oxilia, G., Romandini, M., Silvestrini, S., Ronchitelli, A., Moroni, M., Benazzi, S., Between the hammerstone and the anvil: bipolar knapping and other percussive activities in the late Mousterian and the Uluzzian of Grotta di Castelcivita (Italy). Archaeol Anthropol Sci 12, 271 (2020)

The final authenticated version is available online at: https://doi.org/10.1007/s12520-020-01216-w 
Simona Arrighi ${ }^{\mathrm{a}, \mathrm{b}, \mathrm{c}^{*}}$, Giulia Marciani ${ }^{\mathrm{a}, \mathrm{b}}$, Matteo Rossini ${ }^{\mathrm{b}, \mathrm{d}}$, Marcos César Pereira Santos ${ }^{\mathrm{e}}$, Andrea Fiorini ${ }^{\mathrm{a}}$, Ivan Martini ${ }^{\mathrm{b}}$, Daniele Aureli $^{\text {b,f }}$, Federica Badino ${ }^{\mathrm{a}, \mathrm{g}}$, Eugenio Bortolini ${ }^{\mathrm{a}}$, Carla Figus ${ }^{\mathrm{a}}$, Federico Lugli ${ }^{\mathrm{a}, \mathrm{h}}$, Gregorio Oxilia ${ }^{\mathrm{a}}$, Matteo Romandini $^{\mathrm{a}, \mathrm{d}}$, Sara Silvestrini ${ }^{\mathrm{a}}$; Annamaria Ronchitelli ${ }^{\mathrm{b}}$, Adriana Moroni ${ }^{\mathrm{b}, \mathrm{c}}$, Stefano Benazzi ${ }^{\mathrm{a}, \mathrm{i}}$

\title{
Between the hammerstone and the anvil. Bipolar knapping and other percussive activities in the late Mousterian and the Uluzzian of Grotta di Castelcivita (Italy)
}

*Corrisponding author

a. Dipartimento di Beni Culturali, Università di Bologna, Ravenna, Italy.

Simona Arrighi: simona.arrighi@unibo.it; Giulia Marciani: giulia.marciani@unibo.it; Andrea Fiorini: andrea.fiorini6@unibo.it; Federica Badino: federica.badino@unibo.it; Eugenio Bortolini: eugenio.bortolini2@unibo.it; Carla Figus: carla.figus3@unibo.it; Federico Lugli: federico.lugli6@unibo.it; Gregorio Oxilia: gregorio.oxilia3@unibo.it; Matteo Romandini: matteo.romandini@unibo.it; Sara Silvestrini: sara.silvestrini6@unibo.it; Stefano Benazzi: stefano.benazzi@unibo.it

b. Dipartimento di Scienze Fisiche, della Terra e dell'Ambiente, Università di Siena, Siena, Italy. Ivan Martini: ivan.martini@unisi.it; Daniele Aureli: danieleaureli1@gmail.com; Annamaria Ronchitelli:

annamaria.ronchitelli@unisi.it; Adriana Moroni: adriana.moroni@unisi.it;

c. Centro Studi sul Quaternario, 52037 Sansepolcro, Italy

d. Dipartimento di Studi Umanistici, Università degli Studi di Ferrara, Ferrara, Italy. Matteo Rossini: matteo.rossini@student.unife.it

e. Núcleo de Estudos Paleoambientais-NEPA, Universidade Estadual do Oeste do Paraná, Francisco Beltrão, Brazil. Marcos César Pereira Santos: marcoscesar.arqueologia@gmail.com

f. UMR 7041 ArScAn Equipe An-TET, Université Parigi Ouest Nanterre La Défense, 92023 Nanterre, France

g. C.N.R, Istituto di Geologia Ambientale e Geoingegneria, Milano, Italy.

h. Dipartimento di Scienze Chimiche e Geologiche, Università di Modena e Reggio Emilia, Modena, Italy

i. Department of Human Evolution, Max Planck Institute for Evolutionary Anthropology, Leipzig, Germany

\begin{abstract}
:
Hammerstones and anvils are among the oldest tools used by hominins to perform a variety of tasks-including knapping activities. The bipolar technique on anvil is well documented in prehistory since the Lower Palaeolithic and is usually considered to be an expedient technique in comparison to other knapping systems. This technique plays a pivotal role in the Uluzzian techno-complex lithic production where it is largely used. In the present study we analyse the anvils and hammerstones recovered in the Mousterian and Uluzzian layers of the site of Castelcivita (Campania region-southern Italy) by a multi-disciplinary approach. Our aim is to investigate the function and functioning of anvils and hammerstones by evaluating the presence and the role of bipolar knapping in these two assemblages. To do this, we
\end{abstract}


integrated techno-functional analysis (sensu Boëda) and use-wear study, by defining each techno-functional unit (transformative and prehensile unities) of anvils and hammerstones and identifying the specific use-wear left by the bipolar technique by means of a dedicated experimental program. The obtained results allowed us to observe different technical behaviours, concerning both the production and the use of hammerstones and anvils, between Mousterian and Uluzzian. Differences were encountered in the selection of raw material (limestone in the Uluzzian, sandstone in the Mousterian), and in the technical way of approaching the tool as well as in the function : the Mousterian anvil was used "as is" for crushing materials, unlike the Uluzzian anvils which were exclusively employed for bipolar knapping, after adapting their original volume. Hammerstones were mainly used as pestles or retouchers in the Mousterian and for direct percussion in knapping activities during the Uluzzian.

Keywords: Uluzzian; Mousterian; hammerstone; anvil; use-wear analysis; techno-functional approach.

\section{Declarations}

\section{Funding}

This project has been realised through funding from the European Research Council (ERC) under the European Union's Horizon 2020 research and innovation programme (grant agreement No 724046 to S. Benazzi) http://www.ercsuccess.eu/.

The sedimentological and stratigraphic analysis at Castelcivita were funded by the National Geographic Society/Exploration Grant Program (grant NGS-61617R-19 to I. Martini).

\section{Conflict of interest}

The authors declare that they have no conflicts of interest.

\section{Availability of data and material (data transparency)}

All relevant data are within the manuscript.

\section{Author contributions}

Conceptualisation, original draft: Simona Arrighi, Giulia Marciani, Matteo Rossini.

Experimental protocol analysis: Simona Arrighi, Matteo Rossini, Giulia Marciani, Marcos César Pereira Santos Use-wear analysis: Simona Arrighi

Techno-functional analysis: Giulia Marciani

Experiment: Marcos César Pereira Santos

Clast morphometry: Matteo Rossini, Ivan Martini

Raw material procurement: Daniele Aureli

\section{RTI: Andrea Fiorini}

Review \& editing: Simona Arrighi, Matteo Rossini, Giulia Marciani, Marcos César Pereira Santos, Adriana Moroni, Annamaria Ronchitelli, Ivan Martini, Andrea Fiorini, Stefano Benazzi, Federica Badino, Eugenio Bortolini, Carla Figus, Federico Lugli, Gregorio Oxilia, Matteo Romandini.

Scientific direction of the research project at Castelcivita: Adriana Moroni and Annamaria Ronchitelli Scientific direction of the ERC research project SUCCESS: Stefano Benazzi 


\section{Introduction}

Hammerstones and anvils are simple but efficient tools. An anvil is a blank with a hard surface on which another object is struck. A hammerstone is a tool that delivers a blow (a sudden impact) to an object. Hammerstones vary in shape, size, and structure, depending on their purpose.

Hammerstones and anvils were among the oldest tools used by prehistoric hominins (Peretto 1994; Bietti et al. 20092010; de la Torre and Mora 2005; Diez-Martin et al. 2015; Bourguignon et al. 2016; de Lombera-Hermida et al. 2016; Li 2016), and even the use of such tools by some non-human primates (chimpanzees, long-tailed macaques, bonobos, capuchin monkeys) has been documented (Schick et al. 1999; Boesch and Boesch-Achermann 2000; Boinski et al. 2000; Fragaszy et al. 2004; Marchant and McGrew 2005; Bril et al. 2009; Carvalho et al. 2009; Gumert et al. 2009; Haslam et al. 2009; Visalberghi et al. 2015; Proffitt et al. 2016). For example, capuchin monkeys use hammerstone and anvil to crack open nuts (Fragaszy et al. 2004; Mannu and Ottoni 2009; Visalberghi et al. 2013, 2015; Mangalam and Fragaszy 2015; Falótico and Ottoni 2016) and sea otters use stones to crack open shells (Hall and Schaller 1964; Fujii et al. 2015; Haslam et al. 2019).

In prehistoric and ethnographic studies, the use of anvils and hammerstones is attested for a variety of activities such as pounding various materials (pulp, acorns, tubers), cracking open nuts, and opening bones to get the marrow (GorenInbar et al. 2002, 2015; de Beaune 2004; Byrne 2009; Bril et al. 2012, 2015; Roda Gilabert et al. 2012; Benito-Calvo et al. 2018; Pop et al. 2018; Vettese et al. 2020). Another use of hammerstones and anvils is for making stone tools (Shott 1999; Donnart et al. 2009; Eren 2010; de la Peña 2015; Putt 2015; Pargeter and de la Peña 2017; Horta et al. 2019; Collina et al. 2020).

The flaking technique which uses a hammerstone held by hand to strike a stone upon an anvil is defined as "bipolar technique of percussion on an anvil" (Breuil and Lantier 1951). Generally, a hard, dense rock is chosen to be a hammerstone and the gesture of striking is vertical or tangential to the anvil surface and to the raw material to be flaked (White 1968; Crabtree 1982; Barham1987; Knight 1991; Shott 1989; Bietti et al. 2009-2010; Soriano et al. 2009-2010; Duke and Pargeter 2015). The first attestations of the use of this technique date back to the production of the first stone instruments 3.3 Ma (Harmand et al. 2015). Evidence of such a practice during the Pleistocene is well documented (see for example Peretto 1994; Bietti et al. 2009-2010; de la Torre and Mora 2005; Guyodo and Marchand 2005; DiezMartin et al. 2015; Roda Gilabert et al. 2015; de Lombera-Hermida et al. 2016; Li 2016; Horta et al. 2019; Marciani et al. 2020), as well as in the historical period (Robinson 1938; MacCalman and Grobelaar 1965; Masao 1982; Barham 1987; Wadley 1993) and in different geographical areas: Asia (Feng 2008; Kuijt and Rusell 1993; Lee and Kong 2006; Xie and Bodin 2007; Boëda and Hou 2011), Europe (Mourre 1996a, b, 2004; Méndez 2007; Martínez et al. 2010), Australia and New Guinea (Gould et al. 1971; Hayden 1979; Sillitoe 1982; Strathern 1969; Watson 1995; White 1968; White et al. 1977), North America (Morice 1893; Teit 1900; McPherron 1967; MacDonald 1968; White 1968; Brose 1970; Flenniken 1981; Lothrop and Gramly 1982; Parry and Kelly 1987; Shott 1989; Jeske 1992; Goodyear 1993) and South America (Roth 1924; Miller 1979; Curtoni 1999).

Traditionally, bipolar knapping has been considered as an expedient technique (Breuil and Lantier 1951), mostly used for breaking open small cobbles and pebbles (Breuil 1954; Binford and Quimby 1963; White and Thomas 1972; Patterson 1979; Flenniken 1981; Crabtree 1982; Parry and Kelly 1987; Prous and Alonso 1990; Andrefsky 1994, 1998). However, the use of bipolar technique is also a programmatic choice, as seen in the Uluzzian techno-complex where bipolar flaking on anvil is predominant, and it is not a choice constrained by the size and nature of the raw material (Palma di Cesnola 1964; Moroni et al. 2018; Villa et al. 2018; Peresani et al. 2019; Collina et al. 2020; Marciani et al. 2020). 
The Uluzzian, recognised for the first time at Grotta del Cavallo (municipality of Nardò, Apulia region, southern Italy, Palma di Cesnola 1963, 1964) is a techno-complex known in Italy and Greece dated to a period between 45-40 ka (Douka et al. 2014; Giaccio et al. 2017; Zanchetta et al. 2018). The extinction of Neandertal populations and their replacement by Modern Humans occurred over this time period. The Uluzzian has been attributed to Modern Humans based on the study of two deciduous teeth associated with the Uluzzian industry at Grotta del Cavallo (Benazzi et al. 2011). This stratigraphic association was questioned (Zilhão et al. 2015), but a re-examination of the stratigraphic sequence of Grotta del Cavallo confirmed the integrity of the deposit and the subsequent association between Uluzzian and Modern Humans (Moroni et al. 2018; Ronchitelli et al. 2018). The Uluzzian shows features that are associable to Upper Palaeolithic techno-complexes, such as mechanically delivered weapons (Sano et al. 2019), formal bone tools and the systematic use of pigments and ornaments (Arrighi et al. 2020a, 2020b). The Uluzzian shows clear elements of a break with the Mousterian techno-complex, such as the lack of Levallois and discoid debitage, which imply different technical behaviours in conceiving and making tools (Marciani et al. 2020).

The Uluzzian lithic production is characterised by the predominance of bipolar knapping on anvil, with a consequential production of small sized splintered flakes and blades. Unidirectional debitage with a direct percussion technique is also present (Palma di Cesnola 1963, 1964; Gambassini 1997; Riel Salvatore 2009; 2010; Ronchitelli et al. 2009, 2018; De Stefani et al. 2012; Moroni et al. 2013; 2018; Peresani et al. 2016, 2019; Villa et al. 2018; Sano et al. 2019; Marciani et al. 2020). The bipolar technique in the Uluzzian context of Roccia San Sebastiano (municipality of Mondragone, Campania region, southern Italy) is used together with a freehand percussion in unidirectional reduction sequences (Collina et al. 2020).

The aim of this paper is to assess the presence and the role of anvils and hammerstones recovered in the Mousterian and Uluzzian levels of Castelcivita (Campania, southern Italy), evaluating the characteristics of these tools, especially the ones used for the bipolar knapping technique. Most studies have focused on how to recognise signs of the bipolar percussion technique on products of debitage (Knight 1991; Le Brun-Ricalens 2006; Vergès and Ollé 2011; De La Peña 2015; Li 2016; Horta et al. 2019; Pargeter et al. 2019). Far fewer studies are dedicated to hammerstones and anvils (Donnart et al. 2009; Lunardi 2009; Roda Gilabert et al. 2012; Adams 2014), and even fewer use a combined approach/analysis technique, i.e. use-wear, GIS and 3D (de la Torre et al. 2013; Caruana et al. 2014; Arroyo and de la Torre 2016; Benito-Calvo et al. 2018; Caricola et al. 2018). We have focused our attention on hammerstones and anvils, considering them as tools, and we have applied an integrated approach between traceological and techno-functional (sensu Boëda 2013) studies (Arrighi et al. 2009; Bonilauri 2010; Aureli et al. 2015; Boëda et al. 2015; Abruzzese et al. 2016; Da Costa 2017; Marciani et al. 2018; Venditti et al. 2019; Delpiano and Uthmeier, 2020). This traceo/technofunctional study was performed in order to 1) assess the transformative and prehensile units of anvils and hammerstones, 2) identify different techno-types of anvils and hammerstones, and 3) define the specific use-wear left by the bipolar technique on anvils and hammerstones. A specific controlled experimental session, focused on bipolar knapping on anvil, was also carried out in order to build a better understanding of these aspects.

\subsection{The site}

Castelcivita is a cave site situated in Campania (southern Italy municipality of Castelcivita, Salerno) (Fig. 1). The cave opens at the foot of the Alburni massif, close to the right bank of the Calore river, at $94 \mathrm{~m}$ a.s.1. The hypogeum system of the cave consists of a $5 \mathrm{~km}$ network of tunnels and rooms developing inside the carbonatic rocks (Cafaro et al. 2016). The archaeological deposit, located at the cave entrance, has a thickness of 3,40 m (Gambassini 1997) (Fig. 2). Since 1975 it has been excavated and studied by the Research Unit of Prehistory and Anthropology of the University of Siena. 
The sedimentary succession (Fig. 2) preserves evidence of an important cultural sequence, encompassing Late Mousterian, Uluzzian and Protoaurignacian. The Mousterian occupation consists of three layers (cgr, gar and lower-rsi). The modelled date of the lowermost layer (cgr) spans from 47.6 to $41.1 \mathrm{ka}$ cal BP (95.4\% prob.), with an end boundary of 45.7-41.3 ka cal BP (Higham et al. 2014). The Uluzzian occupation consists of four layers (upper-rsi, rpi, pie and rsa'), and starts after a stratigraphic discontinuity in sedimentation with the Mousterian (Fumanal, 1983; Gambassini, 1997). The uppermost Uluzzian layer (rsa") was radiocarbon dated (ABOx-SC) to 41.9 - $40.6 \mathrm{ka}$ cal BP (95.4\% prob.) (Wood et al. 2012). The Protoaurignacian occupation consists of three layers (rsa', gic, ars), the uppermost of which (ars) is sealed by volcanic sediments attributed to the CI eruption (Campanian Ignimbrite) dating back to $39.85 \pm 0.14 \mathrm{ka} \mathrm{BP}$ (Giaccio et al. 2017).

The knapped lithic assemblage was first typologically studied by Gambassini (1997), while technological and technofunctional analyses are still ongoing (see http://www.erc-success.eu and papers within). The Mousterian lithic assemblage is characterized by the dominance of the Levallois debitage concept (mainly used in its recurrent-unidirectional and convergent modality) with the main objective of debitage being elongated flakes and blades. A high frequency of sidescrapers and points has been noted among the retouched tools. The predominant raw material is flint, mainly collected in the form of blocks and pebbles; quartzite and radiolarite are also present. The acquisition of these raw materials was local and occurred along the alluvial deposit of the Calore river. A modest presence of pieces made in limestone (the rock in which the cave formed), is also attested (Gambassini 1997).

The Uluzzian lithic assemblage uses a debitage characterised by a low degree of preparation. This mainly consists of a unidirectional flaking which exploits one, two or more debitage surfaces. The products are mainly flakes. A significant use of bipolar technique on anvil (i.e. Gambassini's splintered pieces) is attested in all the Uluzzian layers. Among retouched tools there is a significant presence of denticulates and side-scrapers. Lunates typical of the Uluzzian are represented by seven items. Like in the Mousterian, the mainly used raw materials are blocks and pebbles acquired from local sources. Flint is the most used lithotype. In the Uluzzian layers a large amount of limestone is used to produce both retouched tools and debitage products (Gambassini 1997).

The Protoaurignacian lithic assemblage is represented by three layers (from bottom to top) rsa', gic, ars. The layer rsa' is characterized by a large presence of marginally backed bladelets (Dufour bladelets). The following layers (gic and ars) are characterised by a new tool, the backed micro-point typical of Castelcivita. In layer rsa' the debitage is mainly unidirectional and aims at producing blades and overall bladelets. The most frequent retouched tools are denticulates followed by backed items, mainly Dufour bladelets. Layers gic and ars, likewise layer rsa', are characterised by a laminar and lamellar debitage which aimed to produce small laminar products. The retouched tools are characterised by large amounts of backed items, both points and blades, followed by several types of end-scrapers. In the three Protoaurignacian layers (rsa', gic and ars) flint is the most used raw material followed by low percentages of limestone, radiolarite and quartzite. Like the Mousterian and the Uluzzian the acquisition of the raw material is local: the alluvial deposit of the Calore river for siliceous materials, and the area in front of the cave of Castelcivita for limestone (Gambassini 1997).

The macrofaunal data (Masini and Abbazzi 1997) attest to a first phase (gar - Mousterian) marked by a temperate and humid climate with the presence of cervid taxa (fallow deer, Dama dama) and small mammals, like Apodemus sp. and Microtus (Terricola) sp. In the following phase (gar and lower rsi - Mousterian) the increase of chamois (Rupicapra pyrenaica) and the depletion of fallow deer indicate the diffusion of open environments in persisting humid climatic conditions. Among small mammals there is the replacement of Microtus (Terricola) sp. with Microtus agrestis / arvalis. 
During the early Uluzzian (layers upper rsi and lower pie) climatic conditions are colder and drier, as evidenced by the increase in horse (Equus ferus) and Microtus arvalis. Afterwards, (Uluzzian layers upper pie, rpi and rsa "), the abundance of horse and Microtus arvalis / agrestis and the scarcity of deer indicate that cold and arid conditions were well established. The same climatic situation lasts in the initial phase of the Protoaurignacian (layer rsa'), while an abrupt change towards a climatic amelioration is recorded in the upper part of the sequence (gic, ars), with the disappearance of horse and the increase of deer (Cervus elaphus), roe deer (Capreolus capreolus) and chamois (Masini and Abbazzi 1997).

\section{Materials}

There is little agreement on terminology, so in order to avoid ambiguities, this section will specify what is meant by several key words and concepts used in this paper. The term blank means the raw block which is selected to be flaked or used. The term support refers to what is used to support, stand or hold the anvil. The term tool means implement, or utensil, that is to say, a piece of equipment used to accomplish a task. The term hammerstone refers to an active percussive tool that delivers a blow (a sudden impact) to an object, it is used without however specifying its use (i.e. flaking, retouching, pounding, cracking actions). The term pestle refers to a hammerstone (active percussive tool) used for a specific function: for pounding materials. The term retoucher refers to a hammerstone (active percussive tool) used for a specific retouching activity. And lastly the term anvil means a passive percussive tool namely a blank with a hard surface on which another object is struck.

\subsection{Archaeological sample}

The site of Castelcivita yielded several percussive tools (hammerstones and anvils). Some of these objects, such as certain angular anvils recovered in the Uluzzian layers, display traces related to tasks other than knapping activities (i.e. breaking bones), Given that this study is focused on the bipolar knapping technique on anvil, we only examined the specimens showing traces or morphological features possibly related to knapping (3 Mousterian tools and 7 Uluzzian tools) (Fig. 2).. The analysed tools were retrieved during the excavations carried out by P. Gambassini from 1975 to 1988. The characteristics of the examined samples are shown in Table 1. Clast morphometry was classified using the scheme and nomenclature proposed by Zingg (1935). The shapes of the clasts are divided into 4 main classes on the basis of the ratios of the three sedimentological axes: long (a), intermediate (b), short (c). The shapes of end-members are: discoid $(\mathrm{a}=\mathrm{b} \neq \mathrm{c})$; spheroids $(\mathrm{a}=\mathrm{b}=\mathrm{c})$; blades $(\mathrm{a} \neq \mathrm{b} \neq \mathrm{c})$; and $\operatorname{rods}(\mathrm{a} \neq \mathrm{b}=\mathrm{c})$.

In this work we refer to pebbles according to archaeological nomenclature and including those that from a sedimentological point of view are considered as "pebble" (i.e. a rounded clast of rock with a diameter between 4 and $64 \mathrm{~mm}$ ) and "cobble" (64-256 mm). Debris are angular or sub-angular clasts, whose origin could be related to breakdown processes from the vault of the cave or originated as slope detritus. 


\begin{tabular}{|c|c|c|c|c|c|c|c|c|c|c|c|c|}
\hline ID & $\begin{array}{l}\text { Lay } \\
\text { er }\end{array}$ & $\begin{array}{l}\text { Grid } \\
\text { code }\end{array}$ & Raw material & Texture & Morphology & $\begin{array}{l}\mathbf{a} \\
(\mathbf{m} \\
\mathbf{m})\end{array}$ & $\begin{array}{c}\mathbf{b} \\
(\mathbf{m m})\end{array}$ & $\begin{array}{c}\mathrm{c} \\
(\mathrm{mm})\end{array}$ & $\mathbf{b} / \mathbf{a}$ & $\mathbf{c} / \mathbf{b}$ & $\begin{array}{c}\text { Morphome } \\
\text { try (Zingg, } \\
1935)\end{array}$ & $\begin{array}{c}\text { Weight } \\
\text { (g) }\end{array}$ \\
\hline $\begin{array}{c}\text { CTC } \\
12\end{array}$ & $\begin{array}{l}\text { cgr } \\
\text { (M) }\end{array}$ & $?$ & Sandstone & $\begin{array}{c}\text { Fine/Medi } \\
\text { um }\end{array}$ & Pebble & 79 & 62 & 15 & $\begin{array}{c}0,7 \\
8\end{array}$ & $\begin{array}{c}0,2 \\
4\end{array}$ & Discoid & 112 \\
\hline $\begin{array}{c}\text { CTC } \\
01\end{array}$ & $\begin{array}{l}\text { gar } \\
(\mathrm{M})\end{array}$ & G13 & Sandstone & $\begin{array}{c}\text { Fine/Medi } \\
\text { um }\end{array}$ & Pebble & 59 & 50 & 43 & $\begin{array}{c}0,8 \\
5\end{array}$ & $\begin{array}{c}0,8 \\
6\end{array}$ & Spheroid & 159 \\
\hline $\begin{array}{c}\text { CTC } \\
04\end{array}$ & $\begin{array}{l}\text { gar } \\
\text { (M) }\end{array}$ & F14 & Sandstone & Medium & Pebble & 131 & 91 & 54 & $\begin{array}{c}0,6 \\
9\end{array}$ & $\begin{array}{c}0,5 \\
9\end{array}$ & Discoid & 944 \\
\hline $\begin{array}{c}\text { CTC } \\
16\end{array}$ & $\begin{array}{l}\text { rpi } \\
\text { (U) }\end{array}$ & E14 & Limestone & Micrite & $\begin{array}{c}\text { Pebble } \\
\text { (Broken) }\end{array}$ & 96 & 86 & 49 & $\begin{array}{c}0,9 \\
0\end{array}$ & $\begin{array}{c}0,5 \\
7\end{array}$ & Discoid & 330 \\
\hline $\begin{array}{c}\text { CTC } \\
17\end{array}$ & $\begin{array}{l}\text { rpi } \\
\text { (U) }\end{array}$ & G14 & Limestone & Fine & $\begin{array}{c}\text { Pebble } \\
\text { (Broken) }\end{array}$ & 117 & 87 & 35 & $\begin{array}{c}0,7 \\
4\end{array}$ & $\begin{array}{c}0,4 \\
0\end{array}$ & Discoid & 440 \\
\hline $\begin{array}{c}\text { CTC } \\
18\end{array}$ & $\begin{array}{l}\text { rpi } \\
\text { (U) }\end{array}$ & G13 & $\begin{array}{l}\text { Dolomitic } \\
\text { Limestone }\end{array}$ & Fine & Debris & 127 & 98 & 38 & $\begin{array}{c}0,7 \\
7\end{array}$ & $\begin{array}{c}0,3 \\
9\end{array}$ & Discoid & 481 \\
\hline $\begin{array}{c}\text { CTC } \\
02\end{array}$ & $\begin{array}{l}\text { rsa" } \\
\text { (U) }\end{array}$ & H12 & Sandstone & Fine & $\begin{array}{c}\text { Pebble } \\
\text { (Broken) }\end{array}$ & 62 & 53 & 22 & $\begin{array}{c}0,8 \\
5\end{array}$ & $\begin{array}{c}0,4 \\
2\end{array}$ & Discoid & 82 \\
\hline $\begin{array}{c}\text { CTC } \\
06\end{array}$ & $\begin{array}{l}\text { rsa" } \\
\text { (U) }\end{array}$ & H12 & Sandstone & $\begin{array}{c}\text { Medium/F } \\
\text { ine }\end{array}$ & $\begin{array}{c}\text { Pebble } \\
\text { (Broken) }\end{array}$ & 106 & 79 & 56 & $\begin{array}{c}0,7 \\
5\end{array}$ & $\begin{array}{c}0,7 \\
1\end{array}$ & Spheroid & 483 \\
\hline $\begin{array}{c}\text { CTC } \\
07\end{array}$ & $\begin{array}{l}\text { rsa" } \\
\text { (U) }\end{array}$ & H12 & Limestone & Micrite & $\begin{array}{c}\text { Pebble } \\
\text { (Broken) }\end{array}$ & 94 & 92 & 33 & $\begin{array}{c}0,9 \\
8\end{array}$ & $\begin{array}{c}0,3 \\
6\end{array}$ & Discoid & 298 \\
\hline $\begin{array}{c}\text { CTC } \\
15\end{array}$ & $\begin{array}{l}\text { rsa" } \\
\text { (U) }\end{array}$ & E14 & Limestone & Micrite & Debris & 80 & 61 & 45 & $\begin{array}{c}0,7 \\
6\end{array}$ & $\begin{array}{c}0,7 \\
4\end{array}$ & Spheroid & 246 \\
\hline
\end{tabular}

Table 1 Characteristics of the examined lithic assemblage from Mousterian (M) and Uluzzian (U) layers of Castelcivita

\section{Methods}

\subsection{Experimental design}

An experimental program was performed in order to create a reference collection, useful in helping to interpret the archaeological tools. Raw materials were collected according to the size and morphometric features of the archaeological specimens. Cobbles and blocks were gathered in the surroundings of the site of Castelcivita, along the Calore river. In our reference collection we have 5 anvils and 7 hammerstones (Tab.2). 


\begin{tabular}{|c|c|c|c|c|c|c|c|c|c|c|}
\hline Id & $\begin{array}{c}\text { Raw } \\
\text { material }\end{array}$ & Texture & $\begin{array}{c}\text { Morphol } \\
\text { ogy }\end{array}$ & $\begin{array}{c}\mathbf{a} \\
(\mathbf{m m})\end{array}$ & $\begin{array}{l}\mathbf{b} \\
(\mathbf{m} \\
\mathbf{m})\end{array}$ & $\begin{array}{c}\mathbf{c} \\
(\mathbf{m m})\end{array}$ & $\mathbf{b} / \mathbf{a}$ & $\mathbf{c} / \mathbf{b}$ & $\begin{array}{l}\text { Morphometry } \\
\text { (Zingg, 1935) }\end{array}$ & Function \\
\hline Exp. 02 & Limestone & Micrite & Pebble & 165 & 114 & 53 & \begin{tabular}{c|}
0,6 \\
9
\end{tabular} & \begin{tabular}{c|c}
0,4 \\
6
\end{tabular} & Discoid & Anvil \\
\hline Exp. 20 & Sandstone & Fine & Pebble & 141 & 130 & 25 & \begin{tabular}{c|c}
0,9 \\
2
\end{tabular} & \begin{tabular}{c|c}
0,1 \\
9
\end{tabular} & Discoid & Anvil \\
\hline Exp. 13 & Limestone & $\begin{array}{l}\text { Medium/F } \\
\text { ine }\end{array}$ & Pebble & 177 & 156 & 35 & $\begin{array}{c}0,8 \\
8\end{array}$ & \begin{tabular}{c|}
0,2 \\
2
\end{tabular} & Discoid & Anvil \\
\hline Exp. 07 & Sandstone & $\begin{array}{l}\text { Medium/F } \\
\text { ine }\end{array}$ & Pebble & 134 & 110 & 25 & \begin{tabular}{c|}
0,8 \\
2
\end{tabular} & $\begin{array}{c}0,2 \\
3\end{array}$ & Discoid & Anvil \\
\hline Exp. 07bis & Limestone & Micrite & Debris & 140 & 97 & 26 & $\begin{array}{c}0,6 \\
9\end{array}$ & \begin{tabular}{c|}
0,2 \\
7
\end{tabular} & Discoid & Anvil \\
\hline Exp. 04 & Sandstone & Coarse & Pebble & 65 & 59 & 52 & $\begin{array}{c}0,9 \\
1\end{array}$ & $\begin{array}{c}0,8 \\
8\end{array}$ & Spheroid & $\begin{array}{c}\text { Hammerst } \\
\text { one }\end{array}$ \\
\hline Exp. 08 & Sandstone & Medium & Pebble & 83 & 60 & 49 & $\begin{array}{c}0,7 \\
2\end{array}$ & \begin{tabular}{c|}
0,8 \\
2
\end{tabular} & Spheroid & $\begin{array}{c}\text { Hammerst } \\
\text { one }\end{array}$ \\
\hline Exp. 09 & Sandstone & $\begin{array}{l}\text { Medium/F } \\
\text { ine }\end{array}$ & Pebble & 70 & 49 & 37 & $\begin{array}{c}0,7 \\
0\end{array}$ & \begin{tabular}{c|}
0,7 \\
6
\end{tabular} & Spheroid & $\begin{array}{c}\text { Hammerst } \\
\text { one }\end{array}$ \\
\hline Exp. 17 & Sandstone & $\begin{array}{l}\text { Medium/F } \\
\text { ine }\end{array}$ & Pebble & 88 & 47 & 26 & $\begin{array}{c}0,5 \\
3\end{array}$ & \begin{tabular}{c|}
0,5 \\
5
\end{tabular} & Blade & $\begin{array}{c}\text { Hammerst } \\
\text { one }\end{array}$ \\
\hline Exp. 18 & Sandstone & Fine & Pebble & 64 & 44 & 23 & \begin{tabular}{c|}
0,6 \\
9
\end{tabular} & \begin{tabular}{c|}
0,5 \\
2
\end{tabular} & Discoid & $\begin{array}{c}\text { Hammerst } \\
\text { one }\end{array}$ \\
\hline $\begin{array}{c}\text { Exp. } \\
18.14 .38\end{array}$ & Quartzite & $\begin{array}{c}\text { Crystallin } \\
\mathrm{e}\end{array}$ & Pebble & 97 & 63 & 45 & $\begin{array}{c}0,6 \\
5\end{array}$ & \begin{tabular}{c|}
0,7 \\
1
\end{tabular} & Rod & $\begin{array}{c}\text { Hammerst } \\
\text { one }\end{array}$ \\
\hline Exp. 03 & Sandstone & $\begin{array}{l}\text { Medium/F } \\
\text { ine }\end{array}$ & Pebble & 101 & 57 & 56 & $\begin{array}{c}0,5 \\
6\end{array}$ & $\begin{array}{c}0,9 \\
8\end{array}$ & Rod & $\begin{array}{c}\text { Hammerst } \\
\text { one }\end{array}$ \\
\hline
\end{tabular}

Table 2 List of the raw materials collected for the experimental activity

Experimental tests were mainly focused on bipolar technique on anvil, with special attention to the production stages of the knapping activity, and to a lesser extent to breaking open flint blocks. In order to create a reference collection, experiments on direct percussion have also been carried out (Tab.3). In the experimental tests seven flint nodules (average $6 \times 7 \times 3 \mathrm{~cm}$ ) recovered in the surroundings of the site and similar to the ones documented in the archaeological deposit were exploited. 


\begin{tabular}{|c|c|c|c|c|c|c|c|c|}
\hline Id & Function & $\begin{array}{l}\text { Weight } \\
\text { (g) }\end{array}$ & $\begin{array}{l}\text { Knapping } \\
\text { technique }\end{array}$ & $\begin{array}{l}\text { Used hammerstone } \\
\text { or anvil }\end{array}$ & $\begin{array}{l}\text { Production } \\
\text { objective }\end{array}$ & Phase & Gesture & Strikes \\
\hline Exp.01 & Anvil & 1301 & $\begin{array}{l}\text { Bipolar on } \\
\text { anvil }\end{array}$ & $\begin{array}{l}\text { Exp.28 } \\
\text { (hammerstone) }\end{array}$ & $\begin{array}{l}\text { Break open } \\
\text { blocks }\end{array}$ & $\begin{array}{l}\text { Pebble } \\
\text { opening }\end{array}$ & $\begin{array}{l}\text { Receives } \\
\text { blows }\end{array}$ & 20 \\
\hline Exp. 02 & Anvil & 1298 & $\begin{array}{l}\text { Bipolar on } \\
\text { anvil }\end{array}$ & $\begin{array}{l}\text { Exp. } 03 \\
\text { (hammerstone) }\end{array}$ & Flakes/blades & Production & $\begin{array}{l}\text { Receives } \\
\text { blows }\end{array}$ & 139 \\
\hline Exp. 20 & Anvil & 735 & $\begin{array}{l}\text { Bipolar on } \\
\text { anvil }\end{array}$ & $\begin{array}{l}\text { Exp. } 08 \\
\text { (hammerstone) }\end{array}$ & Flakes/blades & Production & $\begin{array}{l}\text { Receives } \\
\text { blows }\end{array}$ & 65 \\
\hline Exp. 13 & Anvil & 1313 & $\begin{array}{l}\text { Bipolar on } \\
\text { anvil }\end{array}$ & $\begin{array}{l}\text { Exp. } 04 \\
\text { (hammerstone) }\end{array}$ & Flakes/blades & Production & $\begin{array}{l}\text { Receives } \\
\text { blows }\end{array}$ & 37 \\
\hline Exp. 07 & Anvil & 599 & $\begin{array}{l}\text { Bipolar on } \\
\text { anvil }\end{array}$ & $\begin{array}{l}\text { Exp. } 09 \\
\text { (hammerstone); } \\
\text { Exp. 18.14.38 } \\
\text { (hammerstone) }\end{array}$ & Flakes/blades & Production & $\begin{array}{l}\text { Receives } \\
\text { blows }\end{array}$ & 95 \\
\hline Exp. 04 & Hammerstone & 235 & $\begin{array}{l}\text { Bipolar on } \\
\text { anvil }\end{array}$ & Exp. 13 (anvil) & Flakes/blades & Production & $\begin{array}{l}\text { Perpendicular } \\
\text { and tangential } \\
\text { blows }\end{array}$ & 37 \\
\hline Exp. 08 & Hammerstone & 304 & $\begin{array}{l}\text { Bipolar on } \\
\text { anvil }\end{array}$ & Exp. 20 (anvil) & Flakes/blades & Production & $\begin{array}{l}\text { Perpendicular } \\
\text { and tangential } \\
\text { blows }\end{array}$ & 65 \\
\hline Exp. 09 & Hammerstone & 165 & $\begin{array}{l}\text { Bipolar on } \\
\text { anvil }\end{array}$ & Exp. 07 (anvil) & Flakes/blades & Production & $\begin{array}{l}\text { Perpendicular } \\
\text { blow }\end{array}$ & 69 \\
\hline $\begin{array}{l}\text { Exp. } \\
18.14 .38\end{array}$ & Hammerstone & 390 & $\begin{array}{l}\text { Bipolar on } \\
\text { anvil }\end{array}$ & Exp. 07 (anvil) & Flakes/blades & Production & $\begin{array}{l}\text { Perpendicular } \\
\text { blow }\end{array}$ & 26 \\
\hline Exp. 03 & Hammerstone & 394 & $\begin{array}{l}\text { Bipolar on } \\
\text { anvil }\end{array}$ & $\begin{array}{l}\text { Exp. } 13 \text { (anvil); } \\
\text { Exp. } 02 \text { (anvil) }\end{array}$ & Flakes/blades & Production & $\begin{array}{l}\text { Perpendicular } \\
\text { blow }\end{array}$ & 139 \\
\hline Exp. 17 & Hammerstone & 165 & Direct & I & Flakes/blades & $\begin{array}{l}\text { Production } \\
\text { and abrasion }\end{array}$ & $\begin{array}{l}\text { Tangential } \\
\text { blow }\end{array}$ & 296 \\
\hline Exp. 18 & Hammerstone & 101 & Direct & l & Flakes/blades & $\begin{array}{l}\text { Striking } \\
\text { platform } \\
\text { configuration, } \\
\text { abrasion }\end{array}$ & $\begin{array}{l}\text { Tangential } \\
\text { blow }\end{array}$ & 213 \\
\hline Exp. 28 & Hammerstone & 210 & $\begin{array}{l}\text { Bipolar on } \\
\text { anvil }\end{array}$ & Exp. 01(anvil) & $\begin{array}{l}\text { Break open } \\
\text { blocks }\end{array}$ & $\begin{array}{l}\text { Pebble } \\
\text { opening }\end{array}$ & $\begin{array}{l}\text { Perpendicular } \\
\text { blow }\end{array}$ & 20 \\
\hline
\end{tabular}

Table 3 List of the experimental hammerstones and anvils with specifications of the used knapping technique, phases of debitage, gestures and number of performed strikes

\subsection{Use-wear analysis}

Use-wear analysis was performed on both the experimental and the archaeological tools. Use-wear identification on percussive tools (hammerstones and anvils) was based on the analytical approach developed by Adams et al (2009) considering the processes related to use-wear formation. Four categories of surface modifications are defined: 1) adhesive wear (residues), 2) fatigue wear (conchoidal fractures or edge removals), 3) abrasive wear (levelling or rounding of edge grains and striations), 4) tribo-chemical wear (polishing) (Adams et al. 2009; Adams 2014; Dubreuil and Savage 2014; Dubreuil et al. 2015). Surface modifications related to use (such as scars, percussive impacts or pit marks, hollows, striations and polishing) have been described following previous studies (Donnart et al. 2009; Adams et al. 2009; Roda Gilabert et al. 2012; de la Torre et al. 2013, Adams 2014).

The analysed specimens were first observed at low magnification classified by means of Reflectance Transformation Imaging (RTI) and of a Hirox KH 7700 3D digital microscope, using a MX-G 5040Z body equipped with an AD-5040 Lows and an AD-5040HS lens. High magnification analysis was performed using the above mentioned Hirox microscope fitted out with an MXG-10C body and an OL-140II lens (140x- 480x). 
Use-wear was interpreted by means of comparison with traces produced during our experimental tests and available literature (e.g. Adams et al. 2009; Donnart et al. 2009; Dubreuil et al. 2015; Dubreuil and Savage 2014; Roda Gilabert et al. 2012; Caricola et al. 2018).

\subsection{Techno-functional analysis}

The techno-functional analysis aims to find the functional logic underlying the tool-making phase by looking for regularities and recurrences in the resulting adjustments and the technical consequences of these adjustments (Soriano 2000, p.131). It was first theorised as Théorie artisanale Lepot (1993), then better defined by Boëda, (1991, 1997, 2001, 2013), and subsequently applied in several contexts (i.e. Soriano 2000; Bonilauri 2010; Lourdeau 2010; Rocca 2013; Aureli et al. 2015, 2016; Boëda et al. 2015; De Weyer 2016; Da Costa 2017; Marciani et al. 2018).

In the techno-functional approach, a tool is defined as an object consisting of three main parts (techno-functional unities - UTF). The transformative techno-functional unity (UTF t) is the part of the tool which enters into contact with and modifies the material. The prehensile techno-functional unity (UTF p) consists of the handle which is the part of the tool in contact with the user, with or without an intermediary body. Or in the case of the anvil it is the portion which rests on a surface. Between UTF t and UTF p, there is the transmitting techno-functional unity (UTF tr), which is seen as the intermediate factor transmitting the force from the handle to the transformative edge (theorical portion whose concrete definition is difficult to find).

A transformative unity UTF t is determined by the presence of homogeneous and regular technical parametres on a part of the item. The UTF t that we found were: hammerstone, anvil and working edge.

In order to describe the location of the traces and UTF on the pieces we gave a conventional orientation to the items: for the hammerstones and the tools with a working edge, the longest measurement is the length; consequently, the shorter is the width, thus with this orientation distal, mesial, proximal, left or right portion are described. For the anvils, we define as 'upper surface' the side where the hitting-traces can be found and as 'lower surface' the opposed side of the item. We define the UTF t-hammerstone as a surface characterised by a percussed area which was assessed by the naked eye or based on use-wear traces. When defining the UTF t-hammerstone, we considered its location (distal, mesial, proximal, left or right); and surface aspects (plane, convex, concave).

The UTF t-anvil is a surface characterised by a percussed area which was evaluated by the naked eye or based on usewear traces. In order to define the UTF t-anvil we considered its location and surface aspects.

The UTF t-working edge is a dihedron made up by the intersection of two surfaces, delineated by a regular plane section and a working angle (Lepot 1993; Soriano 2000). When defining the working edges, we considered their location (distal, mesial, proximal, mesio-distal, mesio-proximal; left or right); the delineation of frontal view (rectilinear, convex, concave and denticulate); the profile view (rectilinear, convex and wavy); the extension (expressed in $\mathrm{mm}$ ); angles and surface relations (Plane/Plane, Plan/Convex, Plan/Concave, Convex/Convex, Concave/Concave) (Lepot 1993; Boëda 1997, 2001; Bonilauri 2010; Lourdeau 2010; Da Costa 2017; Marciani et al. 2018).

The prehensile unit UTF $p$ is usually defined in relation to the UTF t (Lepot 1993; Soriano 2000; Mello 2005; Lourdeau 2010; Rocca 2013; Da Costa 2017) or thanks to the presence of use-wear studies (Bonilauri 2010).

The definition of a techno-type is based on the recurrent combination between UTF $t$ and UTF $p$ on a particular object. After analysing every tool and understanding the functionality of every single UTF, we defined groups of pieces on the basis of the same structural and functional features. 


\subsection{Reflectance Transformation Imaging}

Use-wear analysis by means of low power approach has been improved by Reflectance Transformation Imaging (RTI). This is a method of imaging which enables one to display objects under varying light conditions in order to reveal surface features. By means of a virtual light source, which is obtained after processing images with RTI, it is possible to imitate light from different angles to explore the examined surface (Mudge et al. 2008; Malzbender et al. 2000; Malzbender et al. 2001; CHI 2011; Earl et al. 2010; Nurse 2015; Fiorini 2018; Fiorini et al. 2019).

Experimental and archaeological samples were photographed using a Nikon D7100 camera equipped with a macro lens and a LED light fixture. The points where the camera was positioned to shoot the photos were recorded using a prepared grid. For each examined surface 24 photos were acquired. Finally, obtained images were processed by the following free software (Cultural Heritage Imaging; www.culturalheritageimaging.org): Camera Raw (photo viewing and colour management), RTIBuilder (for creating RTI files), RTIViewer (RTI files viewing). RTI Viewer applies mathematical transformations to surface normals and RGB color information, improving the perception of surface relief. By using the "specular enhancement" mode it is possible to remove color information in order to emphasize only surface reflectivity and detect characteristics that cannot be seen in natural light conditions.

\section{Results}

\subsection{Experimental activity: use-wear reference collection}

\subsubsection{Anvils (bipolar knapping technique)}

Two main activities could be performed by the bipolar knapping technique: the first is knapping in order to produce target objects, the second is to break open raw material blocks. When employed to knap blanks with the aim to produce target objects the bipolar technique produces very distinctive traces on anvils, as recorded in previous research (de Beaune 1993). They are characteristic linear impacts that are clearly recognisable, mostly in the first stages of the activity (Fig. 3a, c, d). These linear percussive impacts are usually arranged in sequence and are produced by the contact between the dihedral part of the core and the anvil when flakes/blades are produced. As the knapping activity progresses, the linear impacts are obliterated by the series of blows which generate large hollows (Fig. 3b). However, sometimes residual linear impacts are noticeable at the edge of the hollows (Fig. 3d). The shape of the hollows is usually sub-rectangular or trapezoidal. The depth of such hollows varies in relation to the raw material of the anvil, as well as the weight of the hammerstone and the force used by the knapper. Usually the surface of the stone within the hollows is fairly homogenous and does not show pit-marks (Fig. 3e). This is because the core could sometimes act as a chisel detaching small flakes from the anvil. At high magnification a few short and shallow striations are detectable, as well as flat polishes, although infrequent.

When the bipolar technique is employed in the first step of knapping, that is breaking open blocks of raw material, the traces produced by this activity are substantially different to the ones made by bipolar knapping in order to produce target objects. They are scattered impact cracks, chaotically distributed on the flat surface of the anvil, with a frosted appearance (Fig. 3g, h).

\subsubsection{Hammerstone (bipolar knapping technique)}

In the initial stages of the experimental activity, the hammerstones used in bipolar knapping showed numerous subrectangular pit-marks and frequent crystal crushing. Then, sub-rectangular and sub-trapezoidal hollows formed, more developed in the central zone of the transformative unit (the part which comes into contact with the core), whilst in the marginal areas the hollows are smaller and can be found next to the pit-marks (Fig.4a, b). As previously mentioned, the 
depth of such hollows is related to the raw material of the hammerstone, to its weight and to the force of the strike employed by the knapper. At high magnification short and shallow striations and rare polishes are noticeable (Fig.4c, d). The traces are located on the transformative unit of the hammerstone, in this case, the short edge.

\subsubsection{Hammerstone (direct percussion)}

The hammerstones used in direct percussion showed numerous sub-circular and sub-rectangular pit-marks (Fig.5a). The presence of short and large striations, chaotically distributed, is more usual than in the bipolar knapping technique (Fig. $5 b)$. Their presence is due to overhang abrasion. Hollows are very rare and smaller than the ones produced during bipolar knapping. The few hollows present display circular or sub-circular shapes whilst the ones produced during bipolar percussion are usually rectangular. At high magnification crushed crystals and sporadic polishing are detectable (Fig.5c, d).

\subsection{Archaeological sample}

\subsubsection{Raw material types and morphometry}

The examined assemblage of Castelcivita contains a limited variety of rock types, mostly sandstone and to a lesser extent limestone. The texture of the selected rocks is predominantly fine-grained for sandstones and micritic for limestone. Limestone is documented only in the Uluzzian layers.

Most of the observed raw materials are in the form of pebbles. Only two limestone blocks do not display evidence of reworking, suggesting that they are probably debris collapsed from the cave vault.

Clast morphometry of hammerstones and anvils from both Mousterian and Uluzzian layers is mainly represented by discoids and to a lesser extent by spheroids (Fig. 6).

\section{.2.2 Use-wear: Mousterian sample}

In the Mousterian sample only three elements (CTC 01, CTC 12, CTC 04) exhibit percussion traces (Tab.4). Two tools were used as hammerstones (CTC 01, CTC 12), and one was used both as hammerstone and anvil (CTC 04). The tools are well preserved without any post-depositional traces.

The first specimen is a spheroid sandstone pebble of small proportions (CTC 01) (used as a hammerstone) displaying similar traces on one flat surface (UTF; Fig. 7 t) and one extremity (UTF t1; Fig. 7). These traces are irregular pit-marks involving partially the extremity and scattered on the whole flat surface, that in some cases are clustered forming small, shallow hollows (Fig.7a). At high magnification crushed crystals and detachments are detected, as well as sporadic polishing with spot distribution on the top of the grains (Fig.7b). The traces on this hammerstone and their distribution are consistent with the use of this tool as a pestle likely exploited to crush medium-hard materials (Adams et al. 2009; Dubreuil 2004; Dubreuil and Savage 2014).

Another discoid sandstone pebble (CTC 12) shows just a few traces on one extremity (UTF t; Fig. 8), which are shallow pit-marks and a few detachment scars, interpretable as accidental removals that occurred due to percussion (Fig. 8a). At high magnification crystal removals and crushing can be observed (Fig. 8b). The small size of this tool and these traces could likely be consistent with the use of the tool as a retoucher, and could indicate a short term use of the object probably due to bad quality of the raw material.

Mousterian layers yielded only a discoid sandstone pebble used as an anvil (CTC 04), which exhibits traces on the flat surface (UTF t; Fig. 9). These traces are sub-circular hollows, where few narrow striations and crushed crystal are present. The absence of linear impacts could suggest that the anvil was not used for bipolar knapping (Fig.9a). At high 
magnification crystals appear well rounded and affected by rough and scarcely developed polishes. These characteristics are different from the experimental ones produced by bipolar knapping. Experimental anvils do not show rounded crystals and flat polishes. Other two used areas (UTF t1 and UTF t2; Fig. 10) are located along the edge of the stone, where numerous sub-circular pit-marks are recorded (Fig. 10a). They are consistent with the use of this part of the tool as hammerstone.

\begin{tabular}{c|c|c|c} 
ID & Layer & Anvil & Hammerstone \\
\hline CTC 01 & gar & & $\mathrm{x}$ \\
(Fig. 7) & (M) & & $\mathrm{x}$ \\
\hline CTC 12 & cgr & & $\mathrm{x}$ \\
(Fig. 8) & (M) & &
\end{tabular}

Table 4 Summary table of the functions carried out by each Mousterian specimen

\subsubsection{Use-wear: Uluzzian sample}

The Uluzzian sequence of Castelcivita yielded seven tools (CTC 16, CTC 17, CTC 18, CTC 02, CTC 06, CTC 07, CTC 15).Two were used only as anvils (CTC 17, CTC 18), three were used both as anvil and hammerstone (CTC 06, CTC 07, CTC 15), one is an anvil also used to perform activities other than percussion (CTC 16), and finally only one tool was used only as hammerstone (CTC 02). (Tab.5). All the examined objects are not affected by post-depositional traces. All the anvils but two, show very developed use-wear, often located in the central area of the flat surface of the stone. Some specimens show several used areas (UTF t). The raw material mainly used for the anvils is fine-grain textured limestone. Only one specimen (CTC 06) is made of sandstone, medium-grain textured.

CTC 06 (Fig. 11-12) has been strongly used and exhibits three different zones of use (the two flat surfaces UTF t, UTF t1 and a lateral edge UTF t2). It has been employed both as hammerstone and anvil. One of the flat surfaces UTF t (A) (Fig. 11a) displays two sub-rectangular hollows, one of which is partially overlapped by the other, showing a chronological sequence. A rectilinear impact is detectable inside the later hollow and it could be the last action performed on this face of the anvil. A few sub-rectangular and sub-circular pit-marks are located near the later hollow. On the other flat surface UTF t1 (B) (Fig.11b, c), a sub-rectangular hollow is in the central area of the stone. It is a shallow hollow showing few residual linear impacts on its extremities. Both the flat surfaces exhibit traces related to an anvil function in bipolar knapping in order to produce target objects, with a more intense use on surface A.

Another used zone UTF $\mathrm{t} 2$ is located on the edge of the block, near the break (Fig.12). It is characterised by numerous sub-circular pit-marks that overlap a few short striations chaotically arranged (Fig. 12a). These traces are different from those observed on the flat surfaces (UTF t and UTF t1) (A and B) and they are consistent with the use of this portion of the tool as a hammerstone.

An intense use is recorded in a small sized specimen (CTC 16), which exhibits an extended battered area located in the central portion of the object (UTF t). In this area two different phases of use can be distinguished (even if a chronological sequence cannot be established). One phase of use is more intense (A) (Fig.13a), in this zone numerous blows formed a deep rectangular hollow, with residual linear impacts at their extremities (Fig. 13b). Zone B (Fig.13a) is adjacent to zone A and it shows less-developed traces. Here, numerous linear impacts are recognisable, but they do not 
form hollows. The traces are consistent with the use of the tool as anvil in bipolar knapping for flakes/blades production.

Some percussive traces (irregular pit-marks) are also recorded on the other side of the anvil UTF p. They were produced by the counterblow created when the anvil was in contact with another hard surface (Fig. 13c).

Another probable use could be inferred for this object: the tool has a working edge (cfr. paragraph 4.2.5) showing a developed edge-rounding and rough polishes distributed along the edge UTF t1 (Fig.14 a, b). These traces could be explained by contact with an abrasive material, such as dry hide. It is less likely that they are due the sediment abrasion, because use-wear are specifically localised only in-this portion.

The tool CTC 15 was used as anvil for the bipolar knapping technique during flakes/blades production stage. It displays a principal used area (UTF t; Fig. 15) together with a marginal battered zone characterised by numerous mostly irregular impact traces, and shallow pit-marks. Their formation could be caused by the hammerstone during the knapping, when the knapper hit the core tangentially. During our experimental tests, we noted how a tangential blow does not stop on the core but continues its trajectory and hits the anvilThe use of a tangential blow while knapping could explain the traces on CTC 15 that show this kind of pattern of scattered arrangement.

The tool CTC 15 (Fig. 16) also exhibits traces on an angular extremity (UTF t1): numerous step fractures, distributed on both sides of the edge and a few polishes, organised in spots. These traces could be consistent with the use of the tool as hammerstone.

The tool CTC 07 also shows a main used area on the flat surface (UTF t) associated with a marginal battered zone near the edge of the cobble (UTF t1). Two deep rectangular hollows displaying a few linear impacts are located on the flat surface (UTF t; Fig. 17a, b). The marginal battered zone (UTF t1) is characterised by percussive impacts arranged in a clustered distribution and striations, as is usually the case for the hammerstone (Fig. 18a). This could suggest a double use for this specimen, as an anvil (UTF t) employed in bipolar technique for producing flakes/blades and as a hammerstone (UTF t1) (this latter function was probably occasional because traces are not well developed). The tools CTC 17 and CTC 18 are the only anvils to show little developed use-wear. CTC 17 displays undeveloped linear hollows, that again, could suggest an occasional use of the tool (UTF t; Fig. 19a). CTC18 (UTF t) displays only a few linear impacts arranged in sequence, due to a short-term phase of knapping activity (Fig. 20a). For both the tools a use as anvils in bipolar knapping for flakes/blades production can be inferred. CTC18 exhibits also two working edges (UTF t1 and UTF t2; Fig. 20; cfr. paragraph 4.2.5), but they do not display use-wear.

In the Uluzzian sample only one tool was used purely as a hammerstone, CTC 02. It is a broken sandstone pebble showing some irregular and shallow pit-marks together with chaotic striations, clustered on the extremity (UTF t) (Fig. 21a). These traces could be consistent with a short-term use as hammerstone/retoucher.

\begin{tabular}{c|c|c|c|c} 
ID & Layer & Anvil & Hammerstone & Tool with working edges \\
\hline CTC16 & rpi & $\mathrm{x}$ & & $\mathrm{x}$ \\
$($ Fig.13-14) & (U) & & & \\
\hline CTC17 & rpi & $\mathrm{x}$ & & \\
(Fig.19) & (U) & & & \\
\hline CTC18 & rpi & $\mathrm{x}$ & & \\
(Fig.20) & (U) & & & \\
\hline CTC02 & rsa" & & $\mathrm{x}$ & \\
(Fig.21) & (U) & & &
\end{tabular}




\begin{tabular}{c|c|c|c|c} 
CTC06 & rsa" & $\mathrm{x}$ & $\mathrm{x}$ & \\
(Fig. 11-12) & (U) & & $\mathrm{x}$ & \\
\hline CTC07 & rsa" & $\mathrm{x}$ & & \\
(Fig.17-18) & (U) & & $\mathrm{x}$ & \\
\hline CTC15 & rsa" & $\mathrm{x}$ & &
\end{tabular}

Table n. 5. Summary table of the functions carried out by each Uluzzian specimen

\subsubsection{Techno-functional analysis: Mousterian sample}

CTC 01 is a spheroid sandstone pebble, it is integral, with no flaking modification of the blank. The natural convexities of the blank were used to perform percussive activities. The blank shows two UTF t: one UTF t/hammerstone-pestle is located on the central portion of the largest side of the blank, the second UTF t1/ hammerstone-pestle is located on the thinnest side of the blank. In both cases, the percussive traces are located on convex surfaces (Fig. 7). The UTF $p$ is found on the opposite side to UTF t and UTF t1 (Fig. 7).

CTC 04 is a discoid sandstone pebble, with two broken sides. On this blank, three UTF t were identified. UTF $t$ is an area used as an anvil (Fig. 9), whereas UTF t1 and UTF t2 are areas used as hammerstones (Fig. 10). The UTF t/anvil is located on the central portion of the flat surface of the blank, and the related UTF $\mathrm{p}$ is the other flat surface of the blank (Fig. 9).

The two unities used as hammerstones (UT Ft1; UTF t2) are located along the edge of the blank, one (UTF t1) on the thinner side and one (UTF t12) on the larger side. The UTF $\mathrm{p} 1$ is found on the opposite side to UTF t1 and UTF t2 (Fig. $10)$.

CTC 12 is a discoid sandstone pebble (Fig. 8), that was used in its natural form without being changed by flaking. The UTF t/hammerstone-retoucher is located on the distal extremity of the thinner side of the blank. The UTF $p$ is found on the opposite side to UTF $\mathrm{t}$.

The Mousterian tools (CTC 01, CTC 04, CTC 12) are three sandstone blanks and for two of these tools (CTC 01 and CTC 04) more than one UTF t was imposed. The tools were all used as hammerstones. CTC 01 and CTC 04 show two UTF t/hammerstone located, in both cases, on the larger and thinner side of the blank. The tool CTC 04 also shows a UTF t/anvil on the larger flat surface of the blank. On all three tools the UT Ft/hammerstone are located on convex surfaces whereas the UTF t/anvil is located on a flat surface. The tools were chosen for their natural shape, and no further modification by flaking was performed.

\subsubsection{Techno-functional analysis: Uluzzian sample}

CTC 07 is a discoid limestone pebble (Fig. 17, Fig. 18), on this blank two UTF t were recognised: one is a UTF t1/hammerstone (Fig. 18) found on the distal convex surface on one side of the blank, and the other is a UTF t/anvil located on the central flat surface of the blank (Fig. 17). What is of particular interest in this tool is the distinctive structuration of the UTF $p$ of the anvil. Specific activity was devoted to altering the original shape of the tool in order to obtain an angular UTF p. A first series of detachments was performed on the lower side of the blank in order to thin the volume of the blank (detachments in purple Fig.17), and a second series of detachments was aimed at defining the morphology of the UTF $p$ (detachments in green Fig. 17). These intentional modifications of the blank caused a diverse rate of stability of the tool (cfr. paragraph 4.3). 
CTC 18 is a discoid limestone fragment (Fig. 20) with two potential functions: an anvil and a working edge. The UTF t/anvil is located on the flat central side of the blank, on the opposite side to an angular UTF p, that was created by removing some flakes. Like CTC 07, the UTF p was intentionally modified by flaking (Fig. 20). Two UTF t/working edges were located on the edges of the tool. One is a transversal rectilinear working edge, and the other is a lateral denticulate working edge (no use-wears were identified on these UTF $\mathrm{t}$ ).

CTC 16 is a discoid limestone pebble (Fig. 13-14) similar in structure and use to CTC 18. In both tools, a blank was selected and modified in order to perform two activities: working edge and anvil. Moreover, in both tools there is evidence of an intentional activity devoted to modifying the prehensile portion of the tools. In the case of UTF t/anvil of CTC 16 (Fig. 13), the percussive traces are located in the central portion of the flat side of the blank. UTF p (on the opposite side) is made by two detachments that build an angular surface, similar to the UTF p of CTC 07 and CTC 18. On the distal side of the tool, it is possible to isolate a UTF t/working edge (Fig. 14). The modification solved two goals: the isolation of the working edge and the definition of the angular prehensile portion.

The removals on the UTFp of CTC 07, CTC 16 and CTC 18 can be interpreted as an intentional action of shaping, performed in order to create stability. We cannot completely exclude the possibility that these pieces were previously cores which were then re-used as an anvil. However, the Uluzzian cores display different kinds of reduction and different sizes of the extracted products in comparison to CTC 07, CTC 16 and CTC 18. This support our interpretation that these pieces were intentionally modified in order to obtain a flat UT Ft opposed to a convergent UTF p, so as to stabilise the anvil.

CTC 15 is a spheroid limestone fragment (Fig. 15-16) The flat surface of the blank was used as UTFt/anvil (Fig. 15), the opposed UTF $\mathrm{p}$ is angular, in this case, it is not made intentionally, but it makes use of the angular shape of the blank. Another characteristic UTF t/hammerstone is located on the edge of the blank (Fig. 16). This is not on a convex surface (as seen in the other hammerstones) but on a convergent edge. On the opposite side the UTF $\mathrm{p}$ is found on a flat surface.

CTC 17 is a discoid limestone pebble (Fig. 19) with two flat opposing surfaces. One side is used as UTF t/anvil and the other as UTF p.

CTC 06 (Fig. 11-12) is a spheroid sandstone pebble, broken on two sides like CTC 04 and CTC 02.

On this blank three UTF t were recognised: UTF t/anvil and UTF t1/anvil respectively on each flat surface (Fig. 11); and UTF t/hammerstone on the convex edge (Fig. 12).

CTC 02 is a discoid sandstone pebble, broken on two sides. The natural convex thin side of the blank was used, without any further flaking modification. The UTF t/hammerstone-retoucher is located on the edge of one side of the blank (Fig. 21).

To sum up, the Uluzzian tools are six blanks on which several UTF t were imposed, usually each tool shows more than two UTF t. All the blanks display one or more UTF t/anvil, CTC 06 and CTC 07 also have one UTF t/hammerstone. In two cases as well as the UTF t anvil, the blank also had a UTF t/working edge. Except for CTC 06 which is made of sandstone, all the other tools were made of limestone. In two cases the blanks were used as they were (natural/original shape), without any activity of flaking. In the other four cases, on the contrary, we note a specific action of flaking aimed at modifying the original volume of the tool.

\subsection{Definition of techno-type: a combined study of techno-functional and use-wear analyses}


By considering the type of blank and the number and location of UTF $t$ and UTF p, their relationship with each other, and their organisation on each blank, we were able to define one or more techno-types for each kind of tool (anvil, hammerstone or working edge). On each blank one or more different UTF t can be found, therefore showing that some pieces were used for more than one function (i.e as anvil and hammerstone or anvil and tool with working edges). Moreover, to a strict techno-functional analysis, we added the use-wear analysis. In this way, we were able to understand these tools from a structural and functional point of view.

We will first consider the techno-types of anvil, hammerstone and working edge, purely from a technical point of view, then we will consider their association to a techno-complex (Mousterian/Uluzzian).

For the anvils, we identified two techno-types (Fig. 22): techno-type 1- structured anvil and techno-type 2- the biflat anvil.

Techno-type 1- structured anvil includes the pieces CTC 07, 18, 16 and 15. These tools are characterised by a UTF t/anvil located on a flat surface opposite to an angular surface, where a UTF p has been created by flaking. The angular UTF $p$ is not stable when placed on a flat surface, and therefore suggests that this purposeful construction of an angular UTF p could be because it was intended to be inserted into a stabiliser-support, i.e. they could be simply inserted into the ground, or into natural hollows or depressions in the cave floor, or into a wooden support (Fig. 23).

Techno-type 2 - the biflat anvil (Fig. 22) includes the pieces CTC 06, 04 and 17. These tools are characterised by two flat surfaces, one devoted to the UTF t/anvil and the other the UTF p. In the case of CTC 06, the two flat surfaces had performed both the roles of transformative UTF and prehensile UTF in different chronological moments.

The Uluzzian anvils (CTC 07, 18, 16, 15, 06, 17) are not only characterised by a purposeful construction of the tool, but also by a specific utilisation. The use-wear analysis and our experimental reference collection show that these tools were anvils used explicitly for the bipolar technique on anvil, this is also supported by other studies (Donnart et al. 2009). This corroborates the large use of bipolar knapping technique in the Uluzzian contexts (Marciani et al. 2020 and reference therein).

Apart from two items, all of the anvils (CTC 06, 07, 15) display two different areas of percussion, usually adjacent. In one case (CTC 06) both the flat surfaces of the tool have been exploited. On these tools bipolar knapping has been employed for blank productions and not for breaking open blocks, as suggested by the clustered distribution of the traces as well as the presence of distinctive use-wear, namely linear impacts, that are produced by the dihedral of the percussed core.

The single Mousterian anvil CTC 04 (in techno-type 2 biflat anvil) belongs to discoid morphological class and it is the only anvil showing use-wear not related to bipolar knapping but possibly to the activity of crushing some materials. It does not show linear impacts, which are the characteristic use-wear related to bipolar knapping production. Instead the anvil shows a clustered distribution of use-traces in a small area. High magnification analysis shows a difference between micro-wear patterns on our experimental anvil employed in bipolar knapping and micro-wear patterns detected on the anvil CTC 04, which would therefore suggest that this tool has been used for processing organic materials. Other percussive activities such as nut cracking, plant pounding and meat tenderising tend to produce a scattered distribution of use-wear on the whole surface of anvils (see for example de la Torre et al. 2013). To explain the difference between the distribution of the traces on UTF t/anvil of CTC 04 and the ones examined by de la Torre and colleagues, we can hypothesise that the pounding activity performed on anvil CTC 04 was short-term and concentrated in a small area. To sum up, structure and function of Mousterian and Uluzzian anvils are different: Mousterian anvil was used for crushing activities whereas Uluzzian anvils were specifically made and used for flaking by bipolar technique. Even 
considering that the Mousterian sample is represented by only one anvil, it is worth noting that this tool shows functional features not recorded in the Uluzzian items.

Among the hammerstones, we identified four techno-types: techno-type 1- round hammerstone/ pestle; techno-type 2 massive hammerstone; techno-type 3 - thin hammerstone/retoucher; techno-type 4 - angular hammerstone (Fig. 24). Techno-type 1- round hammerstone/pestle (Fig. 24) includes tool CTC 01, a round pebble with two UTF t/hammerstone located on convex areas. This techno-type is recorded only in the Mousterian sample.

Techno-type 2 - massive hammerstone (Fig. 24) includes the tools CTC 04 and 06. These tools possess a massive volume, and their convex edges were used as UTF t/hammerstone for active percussion.

Techno-type 3 - thin hammerstone/retoucher (Fig. 24) includes the tools CTC 02, 07 and 12 whose convex edges were used as UTF t/hammerstone. The difference between techno-type 2 and 3 is their different mass, size and subsequent dimension of the contact area, which led to a different use.

Techno-type 4 - angular hammerstone (Fig. 24) includes CTC 15 whose convergent edge was used as UTF t/hammerstone. This techno-type is documented only in the Uluzzian record.

The Uluzzian hammerstones CTC 06, 07, 02 and 15 are of three different techno-types (CTC 06 techno-type 2, CTC 07, 02 techno-type 3 and CTC 15 techno-type 4) and of different raw materials (CTC 06 sandstone and CTC 07,02 and 15 limestone). CTC 06 and 07 have the blank morphology (spheroid) as well as their double function, that is the UTF t/hammerstone and UTF t /anvil. They have been possibly used in knapping, as use-wear patterns as well as traces distribution are consistent with this activity. Both tools were used for direct percussion, as shown by use-wear analysis and as suggested by their shape and size. Usually the hammerstones used for the bipolar knapping have a contact flat surface and a spherical or cubic morphology. These characteristics are useful for holding the hammerstone better and for hitting with more strength (Rault 1992; Donnart et al. 2009), as our experimental tests also showed us. CTC 02 is a discoid and only plays the role of hammerstone/retoucher.

The tool CTC 15, as well as the function of anvil, displays evident percussion traces located on the UTF $\mathrm{t}$ (an angular edge), suggesting that this object has probably been used to crush hard material rather than for knapping activity.

Hammerstones with angular edges are not suitable for knapping, because a uniform surface which transmits uniformly the force is required to produce a conchoidal fracture on the core (de la Torre and Mora 2009-2010).

The three Mousterian hammerstones are one of each techno-type: CTC 01 round hammerstone/pestle; CTC 04 massive hammerstone (which also has a double function as anvil), and CTC 12 which is a thin hammerstone/retoucher. The dispersed distribution of pit-marks along the whole surface of the CTC 01 (UTF t/hammerstone) would suggest that it has been used as a pestle, rather than a hammerstone for knapping activity. Hammerstones for knapping activity usually exhibit concentrated use-wear at one or both extremities of the pebble which is absent on CTC 01. Shallow and rounded pit-marks recorded on the UTF t of tool CTC 01 could be consistent with contact with organic material (i.e. nuts).

The traces localised on the lateral side of CTC 04 (UTFt1/hammerstone), have a large distribution not consistent with a use as hammerstone in knapping activity. It is conceivable that it could have been used to crush hard or medium-hard materials (i.e bone), given the big size of the specimen and the extended depressions caused by the thrusting percussion Only the UTF t/hammerstone of CTC 12 is likely to have been used in knapping activity. The weakly battered zone, located on an extremity of this tool, as well as the dimensions and the weight of this object, suggest that it has been used as retoucher.

To sum up, whilst anvils coming from the two techno-complexes showed essential differences, as far as regards the hammerstone between Mousterian and Uluzzian there are fewer differences. However, it is notable that the function of a hammerstone is strictly related to its techno-type, namely it is the shape and mass of the tool which gives it a different 
function, thus defining the kind of action that is performed. Techno-type 1-hammerstone-pestle is characterised by a tool of a spheroid shape (Mousterian-CTC 01) which was therefore best suited to performing a pounding action.

Techno-type 2 is characterised by tools that are massive in volume and thus were suited to perform direct knapping (Uluzzian tool-CTC 06) and to pound materials (Mousterian tool-CTC 04). Techno-type 3 (Uluzzian tools CTC 02, 07; Mousterian tool CTC 12) is characterised by tools of thin discoid morphology, all made of sandstone, which were suited to perform retouching activities.

Two Uluzzian blanks (CTC 15 and 18) as well as having a function of anvil also possess a UTF t/working edge (Fig. 25). CTC 15 shows traces related to contact with abrasive substances, whilst the potential working edge of the CTC 18 does not exhibit use-wear.

\section{Discussion}

\subsection{Hammerstone and anvil function}

Our experimental results have shown that bipolar knapping produces distinctive use-wear on percussive tools. On the anvils traces are mostly linear impacts together with deep sub-rectangular hollows. These stigmata have already been documented by previous research on this issue (Breuil and Lantier, 1951; Donnart et al., 2009; de la Peña, 2011, Roda Gilabert et al., 2012). Whilst bipolar knapping creates recurrent linear impacts, the traces produced by other percussive activities are significantly different. At macroscopic observation, pounding and crushing different kinds of raw materials produces diffuse pitting and small depressions, whose development could be linked to both the hardness of worked material and the intensity of use (e. g. Roda Gilabert et al., 2012; de la Torre et al. 2013; Arroyo and de la Torre 2016; Hayes et al., 2018)..In our experiments of bipolar knapping the linear impacts are generated by the impact of the dihedron of the core on the anvil when it is strongly hit by the hammerstone (for the structuration of the dihedron on the core see Aureli et al. in preparation). Damages on anvils from cracking and pounding medium or hard materials are usually characterised by impact marks due to accidental hammerstone contact, because the processed materials absorb most of the energy (de la Torre et al. 2013; Arroyo and de la Torre 2016). Furthermore, the use of splintered pieces as wedges also fail to create linear impacts on the anvil, because contact with the anvil surface is prevented by the worked material.

Traces on hammerstones used for bipolar technique are less distinctive, even though the formation of deep hollows is significant enough when compared to hammerstones used in direct percussion. The latter tools usually exhibit diffuse pitting and occasional and shallow hollows. At microscopic level the near absence, or a sporadic presence, of striations could constitute a specific feature of the hammerstone used in bipolar knapping.

No traces denoting bipolar knapping on anvil has been recorded on the Mousterian pieces. The observed use-wear (especially diffuse pit-marks and shallow hollows) instead suggest that Mousterian tools were used as hammerstone or anvil in other percussive activities (e.g. crushing, retouching). One specimen (CTC 01) exhibits diffuse distribution of pit-marks and shallow hollows that suggest that it was used as a pestle for pounding medium/hard materials. On the pebble CTC 12 traces related to knapping (pit-marks and some detachment scars clustered on one side of the stone) have been documented, it was likely used as a retoucher in direct percussion.

The specimen CTC 04 has been employed as both anvil and hammerstone. In both cases the used areas do not show traces related to bipolar knapping, shown by the absence of linear impacts when the specimen functioned as an anvil and the presence of diffuse distribution of pit-marks and shallow hollows when it functioned as hammerstone. It can be inferred that CTC 04 was used in crushing some kind of hard material (such as hard-shell nuts, bones). 
In contrast, all the anvils recovered in the Uluzzian layers show linear impacts often found together with deep hollows showing the use of bipolar knapping. Some of these tools were also used as hammerstones in direct percussion. These tools display sub-circular and sub-rectangular pit-marks together with striations but there is an absence of hollows.

The fact that the Uluzzian tools were also used for other activities apart from knapping can be noted on the specimen CTC 15, the UTFt hammerstone, which has an angular morphology, was used for crushing hard materials. CTC 16 and CTC 18 exhibit a working edge, one of which bears use-wear traces, probably due to the contact with dry hide. Therefore, a double function of several tools, i.e. CTC 15 and CTC 16) can be inferred (even if we are not able to establish a chronological sequence). This fact indicates that Uluzzians may have taken advantage of the same tool to subsequently perform several other activities.

\subsection{The different structures and functions of hammerstones and anvils in the Mousterian and Uluzzian}

Different features can be recognised between the hammerstones and anvils in the Mousterian and the Uluzzian layers at Castelcivita.

Mousterian tools are all made in sandstone, and the most common UTF t is the hammerstone. Only in one case, is a UTF t/anvil attested to, and it would appear to have been used for crushing activities. The Mousterian tools were selected for their natural shape, and no further action was performed to change the volume and shape of the tool before using them.

Such a small sample does not allow us to outline a detailed scenario about the use of these tools in the Mousterian of Castelcivita. Nevertheless, two observations can be made, firstly no bipolar knapping was performed by these tools (absence of use-wear traces indicating bipolar technique) and secondly these tools were employed in various tasks (e.g. crushing, retouching). In this framework, it is worth noting the flexible function of the specimen CTC 04, used as anvil and as hammerstone.

The bipolar flaking technique is however documented in some other Mousterian sites, but it holds a marginal position, which is usually related to the breaking open of little pebbles in the initial stages of the knapping activity (Bietti et al. 2009-2010), rather than for the production of target objects. Study on the Mousterian lithic assemblage of Castelcivita does not yet show the presence of this technique, moreover an exploitation of blocks rather than little pebbles is attested to at the site (Gambassini 1997). However, the involvement of hammerstones and anvils in tasks other than knapping activity is largely documented in Mousterian (e.g. breaking bones, nuts) (Pop et al. 2018).

When looking at the Uluzzian record, a different scenario can be observed. Mostly tools are made in limestone and they have all undergone a first phase of flaking/retouching in order to suit their final use as a tool. Only two objects (CTC 06 and 17) were used without any modification.

Uluzzian anvils have mostly been used in bipolar knapping. Most of the examined tools show an intense exploitation, documented by very developed use traces, and the presence of more than one used zone. The structured anvils (suitably modified anvils) recovered at Castelcivita were made of limestone. Whilst limestone blocks are easily found near the site, limestone blocks with two flat surfaces (easily exploitable as a stable biflat anvil) were difficult to find. This is because blocks of limestone can be found as debris collapsed from the vault of the cave or as slope debris. In both cases, the blocks generally show an irregular shape. On the contrary, sandstone cobbles coming from the Calore river display more regular shapes and roundness. In particular, the more commonly found biflat sandstone cobble (discoidal in shape), that did not need to be modified, would have been the natural choice. Therefore, this also supports our idea that the creation of structured anvils was a technical choice, not driven by the scarcity of raw material. The anvils in the 
Uluzzian record of Castelcivita are generally small and light. This could be a desired characteristic for anvils used in bipolar knapping, maybe because it could signify portable tools.

The collected data show a certain flexibility in the role played by a single tool (both as hammerstone and as anvil), at least in the Uluzzian record of Castelcivita, confirming a functional variability also noted in other studies (Donnart et al. 2009; Roda Gilabert et al. 2012).

In the Uluzzian record, there is a distinct lack of hammerstones used in bipolar percussion, in comparison to the large number of anvils used for this purpose that was found. According to our experimental tests -also supported by the literature (e.g. Donnart et al., 2009; de la Peña, 2011; Roda Gilabert et al., 2012; Caricola et al., 2018)- the Uluzzian percussive tools from Castelcivita are commonly used both as hammerstones in direct percussion and as anvils in bipolar technique. Furthermore, as hammerstones, they do not show developed traces, thus suggesting a short term or occasional use. So far the absence of hammerstones for bipolar knapping in the Uluzzian layers is difficult to explain, hopefully future excavations of the site will shed some light on this conundrum.

To summarise, we can synthesise the main distinctive features of Mousterian and Uluzzian tools at Castelcivita in the following table (Table 6), even if we are aware of the limitation given by the small Mousterian sample. Between the Mousterian and the Uluzzian, we may note a different selection of the raw material and a different technical way of approaching the tool: Mousterian takes advantage of the natural shape of the blank, whilst the Uluzzian changes the original volume of the blank, adapting the natural shape of the blank to their necessities.

\begin{tabular}{|l|l|}
\hline Mousterian & Uluzzian \\
\hline All made in sandstone & Mainly made in limestone (only two in sandstone) \\
\hline Kept the natural shape of blank & Adjustment by flaking of the blank \\
\hline Hammerstones with percussion traces & Hammerstones with percussion traces \\
\hline Anvil with traces NOT related to bipolar knapping & Anvils with traces of flaking by bipolar technique \\
\hline I & Working edges \\
\hline
\end{tabular}

Table 6 Overview of the percussive tools in Mousterian and Uluzzian techno-complex

\subsection{Reflection on the Uluzzian lithic technical behaviour}

The bipolar technique on anvil is one of the distinctive features of the Uluzzian (Marciani et al. 2020 and references therein). Thanks to recent study on the Uluzzian context at Roccia San Sebastiano (Collina et al. 2020) and Castelcivita (ongoing analysis, see http://www.erc-success.eu), it has become clear that the bipolar technique was not an imposition or a constraint imposed by the raw material. In fact, it is a purposeful technological choice which includes not only the selection of the module of raw materials to be flaked but also management and control of guide ribs (Collina et al. 2020) and dihedron on the core in order to channel the force of the impact. As regards this issue, a specific study is in progress with the aim of understanding in greater depth the role of the dihedron in the bipolar knapping on anvil in the Uluzzian techno-complex (Aureli et al., in preparation). The use of the bipolar technique on anvil in the Uluzzian is actually a straightforward choice which gave technical advantages related to the higher versatility in terms of initial blanks to be flaked (pebbles, blocks, flakes), and debitage goals (high productivity of a variety of objects characterised by different size, morphology and edge delineation, rectilinear profiles) (Collina et al. 2020; Rossini 2020; Aureli et al. in preparation).

The Uluzzian sample from Castelcivita reveals a certain level of technical investment concerning the instruments devoted to perform the bipolar production: the anvils. These technical choices began with the accurate selection of the raw 
material, which needed to have specific physical characteristics. The raw material selection to make an anvil appears to be oriented towards compact elastic rocks, probably because they do not absorb the force produced by the hammerstone, but on the contrary, they return it. It has been observed in our experimental tests and confirmed by other studies (Vergès and Ollé 2011) that in bipolar knapping the counterblow produced by the anvil plays a key role in the detachment of flakes. Moreover, the abundance of limestone in the cave could have played a part in this selection. As well as this specific choice in the raw material, we note that there was also a specific choice in how to structure the anvils. There has been a specific technical choice to modify the anvil, creating an unstable UTF p portion, which makes necessary the use of a support which the anvil could be inserted into (e.g. wood, ground, sand). In this regard, we were able to identify specific use-wear on the other side of the anvils only on one specimen (CTC 16), whilst the other specimens show unclear traces. Probably the support in which they were inserted as well as the short time of use do not help the formation of diagnostic traces.

The main question of our interest now is to clarify the reason behind this modification activity on the anvils. Specifically, what does it mean from a technical point of view to insert the anvil into a support? What advantages does it give to the knapper?

Perhaps, an anvil inserted into a support, as well as becoming more stable, also could have given the knapper a greater control of the impact, namely the impact shock would have been low.

During our experimental activity, it was clear that there was a recurrent gestural adaptation to be able to produce the target flakes. These adaptations were, both in the position of the core on the anvil and on the angle and gesture performed by the experimental knapper. During the experimental flaking activity, we tested the physical response of flaking that comes from using biflat anvils placed on different materials. When placed on a hard surface (in this case a block of rock) the double impact, the one of the hammerstone and the counterblow of the anvil were enhanced. Whereas, when we placed the anvil directly on the ground or on a piece of wood, the impacts of the strike and counterblow were lower. We plan to also experiment with structured anvils.

\section{Conclusion}

Hammerstones and anvils are rich in informative potential about the technical behaviours of our ancestors. Even if percussive activities appear simple and easy, they result from accurate technical choices, starting from the selection of raw material. Understanding the way of functioning as well as the function of hammerstones and anvils allowed us to explore in-depth fundamental tasks for the subsistence of Prehistoric people (e.g. tool production, food processing...). Whilst taking into account the limitations of the small Mousterian sample, the Mousterian and Uluzzian tools of Castelcivita are different in raw material and in the way of perceiving the tool, maybe because of the different functions they had in the two techno-complexes. The Mousterian only used unchanged, sandstone blanks to perform various percussive activities (pounding and retouching) but not for bipolar knapping. The Uluzzian people mostly used percussive tools for knapping and more specifically in the bipolar technique. This behaviour probably affected the way of approaching the tool. The Uluzzian people modified the original volume and natural shape of the blank according to their purposes. In particular, the attention that Uluzzians devoted to the construction of the anvils supports the idea that the bipolar technique played a central role in this techno-complex. The bipolar technique should be considered a technical choice, related to the entire procedure of the production: the search for raw materials with specific physical characteristics, the management of the production of target objects and the use of the structured anvils in order to gain a specific reaction from the raw material. 
Our research showed the potentials of an integrated study of use-wear and techno-functional analysis applied to these particular tools, that allowed us to understand their purposeful structure in relation to their actual use. This is a relevant result, at least as regards our knowledge of bipolar knapping on anvil in the Uluzzian techno-complex which does not appear as a simple uncontrolled technique, but as a precise technical choice aimed to obtain specific results in terms of lithic production.

\section{Acknowledgements}

We are grateful to the Soprintendenza Archeologia, Belle Arti e Paesaggio per le Province di Salerno e Avellino for supporting our research and fieldwork over the years (MIBACT permission DG-ABAP_SERV

II_UO1|15/05/2018|0013226-P| [34.31.07/3.5.1/2018]).

We would also like to acknowledge the contribution from the Municipality of Castelcivita, Società Grotte di Castelcivita S.r.l. and Parco Nazionale del Cilento e Vallo di Diano, in the form of logistic support.

We are grateful to Prof. Paolo Gambassini for giving us the possibility of studying the material from his excavations. A special thanks to Mandala Macgregor for revising the English manuscript.

We would also like to thank the two reviewers for their valuable comments, which greatly improved the quality of the manuscript.

\section{References}

Abruzzese C, Aureli D, Rocca R (2016) Assessment of the Acheulean in Southern Italy: New study on the Atella site (Basilicata, Italy). Quat Int 393:158-168. https://doi.org/10.1016/j.quaint.2015.06.005

Adams JL (2014) Ground stone analysis: a technological approach. University of Utah Press. Salt Lake City, UT.

Adams J, Delgado S, Dubreuil L, Hamon C, Plisson H, Risch R (2009) Functional analysis of Macro-Lithic Artefacts. In: Sternke F, Eigeland L, Costa L-J, (eds.) Non-Flint Raw Material Use in Prehistory: Old Prejudices and New Directions. Proceedings of the 25th Congress of the U.I.S.P.P., BAR International Series 1939, Archaeopress, Oxford, pp. 43-66

Andrefsky W (1994) The geological occurrence of lithic material and stone tool production strategies. Geoarchaeology 9: $345-362$

Andrefsky W (1998) Lithics: Macroscopic Approaches to Analysis. Cambridge University Press, Cambridge

Arrighi S, Freguglia M, Ranaldo F, Ronchitelli A (2009) Production and use in the Lithic Industry of the Mousterian in Santa Croce (Bisceglie, Italy). Hum Evol 24(2): 91-106

Arrighi S, Moroni A, Tassoni L, Boschin F, Badino F, Bortolini E, Boscato P, Crezzini J, Figus C, Forte M, Lugli F, Marciani G, Oxilia G, Negrino F, Riel-Salvatore J, Romandini M, Peresani M, Spinapolice EE, Ronchitelli A, Benazzi S (2020a) Bone tools, ornaments and other unusual objects during the Middle to Upper Palaeolithic transition in Italy. Quat Int. https://doi.org/10.1016/j.quaint.2019.11.016

Arrighi S, Bortolini E, Tassoni L, Benocci A, Manganelli G, Spagnolo V, Foresi LM, Bambini AM, Lugli F, Badino F, Aureli D, Boschin F, Figus C, Marciani G, Oxilia G, Silvestrini S, Cipriani A, Romandini M, Peresani M, Ronchitelli A, Moroni A, Benazzi S (2020b) Backdating systematic shell ornament making in Europe to 45,000 years ago. Archaeol Anthropol Sci 12 (59). https://doi.org/10.1007/s12520-019-00985-3 
Arroyo A, de la Torre I (2016) Assessing the function of pounding tools in the Early Stone Age: a microscopic approach to the analysis of percussive artefacts from beds I and II, Olduvai Gorge (Tanzania). J Archaeol Sci 74: 2334. https://doi.org/10.1016/j.jas.2016.08.003

Aureli D, Contardi A, Giaccio B, Jicha B, Lemorini C, Madonna S, Magri D, Marano F, Milli S, Modesti V, Palombo MR, Rocca R (2015) Palaeoloxodon and human interaction: Depositional setting, chronology and archaeology at the Middle Pleistocene Ficoncella site (Tarquinia, Italy). PLOS ONE 10 (4): e0124498.

https://doi.org/10.1371/journal.pone.0124498

Barham LS (1987) The Bipolar Technique in Southern Africa: A Replication Experiment. S Afr Archaeol Bull 42: 4550.

Benazzi S, Douka K, Fornai C, Bauer CC, Kullmer O, Svoboda J, Pap I, Mallegni F, Bayle P, Coquerelle M, Condemi S, Ronchitelli A, Harvati K, Weber GW (2011) Early dispersal of modern humans in Europe and implications for Neanderthal behaviour. Nature 479: 525-528. https://doi.org/10.1038/nature10617

Benito-Calvo A, Crittenden AN, Livengood SV, Sánchez-Romero L, Martínez-Fernández A, de la Torre I, Pante M (2018) 3D $360^{\circ}$ surface morphometric analysis of pounding stone tools used by Hadza foragers of Tanzania: A new methodological approach for studying percussive stone artefacts. J Archaeol Sci Rep 20: 611-621.

https://doi.org/10.1016/j.jasrep.2018.06.003

Bietti A, Cancellieri A, Corinaldesi C, Grimaldi S, Spinapolice S (2009-2010) La percussion sur enclume en Italie centrale Tyrrhénienne. The bipolar-on-anvil percussion in central Thyrrenian Italy. Paléo Numéro special: 143-180. http://journals.openedition.org/paleo/1956

Binford L, Quimby G (1963) Indian sites and chipped stone materials in the northern Lake Michigan area. Fieldiana, Anthropol $36: 277-307$

Boëda E (1991) Approche de la variabilité des systèmes de production lithique des industries du Paléolithique inférieur et moyen : chronologie d'une variabilité attendue. Technique et Culture $17: 37-79$

Boëda E (1997) Technogenèse de systèmes de production lithique au Paléolithique inférieur et moyen en Europe occidentale et au Proche-Orient. Habilitation à diriger des recherches, Université Paris Ouest Nanterre La Défense, Nanterre.

Boëda E (2001) Détermination des Unités Techno-Fonctionnelles de pièces bifaciales provenant de la couche acheuléenne C'3 base du site de Barbas I. In: Cliquet D (ed) Les Industries à Outils Bifaciaux Du Paléolithique Moyen d'Europe Occidentale. Université de Liège, Liège, pp 51-75

Boëda E (2013) Techno-logique \& Technologie : Une paléo-histoire des objets lithiques tranchants. Archéo-éditions, Paris

Boëda E, Hou Y-M (2011) Analyse des artefacts lithiques du site de Longgupo. L'Anthropologie 115: 78-75. https://doi.org/10.1016/j.anthro.2010.12.005

Boëda E, Bonilauri S, Kaltnecker E, Valladas H, Al-Sakhel H (2015) Un débitage lamellaire au Proche-Orient vers 40 000 ans cal BP. Le site d'Umm el Tlel, Syrie centrale. L'Anthropologie 119: 141-169.

https://doi.org/10.1016/j.anthro.2015.04.001

Boesch C, Boesch-Achermann H (2000) The chimpanzees of the Taï Forest: Behavioural ecology and evolution. Cambridge University Press, Cambridge.

Boinski S, Quatrone RP, Swartz H (2000) Substrate and Tool Use by Brown Capuchins in Suriname: Ecological Contexts and Cognitive Bases. Am Anthropol 102 : 741-761. https://doi.org/10.1525/aa.2000.102.4.741 
Bonilauri S (2010) Les outils du Paléolithique moyen : une mémoire technique oubliée ? Approche techno-fonctionnelle appliquée à un assemblage lithique de conception Levallois provenant du site d'Umm el Tlel (Syrie centrale). PhD thesis, Université Paris Ouest Nanterre, Nanterre.

Bourguignon L, Barsky D, Ivorra J, de Weyer L, Cuartero F, Capdevila R, Cavallina C, Oms O, Bruxelles L, Crochet J-Y, Rios Garaizar J (2016) The stone tools from stratigraphical unit 4 of the Bois-de-Riquet site (Lézignan-laCèbe, Hérault, France): A new milestone in the diversity of the European Acheulian. Quat Int 411(B): 160-181. https://doi.org/10.1016/j.quaint.2016.01.065

Breuil H (1954) Prolégomènes à une classification préhistorique. Bull Soc Préhist Fr 51 : 7-15

Breuil H, Lantier R (1951) Les Hommes de la pierre ancienne : Paléolithique et Mésolithique. Payot, Paris

Bril B, Dietrich G, Foucar, J, Fuwa K, Hirata S (2009) Tool use as a way to assess cognition: How do captive chimpanzees handle the weight of the hammer when cracking a nut? Anim Cogn 12: 217-235.

https://doi.org/10.1007/s10071-008-0184-x

Bril B, Smaers J, Steele J, Rein R, Nonaka T, Dietrich G, Biryukova E, Hirata S, Roux V (2012) Functional mastery of percussive technology in nut-cracking and stone-flaking actions: Experimental comparison and implications for the evolution of the human brain. Philos Trans R Soc Lond B: Biol Sci 367: 59-74. https://doi.org/10.1098/rstb.2011.0147

Bril B, Parry R, Dietrich G (2015) How similar are nut-cracking and stone-flaking? A functional approach to percussive technology. Philos Trans R Soc Lond B: Biol Sci 370: 20140355. https://doi.org/10.1098/rstb.2014.0355

Brose D (1970) The Archaeology of Summer Island: Changing Settlement Systems in Northern Lake Michigan. Museum of Anthropology, University of Michigan, Ann Arbor, MI

Byrne RW (2009) The manual skills and cognition that lie behind hominid tool use. In: Russon AE, Begun DR (eds)

The Evolution of Thought. Cambridge University Press, Cambridge, pp 31-44

https://doi.org/10.1017/cbo9780511542299.005

Cafaro S, Gueguen E, Parise M, Schiattarella M (2016) Morphometric analysis of karst features of the Alburni Mts, southern Apennines, Italy. Geografia Fisica e Dinamica Quaternaria 39: 121-128.

https://doi.org/10.4461/GFDQ.2016.39.11

Caricola I, Zupancich A, Moscone D, Mutri G, Falcucci A, Duches R, Peresani M, Cristiani E (2018) An integrated method for understanding the function of macro-lithic tools. Use wear, 3D and spatial analyses of an Early Upper Palaeolithic assemblage from North Eastern Italy. PLoS One 13(12): e0207773.

https://doi.org/10.1371/journal.pone.0207773

Caruana MV, Carvalho S, Braun DR, Presnyakova D, Haslam M, Archer W, Bobe R, Harris JWK (2014) Quantifying traces of tool use: a novel morphometric analysis of damage patterns on percussive tools. PLoS One 9(11): e113856. https://doi.org/10.1371/journal.pone. 0113856

Carvalho S, Biro D, McGrew WC, Matsuzawa T (2009) Tool-composite reuse in wild chimpanzees (Pan troglodytes): Archaeologically invisible steps in the technological evolution of early hominins? Anim Cogn 12: 103-114. https://doi.org/10.1007/s10071-009-0271-7

CHI (2011) Reflectance Transformation Imaging: Guide to Highlight Image Processing v1.4. Cultural Heritage Imaging. http://culturalheritageimaging.org/What_We_Offer/Downloads/rtibuilder/RTI_hlt_Processing_Guide_v14_beta.pdf. Accessed 15 November 2017

Collina C, Marciani G, Martini I, Donadio C, Repola L, Bortolini E, Arrighi S, Badino F, Figus C, Lugli F, Oxilia G, Romandini M, Silvestrini S, Piperno M, Benazzi S (2020) Refining the Uluzzian through a new lithic assemblage from Roccia San Sebastiano. Quat Int. https://doi.org/10.1016/j.quaint.2020.03.056 
Crabtree DE (1982) An Introduction to Flint working. Occasional Papers of the Idaho Museum of Natural History 28: $1-57$

Curtoni RP (1999) Aprovisionamiento de materia prima y técnica de reducción bipolar en un ambiente semidesértico. In: Soplando en el viento. Actas de las Terceras Jornadas de Arqueología de la Patagonia: Facultad de Humanidades, Universidad Nacional del Comahue, Buenos Aires, pp 165 - 176

Da Costa A (2017) Rupture technique et dynamiques d'occupation au cours de l'Holocène moyen au Brésil. PhD thesis, Université Paris Ouest Nanterre La Défense, Nanterre

de Beaune SA (1993) Nonflint Stone Tools of the Early Upper Paleolithic. In: Knecht H. Pike-Tay A, White R (eds) Before Lascaux: complex record of the early upper Paleolithic. CRC Press Inc, Boca Raton, pp 163-191

de Beaune SA (2004) The Invention of Technology: Prehistory and Cognition. Curr Anthropol 45: 139-162.

https://doi.org/10.1086/381045

de la Peña P (2011) Sobre la identificación macroscópica de las piezas astilladas: propuesta experimental. Trabajos de Prehistoria 65 (1): 79-98

de la Peña P (2015) A qualitative guide to recognize bipolar knapping for flint and quartz. Lithic Technology 40: 316331. https://doi.org/10.1080/01977261.2015.1123947

de la Torre I, Mora R (2005) Technological Strategies in the Lower Pleistocene at Olduvai Beds I \& II. ERAUL 112 , University of Liège Press, Liège

de la Torre I, Mora R (2009-2010) A technological analysis of non-flaked stone tools in Olduvai Beds I \& II. Stressing the relevance of percussion activities in the African Lower Pleistocene. Paléo Numéro special: 13-34.

http://journals.openedition.org/paleo/1877

de la Torre I, Benito-Calvo A, Arroyo A, Zupancich A, Proffitt T (2013) Experimental protocols for the study of battered stone anvils from Olduvai Gorge (Tanzania). J Archaeol Sci 40(1): 313-332.

https://doi.org/10.1016/j.jas.2012.08.007

de Lombera-Hermida A, Rodríguez-Álvarez XP, Peña L, Sala-Ramos R, Despriée J, Moncel M-

H, Gourcimault G, Voinchet P, Falguères C (2016) The lithic assemblage from Pont-de-Lavaud (Indre, France) and the role of the bipolar on anvil technique in the lower and early middle Pleistocene technology. J Anthropol

Archaeol 41: 159-184. https://doi.org/10.1016/j.jaa.2015.12.002

De Stefani M, Dini M, Klempererova H, Peresani M, Ranaldo F, Ronchitelli A, Ziggiotti S (2012) Continuity and replacement in flake production across the Middle-Upper Palaeolithic transition: a view over the Italian Peninsula. In:

Pastoors A, Peresani M (eds) Flakes Not Blades: the Role of Flake Production at the Onset of the Upper Palaeolithic in Europe. Neanderthal Museum, Mettmann, pp 135-151

De Weyer L (2016) Systèmes techniques et analyse techno-fonctionnelle des industries lithiques anciennes. Universaux et variabilité en Afrique de l'Est et en Europe. PhD thesis, Université Paris Ouest Nanterre La Défense, Nanterre

Delpiano D, Uthmeier T (2020) Techno-functional and 3D shape analysis applied for investigating the variability of backed tools in the Late Middle Paleolithic of Central Europe. PLoS ONE 15(8): e0236548.

https://doi.org/10.1371/journal.pone.0236548

Diez-Martín F, Sánchez Yustos P, Uribelarrea D, Baquedano E, Mark D, Mabulla A, Fraile C, Duque J, Díaz I, PérezGonzález A, Yravedra J, Egeland CP, Organista E, Domínguez-Rodrigo M (2015) The origin of The Acheulean: the 1.7 million-year-old site of FLK West, Olduvai Gorge (Tanzania). Sci Rep 5 : 17839. https://doi.org/10.1038/srep17839

Donnart K, Naudinot N, Le Clézio L (2009) Approche expérimentale du débitage bipolaire sur enclume :

Caractérisation des produits et analyse des outils de production. Bull Soc Préhist Fr 106: 517-533.

https://doi.org/10.3406/bspf.2009.13873 
Douka K, Higham TFG, Wood R, Boscato P, Gambassini P, Karkanas P, Peresani M, Ronchitelli A (2014) On the chronology of the Uluzzian. J Hum Evol 68: 1-13. https://doi.org/10.1016/j.jhevol.2013.12.007

Dubreuil L (2004) Long-term trends in Natufian subsistence: a use-wear analysis of ground stone tools. J Archaeol Sci 31(11): 1613-1629. https://doi.org/10.1016/j.jas.2004.04.003

Dubreuil L, Savage D (2014) Ground stones: A synthesis of the use-wear approach. J Archaeol Sci 48: $139-153$. https://doi.org/10.1016/j.jas.2013.06.023

Dubreuil L, Savage D, Delgado-Raack S, Plisson H, Stephenson B, de la Torre I (2015) Current analytical frameworks for studies of use - wear on ground stone tools. In: Marreiros JM, Gibaja Bao JF, Ferreira Bicho N (eds) Use-wear and residue analysis in archaeology. Springer, Switzerland, pp 105-158

Duke I, Pargeter J (2015) Weaving simple solutions to complex problems: an experimental study of skill in bipolar cobble-splitting. Lithic Technology 40: 349-365. https://doi.org/10.1179/2051618515y.0000000016

Earl G, Martinez K, Malzbender T (2010) Archaeological applications of polynomial texture mapping: Analysis, conservation and representation. J Archaeol Sci 37(8): 2040-2050. https://doi.org/10.1016/j.jas.2010.03.009

Eren MI (2010) Anvil Reduction at the Early-Paleoindian Site of Paleo Crossing (33ME274), Northeast Ohio. Current Research in the Pleistocene 27: 75-77

Falótico T, Ottoni EB (2016) The manifold use of pounding stone tools by wild capuchin monkeys of Serra da Capivara National Park, Brazil. Behaviour 153: 421-442. https://doi.org/10.1163/1568539X-00003357

Feng X (2008) Technological characterization of China and Europe lower Paleolithic industry from 1 Ma to 400.000 years. Similarity and difference between the Yunxianhominid culture and European Acheulean. L'Anthropologie 112: 423-447. https://doi.org/10.1016/j.anthro.2008.04.014

Fiorini A (2018).Il metodo fotografico RTI (Reflectance Transformation Imaging) per la documentazione delle superfici archeologiche. L'applicazione ai materiali di età protostorica. Archeologia e calcolatori 29: 241-258

Fiorini A, Curci A, Spinapolice EE, Benazzi S (2019) Grotta di Uluzzo C (Nardò-Lecce): risultati preliminari, strumenti e metodi dell'indagine archeologica. FOLD\&R Italy 440. www.fastionline.org/docs/FOLDER-it-2019-440.pdf

Flenniken JJ (1981) Replicative Systems Analysis: A Model Applied to the Vein Quartz Artifacts from the Hoko River Site. Report of Investigations 59. Washington State University, Laboratory of Anthropology, Pullman, WA

Fragaszy D, Izar P, Visalberghi E, Ottoni EB, De Oliveira MG (2004) Wild capuchin monkeys (Cebus libidinosus) use anvils and stone pounding tools. Am J Primatol 64: 359-366. https://doi.org/10.1002/ajp.20085

Fujii JA, Ralls K, Tinker MT (2015) Ecological drivers of variation in tool-use frequency across sea otter populations. Behav Ecol 26: 519-526. https://doi.org/10.1093/beheco/aru220

Gambassini P (1997) Il Paleolitico di Castelcivita: Culture e Ambiente. Electa, Napoli

Giaccio B, Hajdas I, Isaia R, Deino A, Nomade S (2017) High-precision 14C and 40Ar/ 39Ar dating of the Campanian Ignimbrite (Y-5) reconciles the time-scales of climatic-cultural processes at $40 \mathrm{ka}$. Sci Rep 7: 45940.

https://doi.org/10.1038/srep45940

Goodyear AC (1993) Tool kit entropy and bipolar reduction: a study of interassemblage lithic variability among PaleoIndian sites in the northeastern United States. North Am Archaeol 14: 1-23. https://doi.org/10.2190/HN4D-3MNN5NRX-QPC8

Goren-Inbar N, Sharon G, Melamed Y, Kislev M (2002) Nuts, nut cracking, and pitted stones at Gesher Benot Ya'aqov, Israel. Proc Natl Acad Sci 99: 2455-2460. https://doi.org/10.1073/pnas.032570499 
Goren-Inbar N, Sharon G, Alperson-Afil N, Herzlinger G (2015) A new type of anvil in the Acheulian of Gesher Benot Ya‘aqov, Israel. Philos Trans R Soc Lond B: Biol Sci 370: 20140353. https://doi.org/10.1098/rstb.2014.0353

Gould RA, Koster DA, Sontz AH (1971) The Lithic Assemblage of the Western Desert Aborigines of Australia. Am Antiq 36 (2): 149-169

Gumert MD, Kluck M, Malaivijitnond S (2009) The physical characteristics and usage patterns of stone axe and pounding hammers used by long-tailed macaques in the Andaman sea region of Thailand. Am J Primatol 71: 594-608. https://doi.org/10.1002/ajp.20694

Guyodo JN, Marchand G (2005) The bipolar percussion on an anvil in Western France from the end of the Paleolithic up to the Chalcolithic: An economic and social lecture. Bull Soc Préhist Fr 102: 539-549.

https://doi.org/10.3406/bspf.2005.13141

Hall KRL, Schaller GB (1964) Tool-Using Behavior of the California Sea Otter. J Mammal 45: $287-298$.

https://doi.org/10.2307/1376994

Harmand S, Lewis JE, Feibel CS, Lepre CJ, Prat S, Lenoble A, Boës X, Quinn RL, Brenet M, Arroyo A, Taylor N, Clément S, Daver G, Brugal JP, Leakey L, Mortlock RA, Wright JD, Lokorodi S, Kirwa C, Kent DV, Roche H (2015) 3.3-million-year-old stone tools from Lomekwi 3, West Turkana, Kenya. Nature 521: 310-315. https://doi.org/10.1038/nature14464

Haslam M, Hernandez-Aguilar A, Ling V, Carvalho S, de la Torre I, DeStefano A, Du A, Hardy B, Harris J, Marchant L, Matsuzawa T, McGrew W, Mercader J, Mora R, Petraglia M, Roche H, Visalberghi E, Warren R (2009) Primate archaeology. Nature 460: 339-344. https://doi.org/10.1038/nature08188

Haslam M, Fujii J, Espinosa S, Mayer K, Ralls K, Tinker MT, Uomini N (2019) Wild sea otter mussel pounding leaves archaeological traces. Sci Rep 9: 1-11. https://doi.org/10.1038/s41598-019-39902-y

Hayden B (1979) Paleolithic Reflections: Lithic Technology of the Australian Western Desert. Humanities Press, Canberra: Australian Institute of Aboriginal Studies, Atlantic Highlands, N.J.

Hayes E, Pardoe C, Fullagar R (2018) Sandstone grinding/pounding tools: Use-trace reference libraries and Australian archaeological application. J Archaeol Sci Rep 20 : 97-114. https://doi.org/10.1016/j.jasrep.2018.04.021

Higham T, Douka K, Wood R, Ramsey CB, Brock F, Basell L, Camps M, Arrizabalaga A, Baena J, Barroso-Ruíz C, Bergman C, Boitard C, Boscato P, Caparrós M, Conard NJ, Draily C, Froment A, Galván B, Gambassini P, GarciaMoreno A, Grimaldi S, Haesaerts P, Holt B, Iriarte-Chiapusso MJ, Jelinek A, Jordá Pardo JF, Maíllo-Fernández JM, Marom A, Maroto J, Menéndez M, Metz L, Morin E, Moroni A, Negrino F, Panagopoulou E, Peresani M, Pirson S, De La Rasilla M, Riel-Salvatore J, Ronchitelli A, Santamaria D, Semal P, Slimak L, Soler J, Soler N, Villaluenga A, Pinhasi R, Jacobi R (2014) The timing and spatiotemporal patterning of Neanderthal disappearance. Nature 512: 306309. https://doi.org/10.1038/nature13621.

Horta P, Cascalheira J, Bicho N (2019) The Role of Lithic Bipolar Technology in Western Iberia's Upper Paleolithic: the Case of Vale Boi (Southern Portugal). J Paleo Arch 2: 134-159. https://doi.org/10.1007/s41982-019-0022-5

Jeske RJ (1992) Energetic Efficiency and Lithic Technology: An Upper Mississippian Example. Am Antiq 57(3): 467481. https://doi.org/10.2307/280935

Knight J (1991) Technological analysis of the anvil (bipolar) technique. Lithics: The Journal of the Lithic Studies Society 12: $57-87$

Kuijt I, Rusell KW (1993) Tur Imdai Rockshelter, Jordan: Debitage Analysis and Historic Bedouin Lithic Technology. J Archaeol Sci 20(6): 667-680. https://doi.org/10.1006/jasc.1993.1041

Le Brun-Ricalens F (2006) Les pièces esquillées: état des connaissances après un siècle de reconnaissance. Paléo 18 : 95-114. 
Lee Y, Kong S (2006) Le site Paléolithique de Suyanggae, Corée. L’Anthropologie 110 : 223-240. https://doi.org/10.1016/j.anthro.2006.03.008

Lepot M (1993) Approche techno-fonctionnelle de l'outillage moustérien : essai de classification des parties actives en termes d'efficacité technique. Mémoire de maîtrise, Université Paris Ouest Nanterre La Défense, Nanterre

Li F (2016) An experimental study of bipolar reduction at Zhoukoudian locality 1, north China. Quat Int 400: 23-29. https://doi.org/10.1016/j.quaint.2015.08.064

Lothrop JC, Gramly RM (1982) Pièces Esquillées from the Vail Site. Archaeol East N America 10 : 1-22

Lourdeau A (2010) Le technocomplexe Itaparica : définition techno-fonctionnelle des industries unifacialement à une face plane dans le centre et le nord-est du Brésil pendant la transition Pléistocène-Holocène et l'Holocène ancien. Dissertation, Université Paris Ouest Nanterre La Dèfense, Nanterre

Lunardi A (2009) Quinzano and Rivoli, two Middle Neolithic sites in the Adige Valley (Verona, North-eastern Italy): lithic choices and functional aspects of the non-flint stone implements. In: Sternke F, Eigeland L, Costa LJ (eds) NonFlint Raw Material Use in Prehistory. Old prejudices and new directions. Proceedings of the XV World Congress UISPP 11. BAR International Series, 1939. Archaeopress, Oxford, pp 11-121

MacCalman HR, Grobelaar BJ (1965) Preliminary report of two stone-working OvaTjimba groups in the northern Kaokoveld of South West Africa. Cimbebasia 13: 1-39

MacDonald G (1968) Debert: A Paleo-Indian Site in Central Nova Scotia. Anthropology papers 16. National Museum of Canada, Ottawa

Malzbender T, Gelb D, Wolters H (2001) Polynomial texture maps. In: Pocock L (ed) Computer Graphics, SIGGRAPH 2001 Proceedings (Los Angeles 2001). ACM, New York pp 519-528

Malzbender T, Gelb D, Wolters H, Zuckerman B (2000) Enhancement of shape perception by surface reflectance transformation, Hewlett-Packard Laboratories Technical Report, HPL-2000-38R1.

www.hpl.hp.com/techreports/2000/HPL-2000-38R1.pdf. Accessed 13 November 2017.

Mangalam M, Fragaszy DM (2015) Wild bearded capuchin monkeys crack nuts dexterously. Curr Biol 25: 1334-1339. https://doi.org/10.1016/j.cub.2015.03.035

Mannu M, Ottoni EB (2009) The enhanced tool-kit of two groups of wild bearded capuchin monkeys in the caatinga: Tool making, associative use, and secondary tools. Am J Primatol 71: 242-251. https://doi.org/10.1002/ajp.20642

Marchant LF, McGrew WC (2005) Percussive technology: chimpanzee baobab smashing and the evolutionary modelling of hominid knapping. In: Roux V, Bril B (eds) Stone Knapping: The Necessary Conditions for a Uniquely Human Behaviour. McDonald Institute for Archaeological Research, Cambridge, pp 341-350

Marciani G, Arrighi S, Aureli D, Spagnolo V, Boscato P, Ronchitelli A (2018) Middle Palaeolithic lithic tools. Technofunctional and use-wear analysis of target objects from SU 13 at the Oscurusciuto rock shelter, Southern Italy. Journal of Lithic Studies 5. https://doi.org/10.2218/j1s.2745

Marciani G, Ronchitelli A, Arrighi S, Badino F, Bortolini E, Boscato P, Boschin F, Crezzini J, Delpiano D, Falcucci A, Figus C, Lugli F, Oxilia G, Romandini M, Riel-Salvatore J, Negrino F, Peresani M, Spinapolice EE, Moroni A, Benazzi S (2020) Lithic techno-complexes in Italy from 50 to 39 thousand years BP: An overview of lithic technological changes across the Middle-Upper Palaeolithic boundary. Quat Int. https://doi.org/10.1016/j.quaint.2019.11.005

Martínez K, García J, Carbonell E, Agustí J, Bahain JJ, Blain H, Burjachs F, Cáceres I, Duval M, Falguères C, Gómez M, Huguet R (2010) A new lower Pleistocene archeological site in Europe (Vallparadís, Barcelona, Spain). Proc Natl Acad Sci 107: 5762-5767. https://doi.org/10.1073/pnas.0913856107 
Masao FT (1982) On possible use of unshaped flakes: an ethno-historical approach from central Tanzania. Ethnos 47: 262-270

Masini F, Abbazzi L (1997) L'associazione di mammiferi della Grotta di Castelcivita. In: Gambassini P (ed) Il Paleolitico di Castelcivita: Culture e Ambiente. Napoli, Electa, pp 60-74

McPherron AL (1967) The Juntenen Site and the Late Woodland Prehistory of the Upper Great Lakes Area. Anthropological papers 30. Museum of Anthropology, Ann Arbor, MI

Mello PJ (2005) Análise de sistemas de produção e da variabilidade tecnofuncional de instrumentos retocados : indústrias líticas de sítios a ceú aberto do Vale do Rio Manso (Mato Grosso, Brasil). PhD thesis, PUC-RS, Porto Alegre

Méndez E (2007) The Acheulian site of As Gándaras de Budiño. The industry in fluvial environments. Complutum 18: $27-46$

Miller TO (1979) Stonework of the Xeta Indians of Brazil. In: Hayden B (ed) Lithic Use-Wear Analysis, Academic Press, New York, pp 401-407

Morice AG (1893) Notes archaeological, industrial and sociological, on the western Denes. Transactions of the Canadian Institute 4: 1-221

Moroni A, Boscato P, Ronchitelli A (2013) What roots for the Uluzzian? Modern behaviour in Central-Southern Italy and hypotheses on AMH dispersal routes. Quat Int 316: 27-44. https://doi.org/10.1016/j.quaint.2012.10.051

Moroni A, Ronchitelli A, Arrighi S, Aureli D, Bailey SE, Boscato P, Boschin F, Capecchi G, Crezzini J, Douka K, Marciani G, Panetta D, Ranaldo F, Ricci S, Scaramucci S, Spagnolo V, Benazzi S, Gambassini P (2018) Grotta del Cavallo (Apulia - Southern Italy). The Uluzzian in the mirror. J Anthropol Sci 96: 1-36.

https://doi.org/10.4436/jass.96004

Mourre V (1996a) Le débitage sur enclume au Paléolithique inférieur et moyen. Techniques, méthodes et schémas conceptuels. DEA thesis, Université de Paris X, Nanterre

Mourre V. (1996b) Les industries en quartz au Paléolithique. Terminologie, méthodologie et technologie. Paléo 8 : 205 223

Mourre V (2004) Le débitage sur enclume au Paléolithique moyen dans le Sud-Ouest de la France. In : Van Peer P, Bonjean D, Semal P (eds) Session 5 : Paléolithique moyen. BAR International Series 1239, Oxford, pp 29-38

Mudge M, Malzbender T, Chalmers A, Scopigno R, Davis J, Wang O, Gunawardane P, Ashley M, Doerr M, Proenca A, Barbosa J (2008) Image-based empirical information acquisition, scientific reliability, and long-term digital preservation for the natural sciences and Cultural Heritage. In: Roussou M,.Leigh J (eds) Eurographics 2008 Tutorials. The Eurographics Association.

http://culturalheritageimaging.org/What_We_Do/Publications/eurographics2008/eurographics_2008_tutorial_notes.pdf; Accessed 16 November 2017.

Nurse J (2015) RTI Dome: Casting new light on our past. Future Worlds, University of Southampton. https://futureworlds.com/rti-dome-casting-new-light-past/ Accessed 29 November 2017.

Palma di Cesnola A (1963) Prima campagna di scavi nella Grotta del Cavallo presso Santa Caterina (Lecce). Rivista Scienze Preistoriche 18: 41-74

Palma di Cesnola A (1964) Seconda campagna di scavi nella Grotta del Cavallo presso Santa Caterina (Lecce). Rivista Scienze Preistoriche 19: 23-39

Pargeter J, de la Peña P (2017) Milky Quartz Bipolar Reduction and Lithic Miniaturization: Experimental Results and Archaeological Implications. J Field Archaeol 42: 551-565. https://doi.org/10.1080/00934690.2017.1391649 
Pargeter J, de la Peña P, Eren MI (2019) Assessing raw material's role in bipolar and freehand miniaturized flake shape, technological structure, and fragmentation rates. Archaeol Anthropol Sci 11:5893-5907. doi: 10.1007/s12520-0180647-1

Parry W, Kelly RL (1987) Expedient core technology and sedentism. In: Johnson JK, Morrow CA (eds) The Organization of Core Technology. Westview Press, Boulder, CO, pp 285-304

Patterson LW (1979) Dynamics of the bipolar technique. Flintknappers' Exchange 2: 13-16

Peresani M, Cristiani E, Romandini M (2016) The Uluzzian technology of Grotta di Fumane and its implication for reconstructing cultural dynamics in the Middle-Upper Palaeolithic transition of Western Eurasia. J Hum Evol 9136-56. https://doi.org/10.1016/j.jhevol.2015.10.012

Peresani M, Bertola S, Delpiano D, Benazzi S, Romandini M (2019) The Uluzzian in north Italy: insights around the new evidence at Riparo del Broion. Archaeol Anthropol Sci 11: 3503-3536. https://doi.org/10.1007/s12520-018-0770-z

Peretto C (1994) Le industrie litiche del giacimento paleolitico di Isernia La Pineta. La tipologia, le tracce d'utilizzazione, la sperimentazione. Cosmo Iannone Editore, Campobasso

Pop E, Charalampopoulos D, Arps CS, Verbaas A, Roebroeks W, Gaudzinski-Windheuser S, Langejans G (2018) Middle Palaeolithic Percussive Tools from the Last Interglacial Site Neumark-Nord 2/2 (Germany) and the Visibility of Such Tools in the Archaeological Record 2. J Paleo Arch 1: 81-106. https://doi.org/10.1007/s41982-018-0008-8

Proffitt T, Luncz LV, Falótico T, Ottoni EB, de la Torre I, Haslam M (2016) Wild monkeys flake stone tools. Nature 539: 85-88. https://doi.org/10.1038/nature20112

Prous A, Alonso M (1990) A tecnologia de debitagem do quartzo no Centro de Minas Geráis: lascamento bipolar. Arquivos do Museu de História Natural 11: 91-114

Putt SS (2015) The origins of stone tool reduction and the transition to knapping: An experimental approach. J Archaeol Sci Rep 2: 51-60. https://doi.org/10.1016/j.jasrep.2015.01.004

Rault O (1992) L'économie de débitage sur le site Mésolithique récent/final de Beg an Dorchenn (Plomeur, Finistère). Mémoire de Maîtrise, Université de Paris I

Riel-Salvatore J (2009) What is a 'transitional' industry? The Uluzzian of southern Italy as a case study. In: Camps M, Chaucan P (eds) Sourcebook of Paleolithic Transitions. Springer, New York, pp 377-396. https://doi.org/10.1007/9780-387-76487-0_25

Riel-Salvatore J (2010) A Niche Construction Perspective on the Middle-Upper Paleolithic Transition in Italy. J Archaeol Method Th 17: 323-355. https://doi.org/10.1007/s10816-010-9093-9.

Robinson TR (1938) A survey of flake-technique in southern Rhodesia. Man 38 : 208-208

Rocca R (2013) Peut-on définir des aires culturelles au Paléolithique inférieur ? Originalité des premières industries lithiques en Europe centrale dans le cadre du peuplement de l'Europe. PhD thesis. Université Paris Ouest Nanterre La Défense, Nanterre

Roda Gilabert X, Martinez Moreno J, Mora Torcal R (2012) Pitted stone cobbles in the Mesolithic site of Font del Ros (Southeastern Pre-Pyrenees, Spain): Some experimental remarks around a controversial tool type. J Archaeol Sci 39: 1587-1598. https://doi.org 10.1016/j.jas.2011.12.017

Roda Gilabert X, Mora R, Martınez-Moreno J (2015) Identifying bipolar knapping in the Mesolithic site of Font del Ros (northeast Iberia). Philos Trans R Soc Lond B: Biol Sci 370: 20140354. http://dx.doi.org/10.1098/rstb.2014.0354

Ronchitelli A, Boscato P, Gambassini P (2009) Gli ultimi Neandertaliani in Italia: aspetti culturali. In: Facchini F, Belcastro GM (eds) La lunga storia di Neandertal. Biologia e comportamento. Jaka Book, Bologna, pp 257-288 
Ronchitelli A, Moroni A, Boscato P, Gambassini P (2018) The Uluzzian 50 years later. In: Valde-Nowak KSP (ed) Multas per Gentes et Multa per Saecula. Alter Radosław Palonka, Kraków, pp 71-76

Rossini, M (2020) Studio tecnologico dell'industria litica Uluzziana proveniente dal livello rpi della Grotta di Castelcivita (Salerno, Campania). Tesi magistrale. Università degli Studi di Ferrara, Ferrara

Roth WE (1924) An introductory study of the arts, crafts, and customs of the Guiana Indians. Annual Report of the Bureau of American Ethnology 38: 25-745

Sano K, Arrighi S, Stani C, Aureli D, Boschin F, Fiore I, Spagnolo V, Ricci S, Crezzini J, Boscato P, Gala M, Tagliacozzo A, Birarda G, Vaccari L, Ronchitelli A, Moroni A, Benazzi S (2019) The earliest evidence for mechanically delivered projectile weapons in Europe. Nat Ecol Evol 3: 1409-1414. https://doi.org/10.1038/s41559-0190990-3

Schick KD, Toth N, Garuf, G, Savage-Rumbaugh ES, Rumbaugh D, Sevcik R (1999) Tool-using Capabilities of a Bonobo (Pan paniscus). J Archaeol Sci 26: 821-832

Shott MJ (1989) Bipolar industries: ethnographic evidence and archaeological implications. North Am Archaeol 10: 124. https://doi.org/10.2190/AAKD-X5Y1-89H6-NGJW

Shott MJ (1999) On Bipolar Reduction and Splintered Pieces. North Am Archaeol 20: 217-238. https://doi.org/10.2190/0VP5-TT1E-3WLC-9RCA

Sillitoe P (1982) The lithic technology of a Papua New Guinea highland people. The Artefact 7 : 19-38

Soriano S 2000 Outillage bifacial et outillage sur éclat au Paléolithique ancien et moyen : coexistence et interaction. PhD thesis, Université Paris Ouest Nanterre La Défense, Nanterre

Soriano S, Robert A, Huysecom É (2009-2010) Percussion bipolaire sur enclume : choix ou contrainte ? L'exemple du Paléolithique d'Ounjougou (Paysdogon, Mali). Paléo Numéro spécial : 123-132.

https://journals.openedition.org/paleo/1962

Strathern M (1969) Stone axes and flake tools: evaluations from New Guinea. Proceedings of the Prehistoric Society, 35: $311-329$

Teit J (1900) The Thompson Indians of British Columbia. American Museum of Natural History Memoir 2: 163-392

Vergès JM, Ollé A (2011) Technical microwear and residues in identifying bipolar knapping on an anvil: Experimental data. J Archaeol Sci 38: 1016-1025. https://doi.org/10.1016/j.jas.2010.11.016

Venditti F, Agam A, Barkai R (2019) Techno-functional analysis of small recycled flakes from Late Acheulian Revadim (Israel) demonstrates a link between morphology and function. J Archaeol Sci Rep 28.

http://dx.doi.org/10.1016/j.jasrep.2019.102039

Vettese D, Blasco R, Cáceres I, Gaudzinski-Windheuser S, Moncel M, Thun-Hohenstein U, Daujeard C (2020) Towards an understanding of hominin marrow extraction strategies: a proposal for a percussion mark terminology. Archaeol Anthropol Sci 12 (48). https://doi.org/10.1007/s12520-019-00972-8

Villa P, Pollarolo L, Conforti J, Marra F, Biagioni C, Degano I, Lucejko JJ, Tozzi C, Pennacchioni M, Zanchetta G, Nicosia C, Martini M, Sibilia E, Panzeri L (2018) From Neandertals to modern humans: new data on the Uluzzian. PLoS One 13: e0196786. http://dx.doi.org/10.1371/journal.pone.0196786

Visalberghi E, Haslam M, Spagnoletti N, Fragaszy D (2013) Use of stone hammer tools and anvils by bearded capuchin monkeys over time and space: Construction of an archeological record of tool use. J Archaeol Sci 40: 3222-3232. http://dx.doi.org/10.1016/j.jas.2013.03.021 
Visalberghi E, Sirianni G, Fragaszy D, Boesch C (2015) Percussive tool use by Taï Western chimpanzees and Fazenda Boa Vista bearded capuchin monkeys: a comparison. Philos Trans R Soc Lond B: Biol Sci 370: 20140351. http://dx.doi.org/10.1098/rstb.2014.0351

Wadley L (1993) The Pleistocene later stone age south of the Limpopo river. J World Prehist 7: 243-296.

Watson VD (1995) Simple and significant: stone tool production in highland New Guinea. Lithic Technology 20: 89-99

White JP (1968) Fabricators, outils écaillés or scalar cores? Mankind 6: 658-666. http://dx.doi.org/10.1111/j.18359310.1968.tb00759.x

White JP, Thomas DH (1972) What mean these stones? Ethno-taxonomic models and archaeological interpretations in the New Guinea highlands. In: Clarke DL (ed) Models in Archaeology. Methuen, London, pp 275-308

White JP, Modjeska N, Hipuya I (1977) Group definitions and mental templates: an ethnographic experiment. In: Wright RVS (ed) Stone Tools as Cultural Markers: Change, Evolution and Complexity. Australian Institute of Aboriginal Studies, Canberra, pp 380-390

Wood RE, Douka K, Boscato P, Haesaerts P, Sinitsyn A, Higham TFG (2012) Testing the ABOx-SC method: Dating known-age charcoals associated with the Campanian Ignimbrite. Quat Geochronol 9: 16-26.

http://dx.doi.org/10.1016/j.quageo.2012.02.003

Xie G, Bodin E (2007) Paleolithic industries of the Bose Basin (South China). L'Anthropologie 111: $182-206$

Zanchetta G, Giaccio B, Bini M, Sarti L (2018) Tephrostratigraphy of Grotta del Cavallo, Southern Italy: insights on the chronology of Middle to Upper Palaeolithic transition in the Mediterranean. Quat Sci Rev 182: 65-77.

http://dx.doi.org/10.1016/ j.quascirev.2017.12.014

Zilhão J, Banks WE, d'Errico F, Gioia P (2015) Analysis of site formation and assemblage integrity does not support attribution of the Uluzzian to modern humans at Grotta del Cavallo. PLoS One 10: e0131181.

http://dx.doi.org/10.1371/journal.pone.0131181

Zingg T (1935) Beitrage zur Schotteranalyse. Schweiz Min u Pet Mitt 15: 39-140

\section{List of captions}




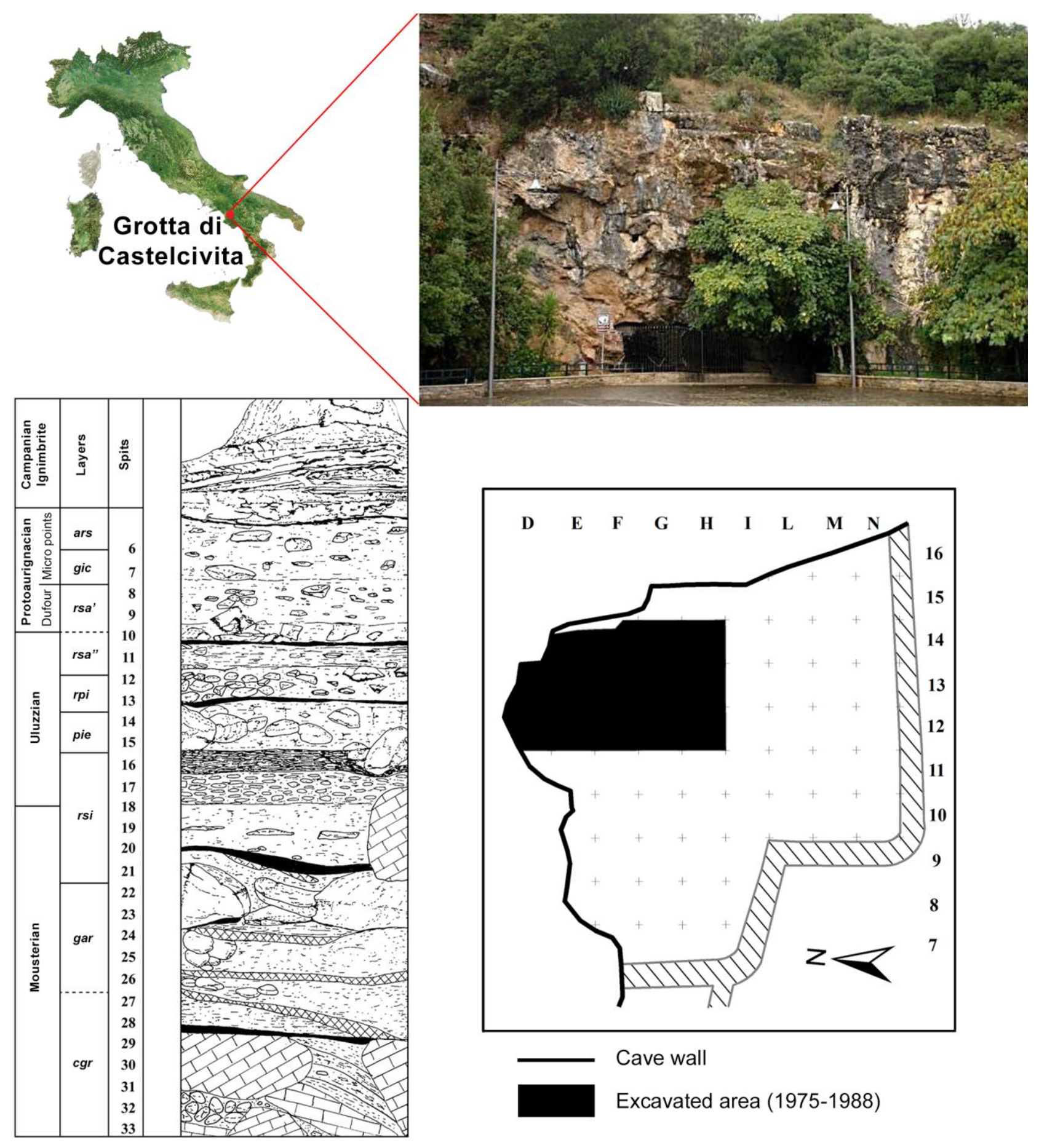

Fig 1 Localisation of Grotta di Castelcivita, view of the cave entrance, stratigraphic sequence, and plan of the area excavated by Gambassini (1975-1988), where the examined tools were retrieved 


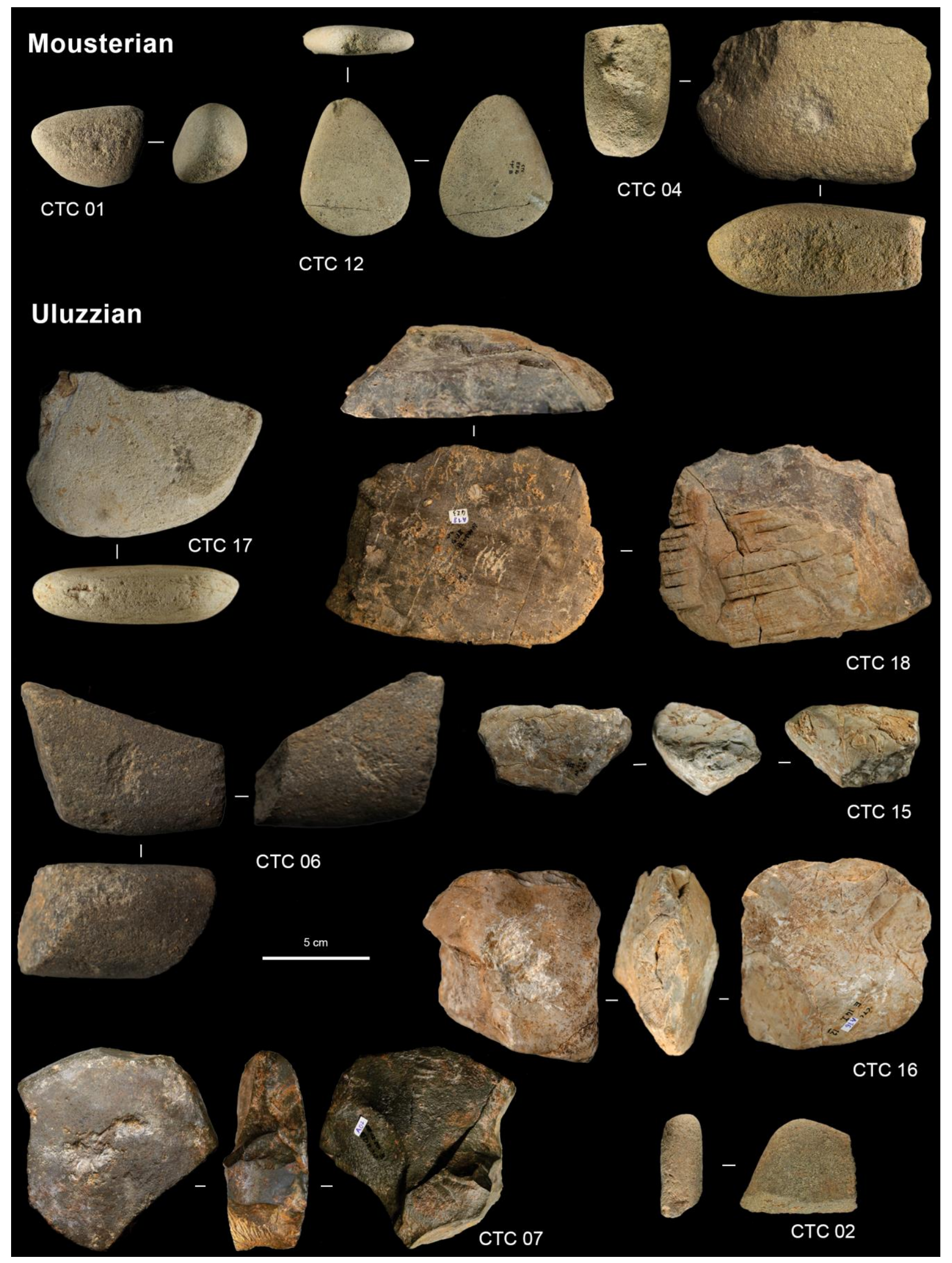

Fig 2 Anvils and hammerstones from the Mousterian and Uluzzian layers of Castelcivita 

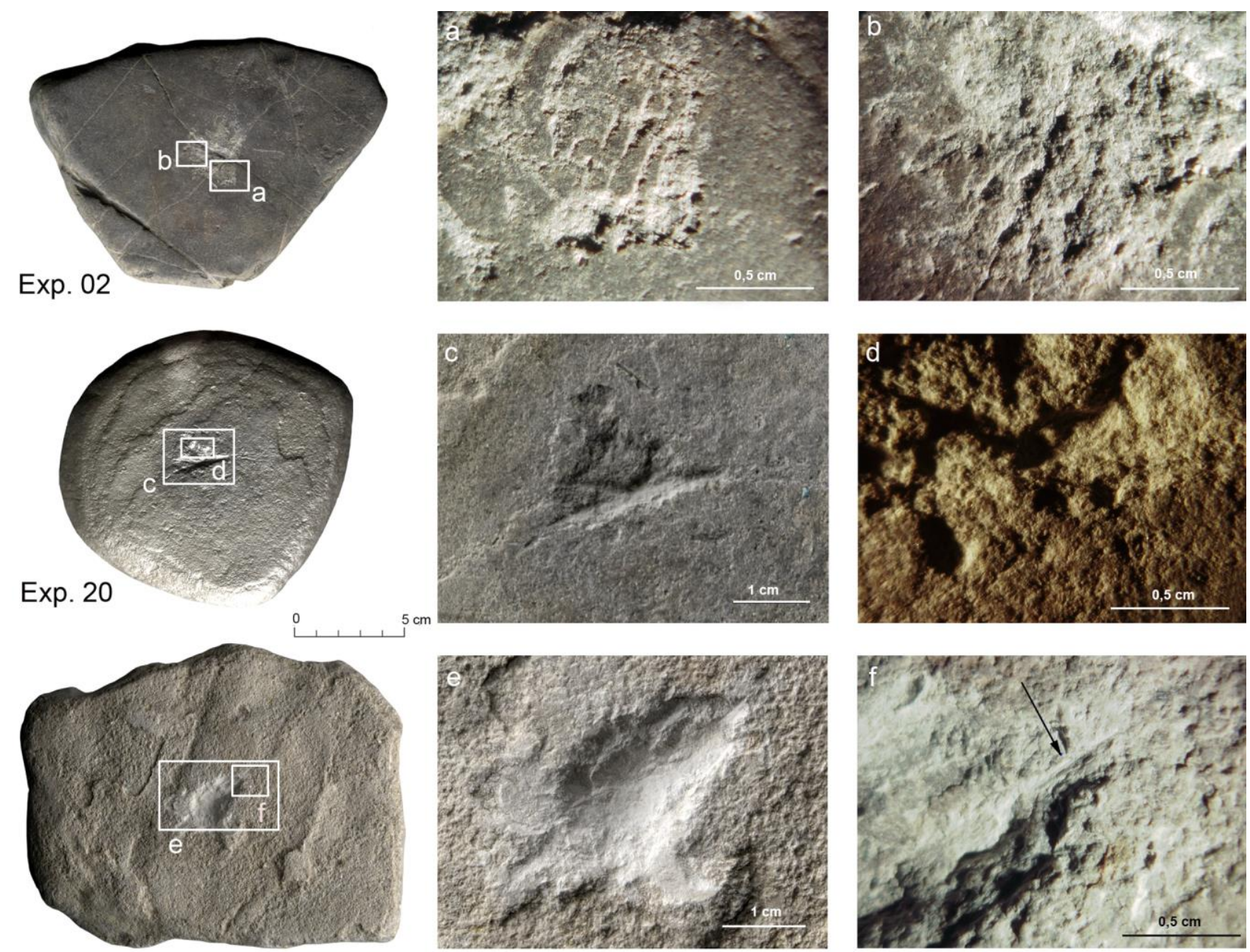

\section{Exp.13}
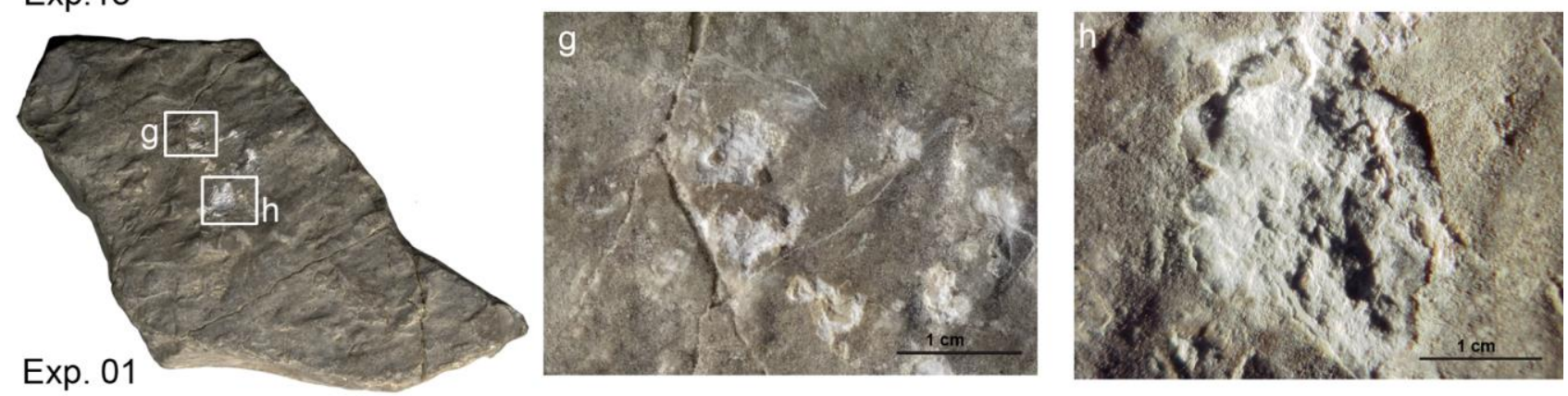

Fig 3 Experimental traces on anvil produced by bipolar knapping technique. Exp. 02 (anvil used for flakes/blades production) a. Linear impacts arranged in sequence; b. Formation of hollow after a series of blows. Exp. 20 (anvil used for flakes/blades production) c. Linear impacts; d. Close-up of percussion impact. Exp 13 (anvil used for flakes/blades production) e. Sub-rectangular hollow produced after 1313 blows; f. Residual linear impact. Exp. 01 (anvil used for breaking open blocks) g. Scattered impact cracks; h. Close-up of a crack 



Fig 4 Experimental traces on hammerstone used in bipolar knapping. Exp.08. a. Deep rectangular hollows and pitmarks in the marginal zone of the used area. b. Close-up of a deep hollow; c. Striations inside a hollow; d. sporadic polishing and striations
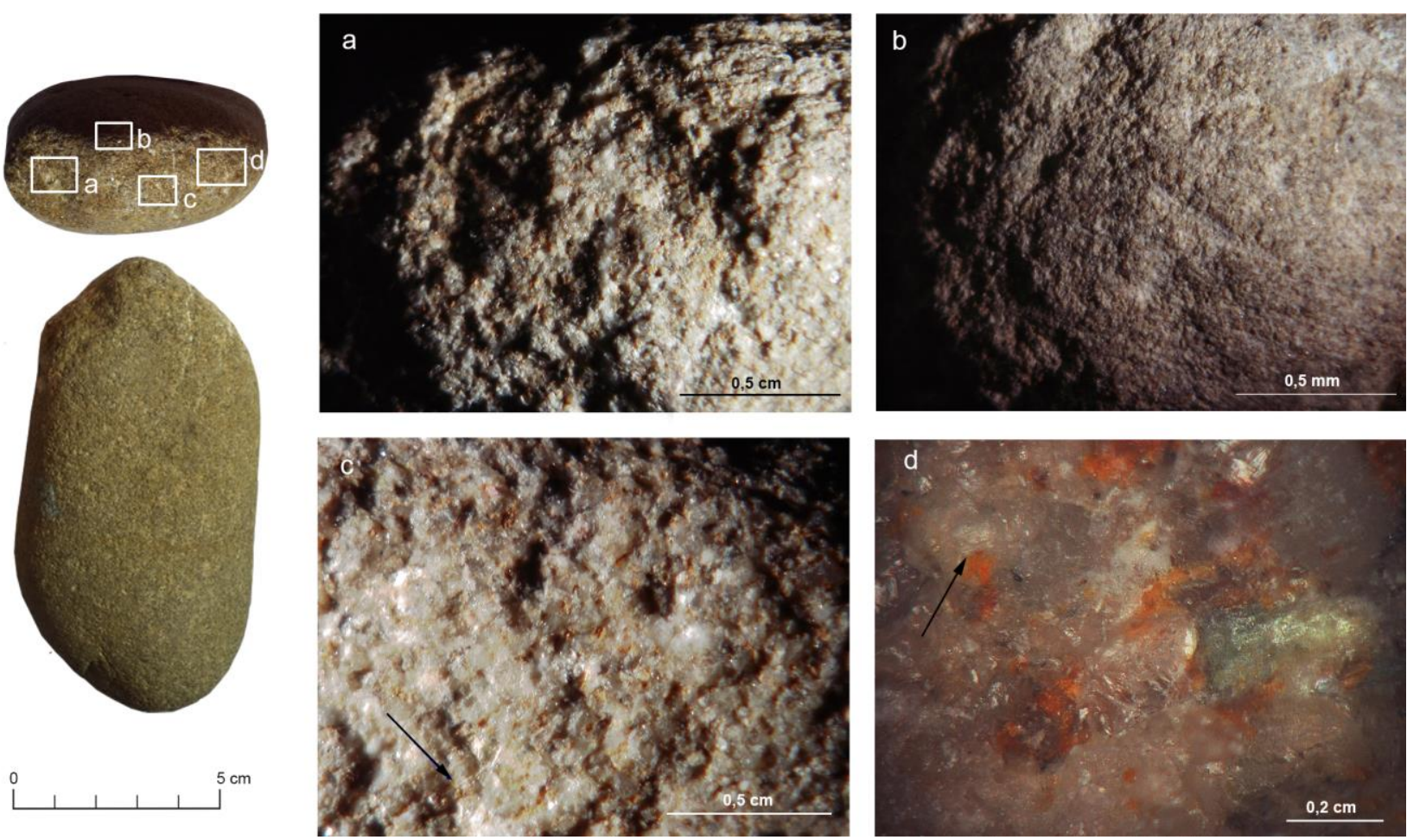

Fig 5 Experimental traces on hammerstone used in direct percussion. Exp.17. a. Sub-circular pit-marks; b. large striations caused by overhang abrasion. c Crystal crushing; d. Sporadic polishing 


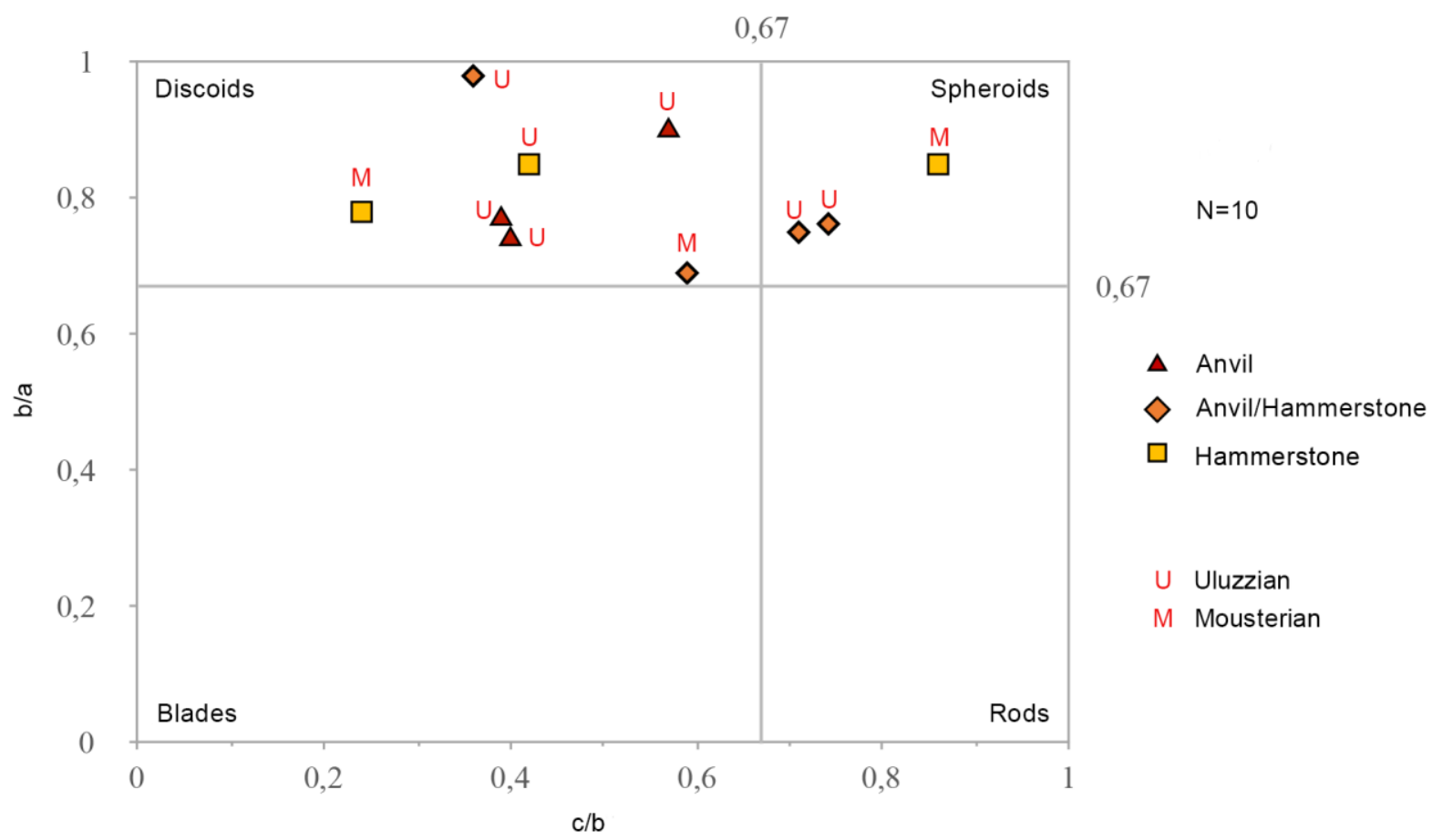

Fig 6 Clast morphometry distribution of hammerstones and anvils from Mousterian and Uluzzian layers of Castelcivita according to Zingg (1935) 
CTC 01

Raw Material: Fine medium grained sandstone

Blank: Spheroid pebble

Function: Hammerstone-pestle

Techno-complex: Mousterian

Techno-type 1
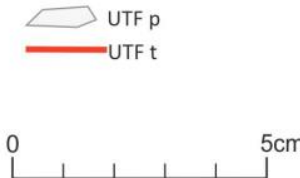

Hammerstone

UTFt

localisation = larger side of the blank

surface aspect $=$ convex

UTF t1

localisation $=$ shorter side of the blank

surface aspect $=$ convex

\section{UTF $\mathrm{p}$}

localisation = opposite to the UTFt

realisation $=$ natural surfaces of the blank
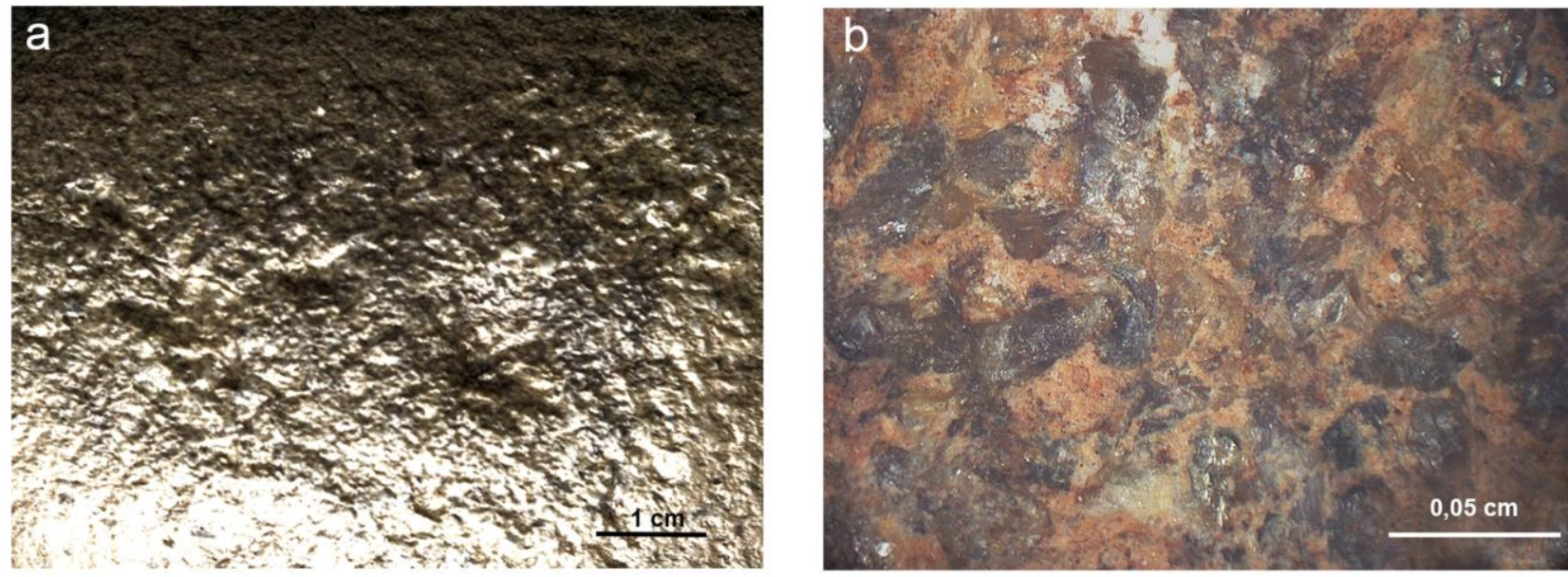

Fig 7 CTC 01: Mousterian hammerstone-pestle. To note: main features of the tool; description of techno-functional units; use-wear related to UTF t : a. Irregular pit marks and small hollows scattered on the flat surface (RTI image with specular enhancement); b. Crystal crushing and few polishes organized in spots 
CTC 12

Raw Material: Fine/Medium grained sandstone Blank: Discoid broken pebble

Function: Hammerstone

Techno-complex: Mousterian

Techno-type 3
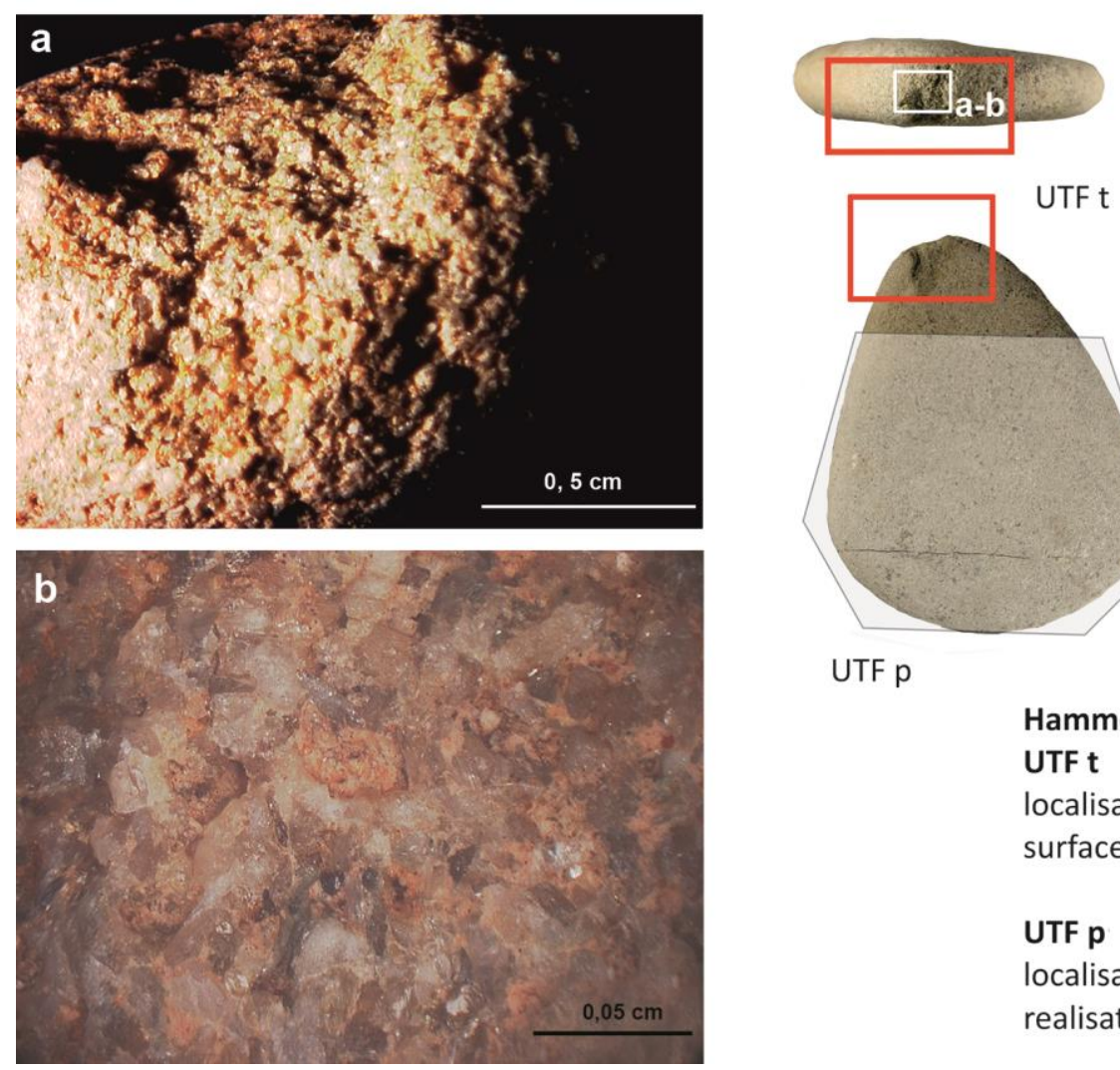

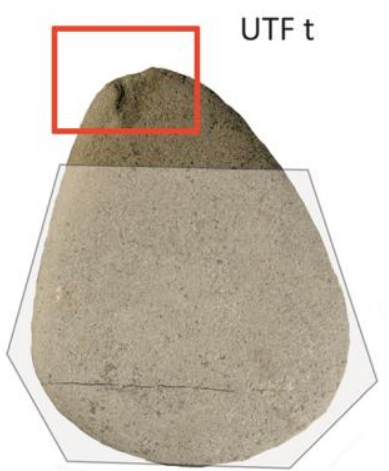

UTF $p$
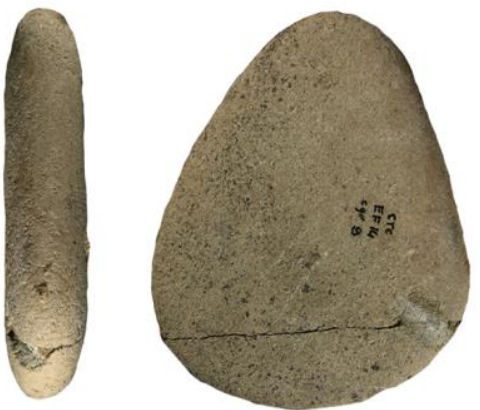

\author{
Hammerstone \\ UTF $\mathbf{t}$ \\ localisation = edge of the blank, shorter side \\ surface aspect $=$ convex \\ UTF $\mathbf{p}$ \\ localisation = opposite to the UTF $t$ \\ realisation $=$ natural surfaces of the blank
}

Fig.8 CTC 12: Mousterian thin hammerstone-retoucher. To note: main features of the tool; description of technofunctional units; use-wear related to UTF t: a. Battered zone on the extremity of the tool; b. Crystal removal; 
CTC 04

Raw Material: Medium grained sandstone Blank: Discoid pebble

Function: Anvil. Hammerstone

Techno-complex: Mousterian

Techno-type 2

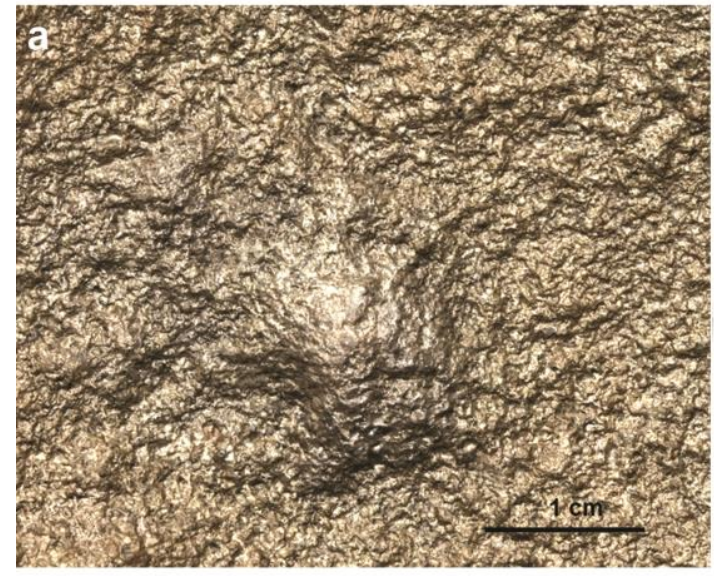

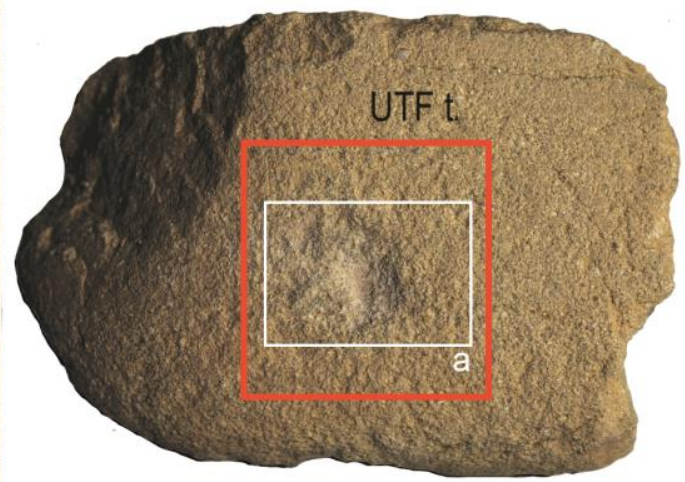

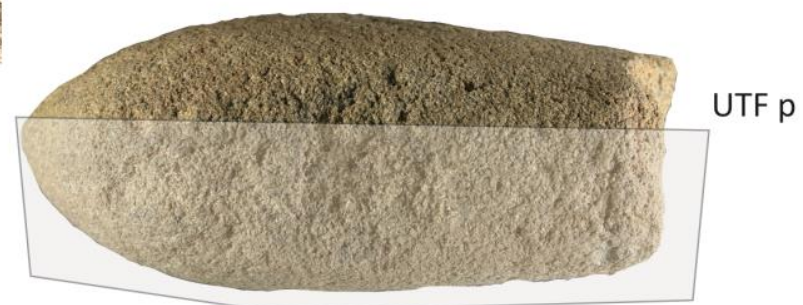

Anvil

\section{UTF $\mathrm{t}$}

localisation = centre of the larger surface surface aspect $=$ flat

\section{UTF $p$}

localisation = opposite to the UTF t2

realisation $=$ natural flat surfaces of the blank

Fig. 9 CTC 04: Mousterian anvil/hammerstone. To note: main features of the tool; description of techno-functional units; use-wear related to UTF t (anvil): a. Sub-circular hollow on the flat surface of the stone, without linear impacts (RTI image with specular enhancement); 
CTC 04

Raw Material: Medium grained sandstone

Blank: Discoid pebble

Function: Anvil. Hammerstone

Techno-complex: Mousterian

Techno-type 2

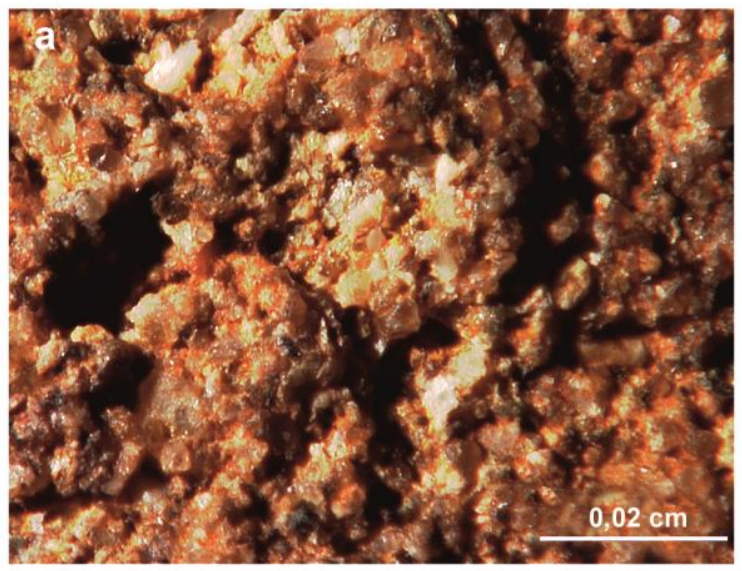

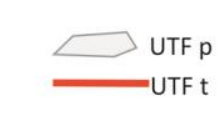

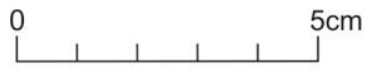

Hammerstone

UTF t1

localisation $=$ shorter side of the blank

surface aspect $=$ convex

\section{UTF $\mathrm{t} 2$}

localisation $=$ larger side of the blank

surface aspect $=$ convex

\section{UTF p1}

localisation = opposite to the UTF $t$ and UTF t1 realisation $=$ natural surfaces of the blank
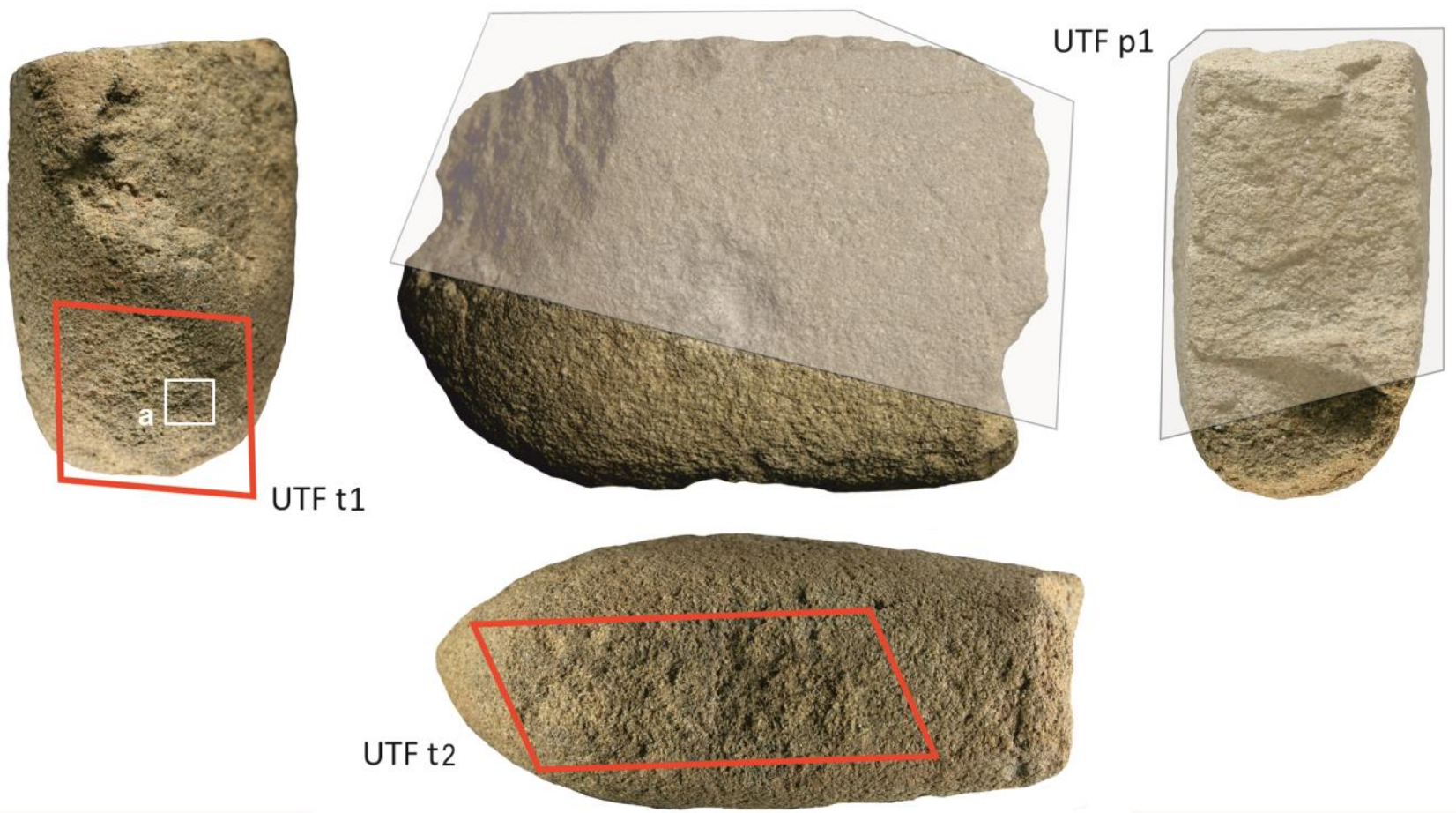

Fig 10 CTC 04: Mousterian anvil/hammerstone. To note: main features of the tool; description of techno-functional units; use-wear related to UTF t1 (hammerstone): a. Pit-marks on the lateral side of the stone 
CTC 06

Raw Material: Medium\fine grained sandstone

Blank: Spheroid broken pebble

Function: Anvil; Hammerstone

Techno-complex: Uluzzian

Techno-type 2 (Anvil)
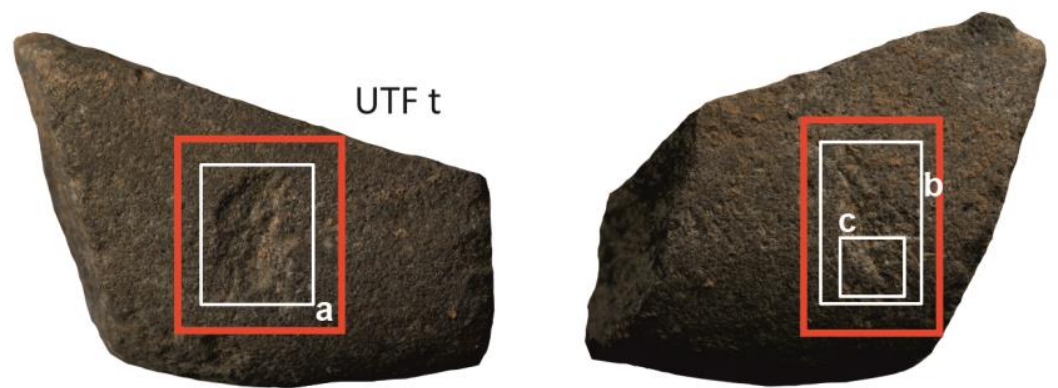

UTF t1
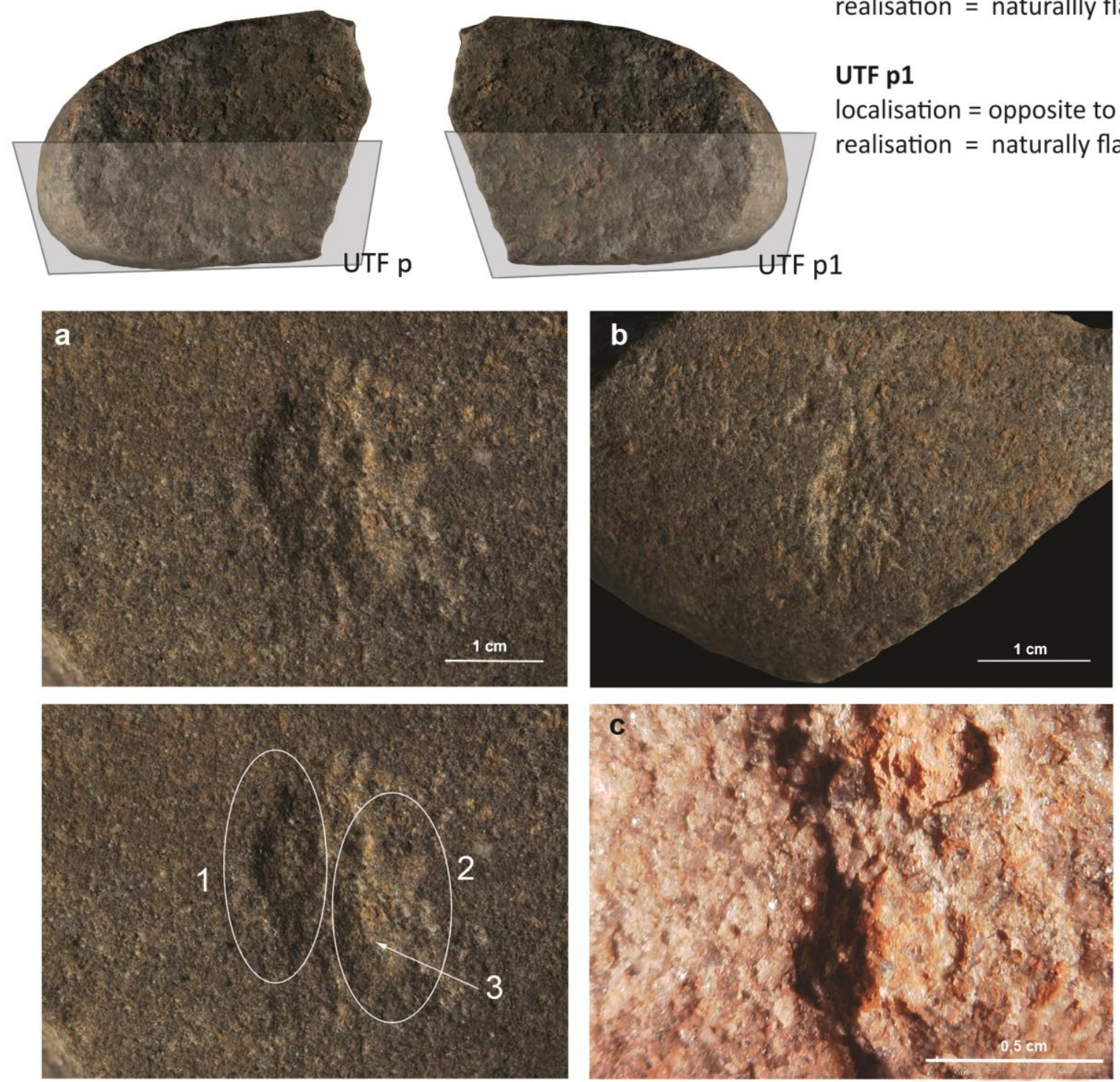

Fig. 11 CTC 06: Uluzzian hammerstone and double anvil. To note: main features of the too; description of technofunctional units (double anvil); use-wear related to UTF t (anvil-face A): a. Sub-rectangular hollows, in chronological
Anvil

UTF $\mathbf{t}$

localisation = central upper side surface aspect $=$ flat

\section{UTF t1}

localisation = central lower side surface aspect $=$ flat

\section{UTF $p$}

localisation = opposite to UTF $\mathrm{t}$ realisation $=$ naturallly flat surface

\section{UTF p1}

localisation = opposite to UTF t1 realisation $=$ naturally flat surface 
sequence (1-2) and rectilinear impact that could be the last action performed on this face of the anvil (3); use-wear related to UTF t1 (anvil-face B): b. Shallow hollow with linear impacts. c. Close-up of the hollow

\section{CTC 06}

Raw Material: Medium \fine grained sandstone

Blank: Spheroid broken pebble

Function: Anvil. Hammerstone

Techno-complex: Uluzzian

Techno-type 2 (Hammerstone)

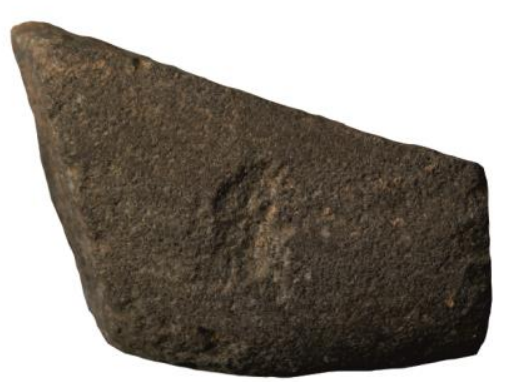

UTF t2

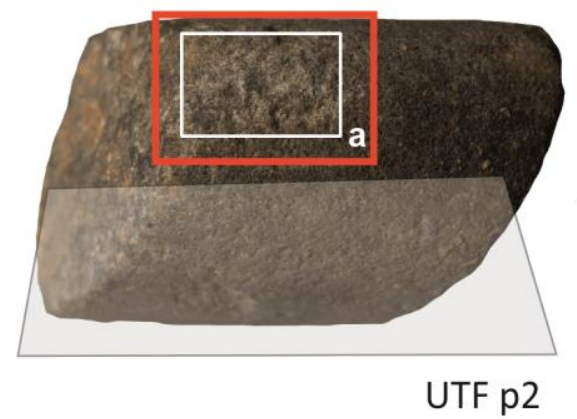

Hammerstone

UTF t2

localisation $=$ shorter side on the lateral edge

surface aspect $=$ convex

\section{UTF p2}

localisation = opposite to the UTF t2

realisation $=$ natural surface of the blank
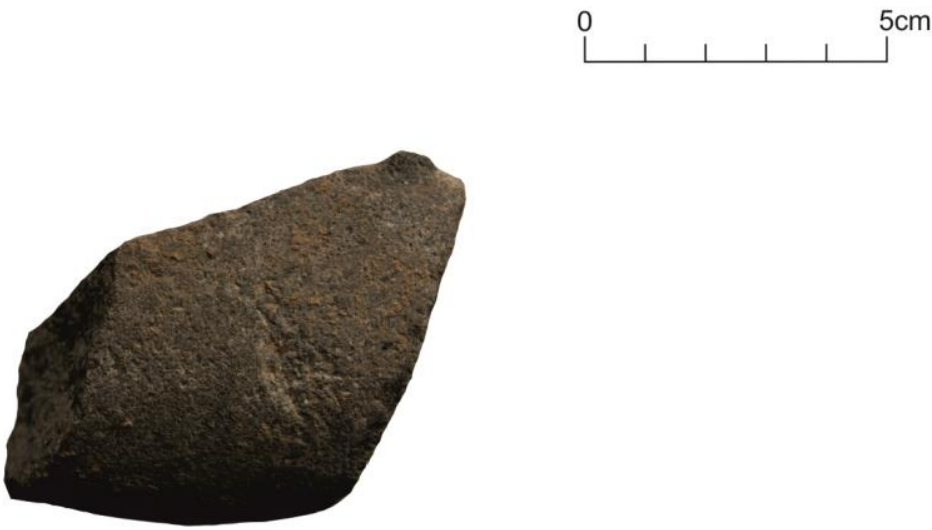

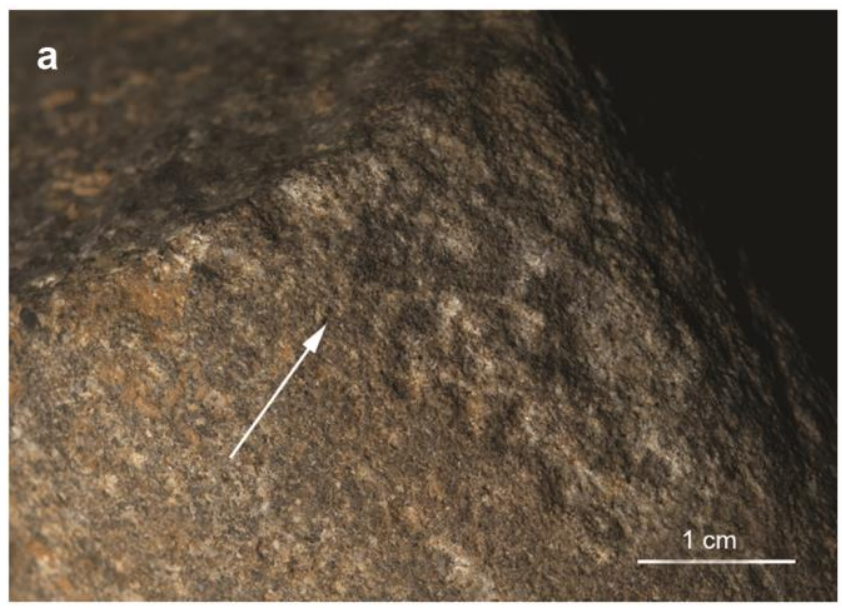

Fig. 12 CTC 06: Uluzzian hammerstone and double anvil. To note: main features of the tool; description of technofunctional units (hammerstone); use-wear related to UTF t2 (hammerstone): a. Clustered sub-circular pit-marks and striations 
СTC 16

Raw Material: Micritic limestone

Blank: Discoid broken pebble

Function: Anvil, Tool with working edges

Techno-complex: Uluzzian

Techno-type 1
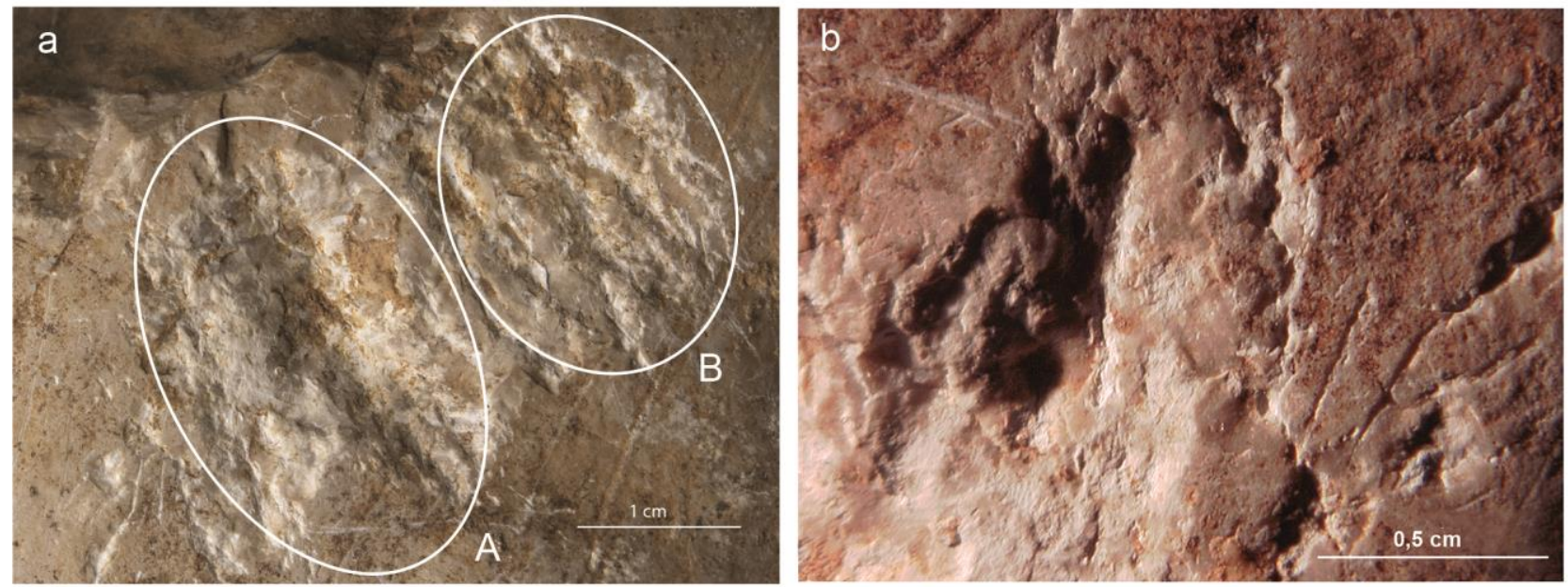

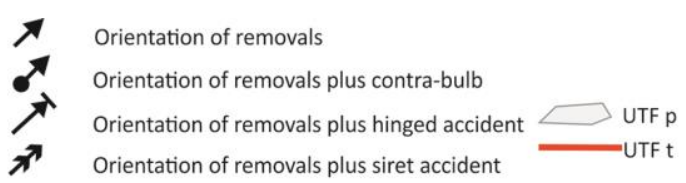

$\mathrm{n}: 1,2 \ldots$ Chronology of removals

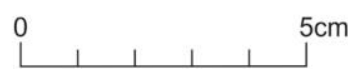

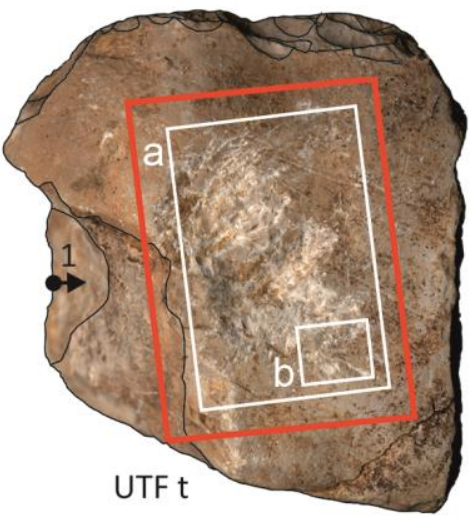

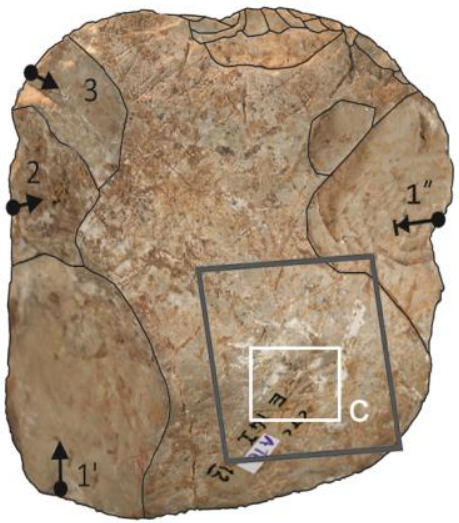

\section{Anvil}

UTF $\mathbf{t}$

localisation $=$ central

surface aspect $=$ flat

\section{UTF $p$}

localisation $=$ opposite to the UTFt realisation $=$ volume of prehensile unit obtained by removals 1, 1', 1", 2
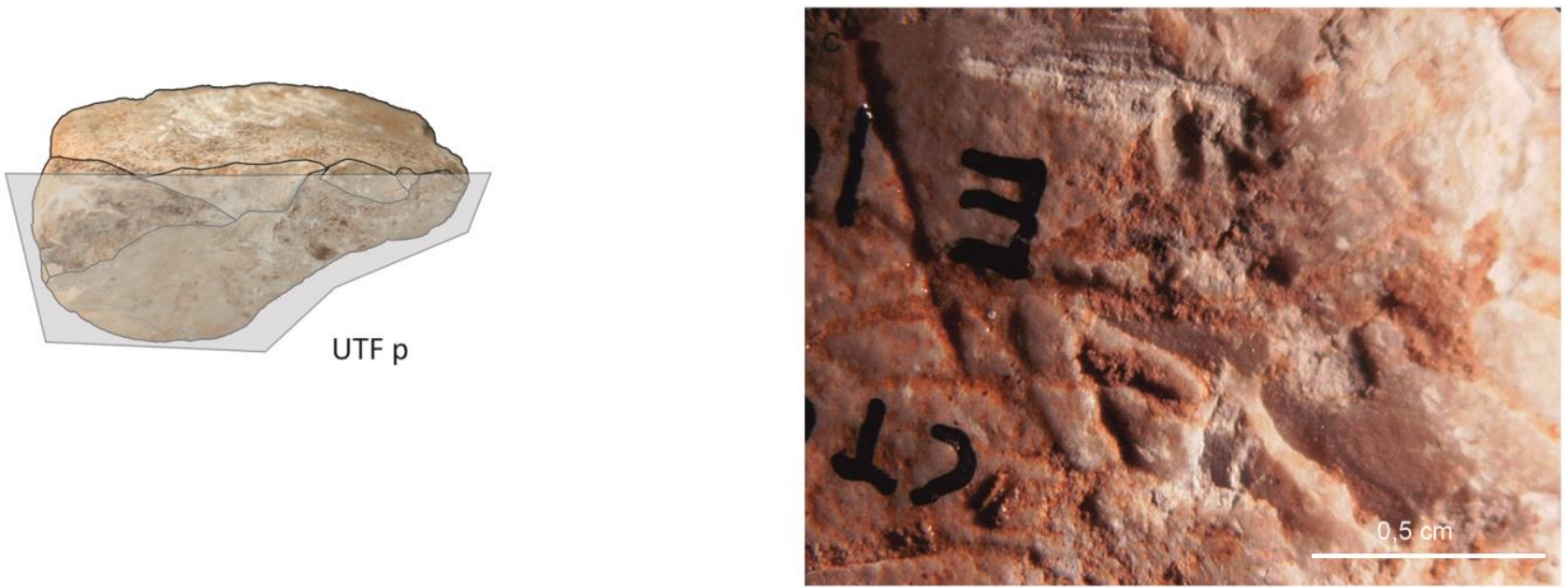

Fig 13 CTC 16: Uluzzian anvil with a working edge. To note: features of the tool; description of techno-functional units (anvil); use-wear related to UTF t (anvil): a. Used area on the flat surface of the specimen, showing two different phase of use A (more intense) and B (less intense). b. Close-up of area A, displaying a rectangular hollow with residual linear impacts; use-wear related to UTF p: c. Percussive impact on the other side of the anvil 
CTC 16

Raw Material: Micritic limestone

Blank: Discoid broken pebble

Function: Anvil, Tool with working edges

Techno-complex: Uluzzian
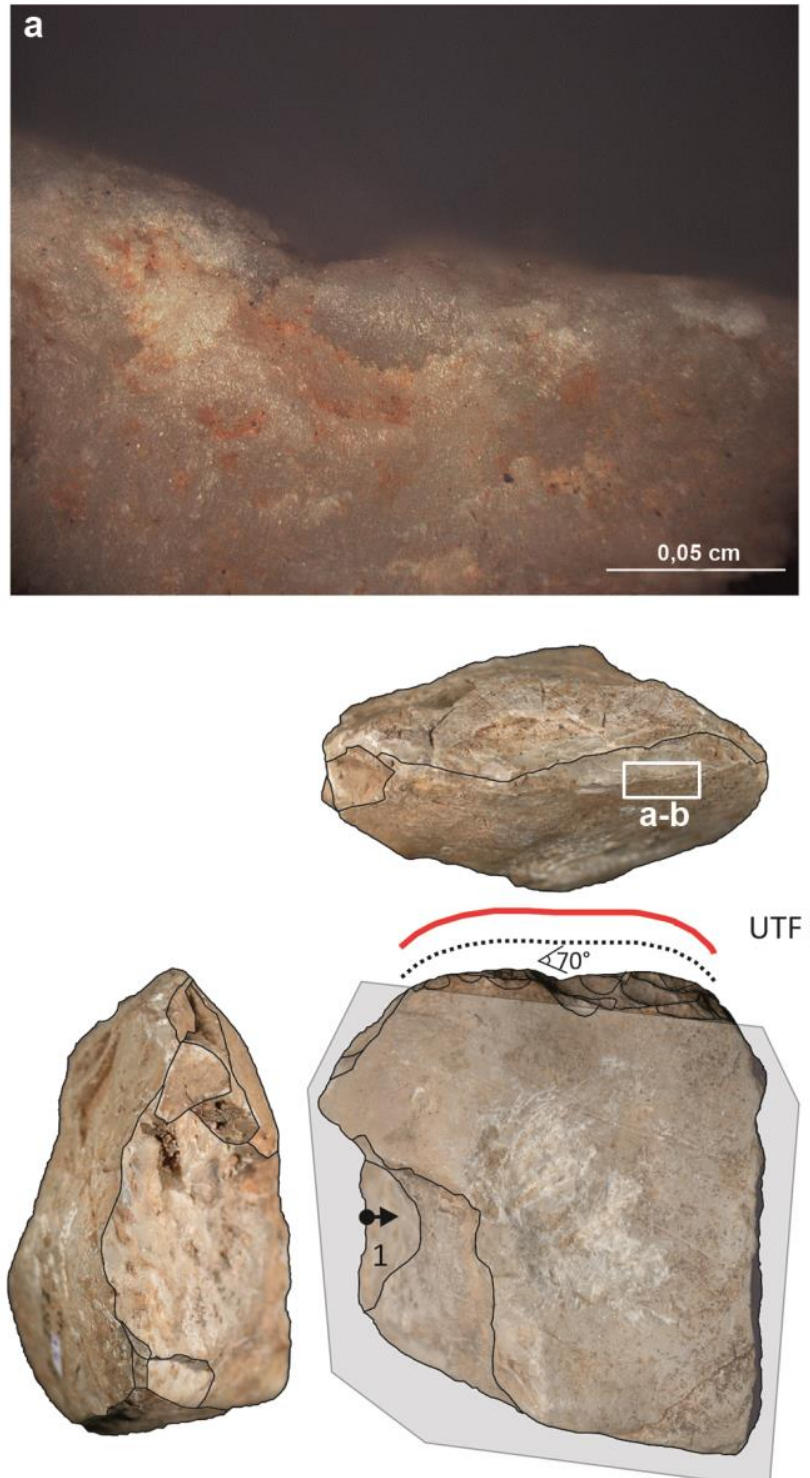

UTF t1
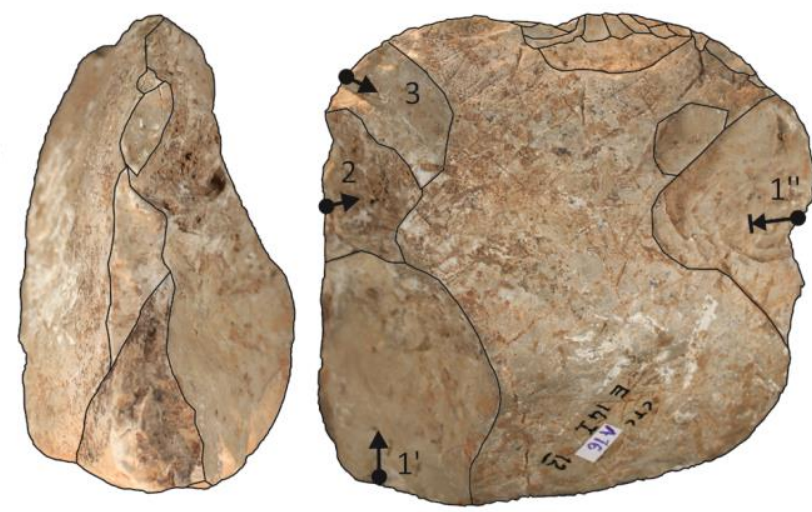

UTF p1

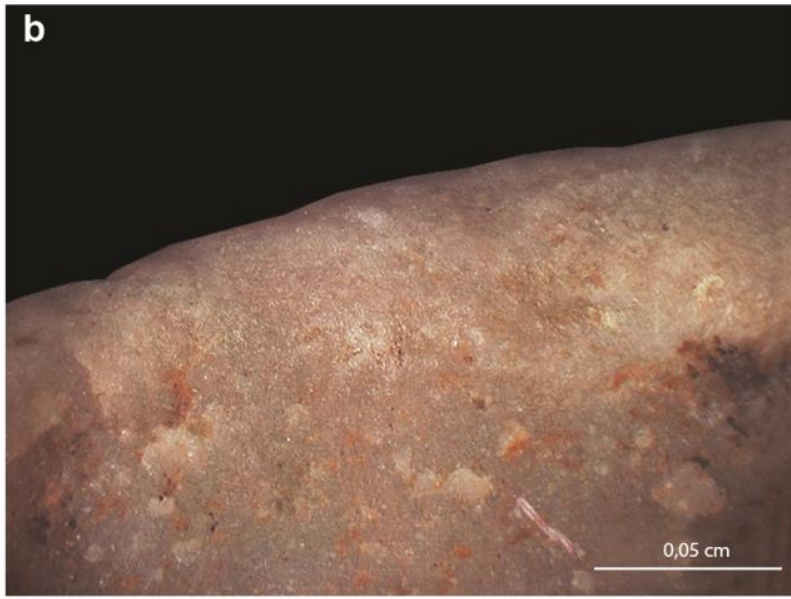

\section{Tool with working edges}

\section{UTF t1}

localisation $=$ distal

delineation $=$ convex

surface relation $=$ flat $\backslash$ flat

angles $=70^{\circ}-80^{\circ}$

profile $=$ wavy

removals 3, 1"aimed at isolating the cutting edge

\section{UTF p1}

localisation = proximal, lateral right, lateral left

realisation $=1,1^{\prime}, 2$ removals possibly aimed at isolating the prehensile unit of the blank

Fig 14 CTC 16: Uluzzian anvil with a working edge. To note: main features of the tool; description of techno-functional units (working edge); use-wear related to UTF t (working edge): a-b. Edge rounding with rough polishes on the working edge of the anvil 


\section{CTC 15}

Raw Material: Micritic limestone

Blank: Spheroid fragment

Function: Anvil; Hammerstone

Techno-complex: Uluzzian

Techno-type 1
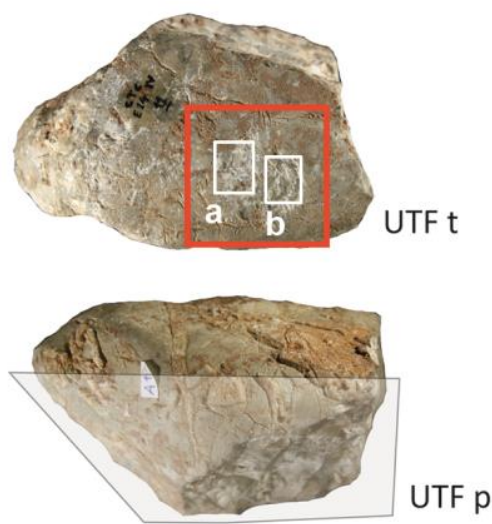

Anvil

UTF $\mathbf{t}$

localisation $=$ lateral

surface aspect $=$ flat

\section{UTF $p$}

localisation = opposed side

realisation $=$ natural angular shape of the blank
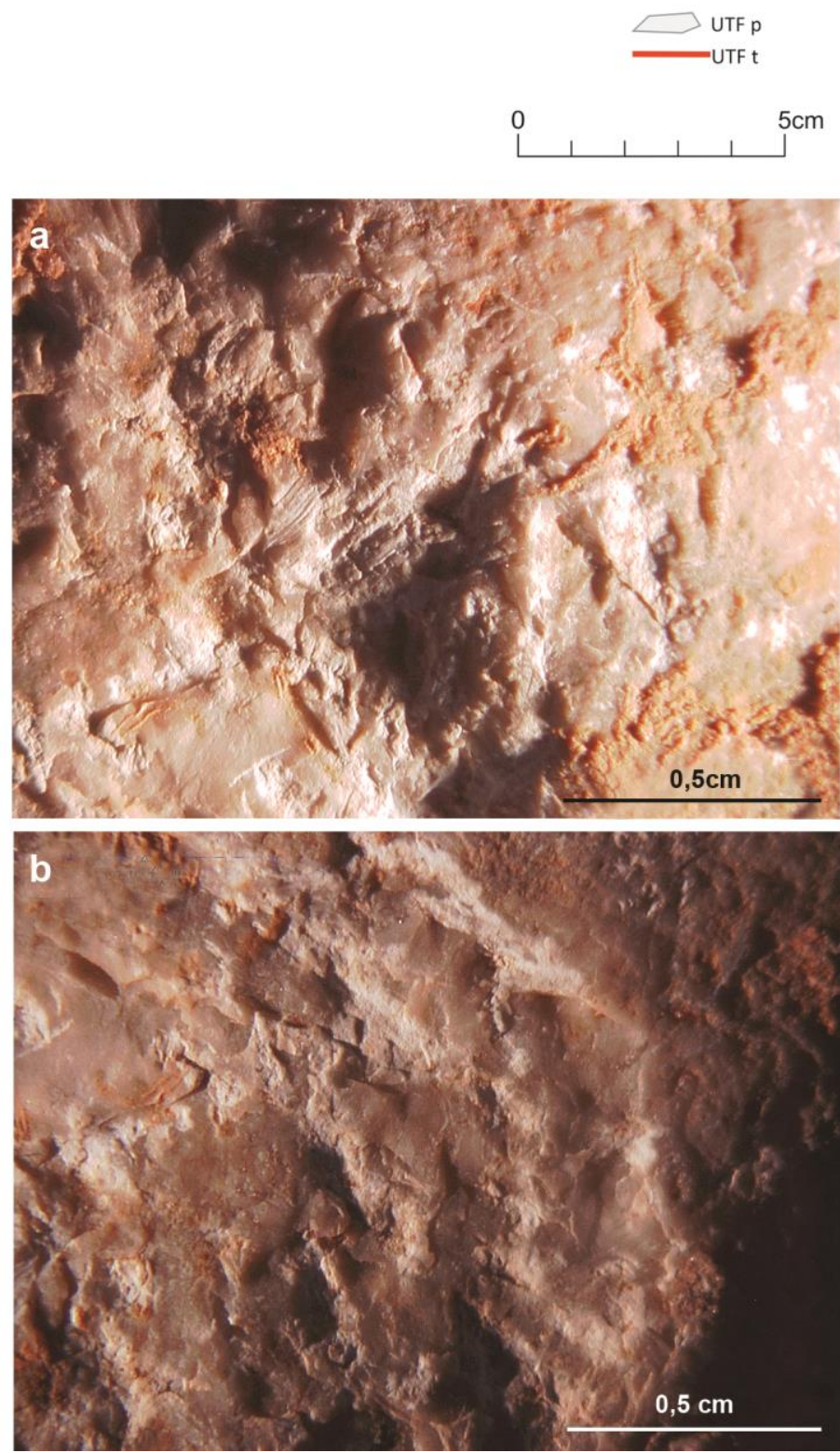

Fig. 15 CTC 15: Uluzzian anvil and angular hammerstone. To note: main features of the tool; description of technofunctional units (anvil); use-wear related to UTF t (anvil): a-b. Close-up of the principal used area showing subrectangular hollow and linear impacts arranged in sequence 
CTC 15

Raw Material: Micritic limestone

Blank: Spheroid fragment

Function: Anvil. Hammerstone

Techno-complex: Uluzzian

Techno-type 4
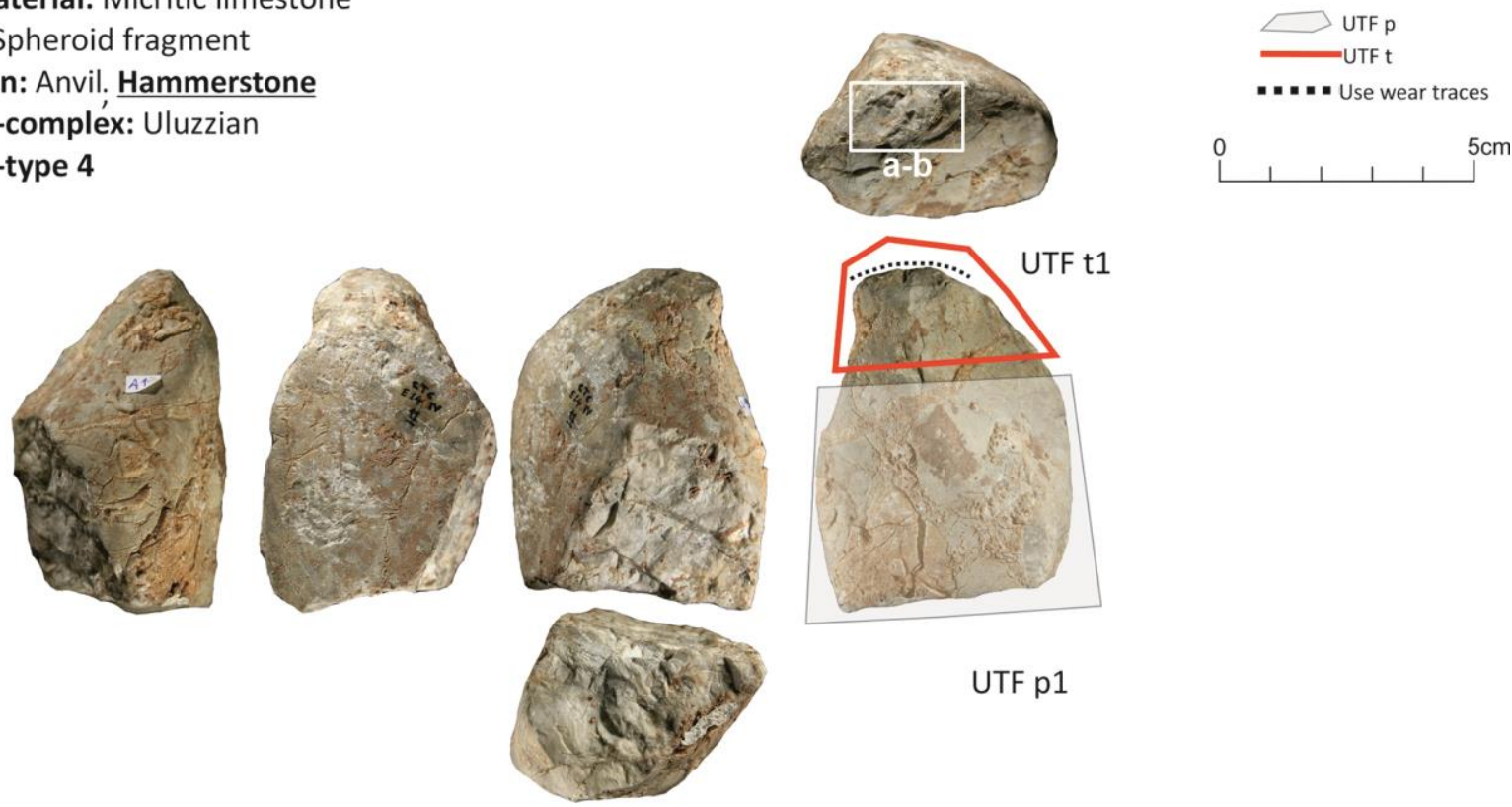

UTF p1
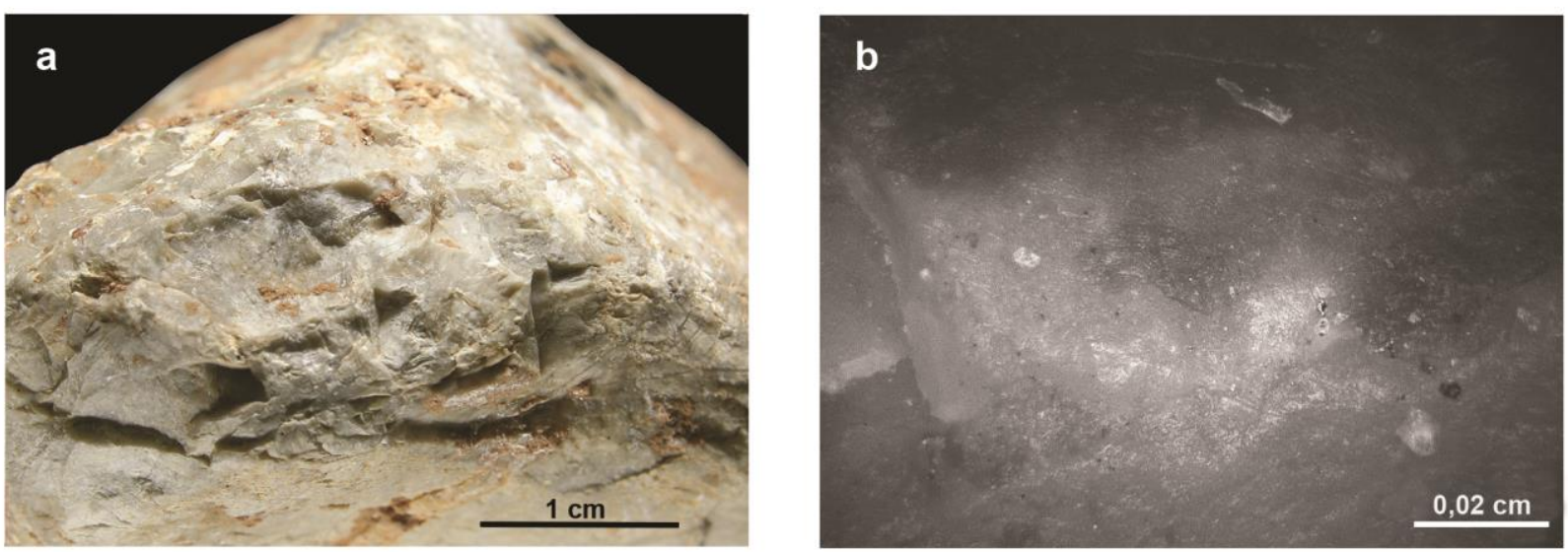

\section{Hammerstone}

\section{UTF t1}

localisation $=$ distal edge of the blank surface aspect = convergent/angular

\section{UTF $\mathrm{p} 1$}

localisation = opposite to the UTF t1

realisation = naturally flat; broken surface of the blank

Fig. 16 CTC 15: Uluzzian anvil and angular hammerstone. To note: t main features of the tool; description of technofunctional units (angular hammerstone); use-wear related to UTF t1 (angular hammerstone):a. Step fractures b. Polishes organized in spots located on the angular extremity of the anvil. 
CTC 07

Raw Material: Micritic limestone

Blank: Discoid broken pebble

Function: Anvil; Hammerstone

Techno-complex: Uluzzian

Techno-type 1
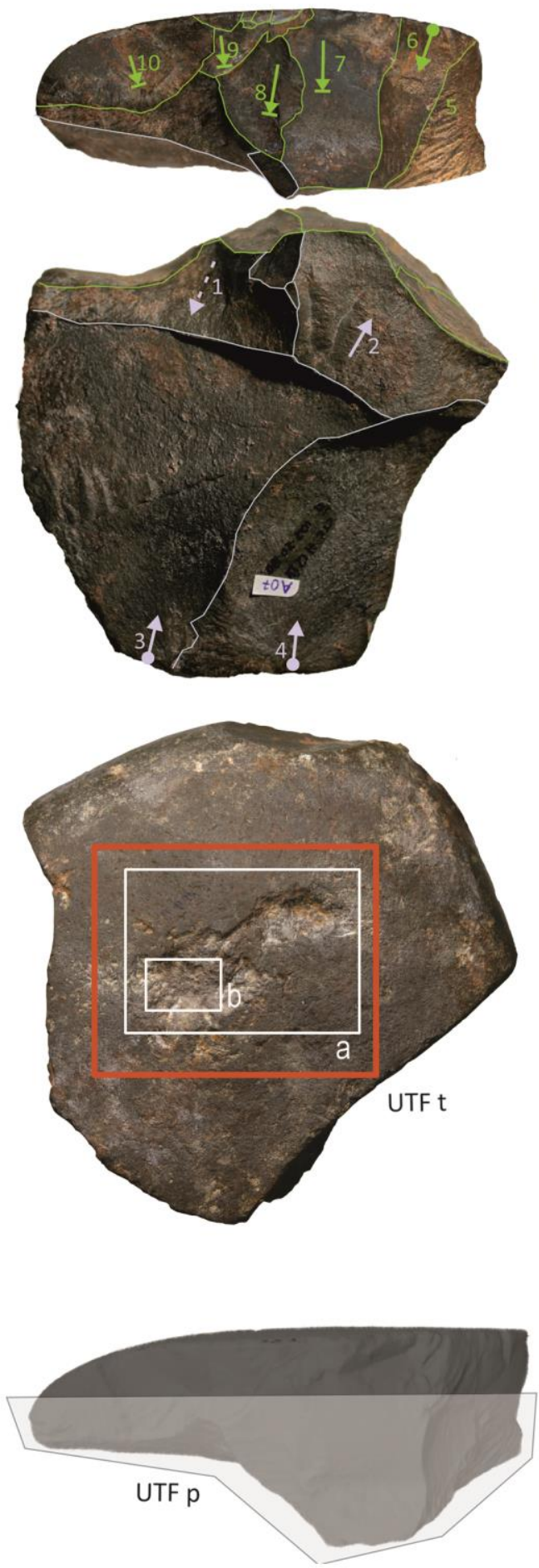

$\nearrow$ Orientation of removals

Orientation of removals plus contra-bulb

$\lambda$ Orientation of removals plus hinged accident $\longrightarrow$ UTF $p$

Orientation of removals plus

$\mathrm{n}: 1,2 \ldots$ Chronology of removals

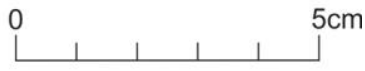

Anvil

UTF $\mathbf{t}$

localisation = centre of the flat surface of the blank surface aspect $=$ flat

UTF $p$

localisation = opposite to the UTF t side

realisation $=$ shape and volume of prehensile

portion intentionally obtained by removals

1-2-3-4 = perpendicular removals aimed at thinning

the blank

5-6-6'-7-8-9-10 = orthogonal removals aimed at

defining the lateral volume of the blank
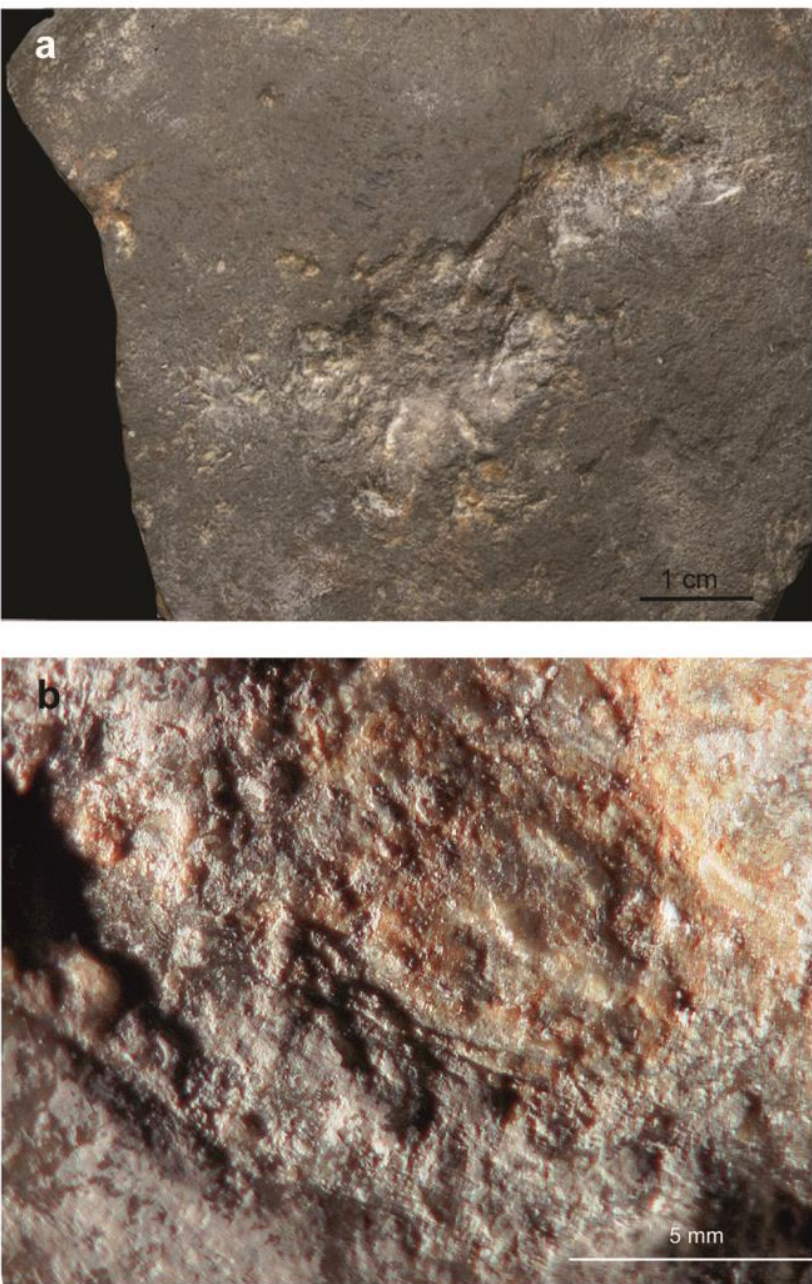

Fig. 17 CTC 07: Uluzzian anvil/hammerstone. To note: main features of the tool; description of techno-functional units (anvil); use-wear related to UTF t (anvil): a. Close-up of the principal used area showing sub-rectangular hollows and linear impacts. b Detail of a hollow with linear impacts 


\section{CTC 07}

Raw Material: Micritic limestone

Blank: Discoid broken pebble

Function: Anvil. Hammerstone

Techno-comple' Uluzzian

Techno-type 3
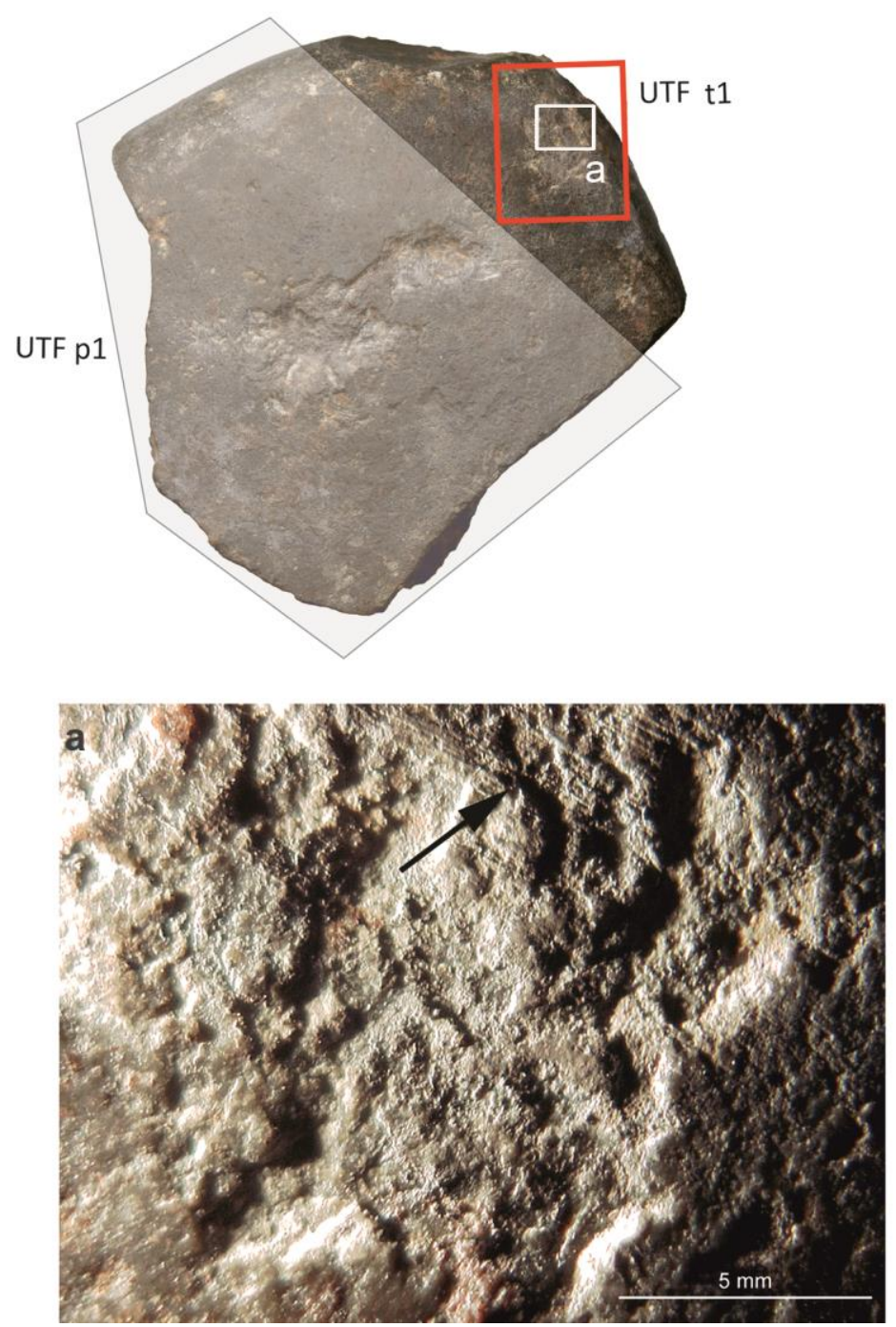

Fig. 18 CTC 07: Uluzzian anvil/hammerstone. To note: main features of the tool; description of techno-functional units (hammerstone); use-wear related to UTF t1 (hammerstone): a. Marginal battered zone showing percussive impacts in clustered distribution and striations

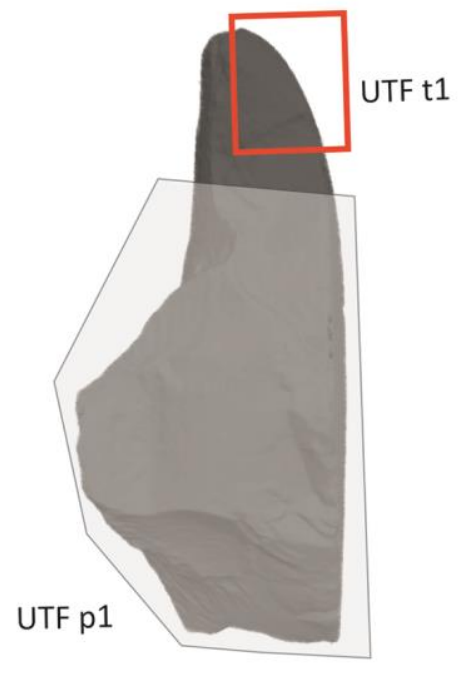

Hammerstone

\section{UTF t1}

localisation $=$ distal edge of the blank surface aspect $=$ convex

\section{UTF $p 1$}

localisation $=$ proximal

realisation $=$ created by removals 
CTC 17

Raw Material: Fine grained limestone Blank: Discoid broken pebble

Function: Anvil

Techno-complex: Uluzzian

Techno-type 2
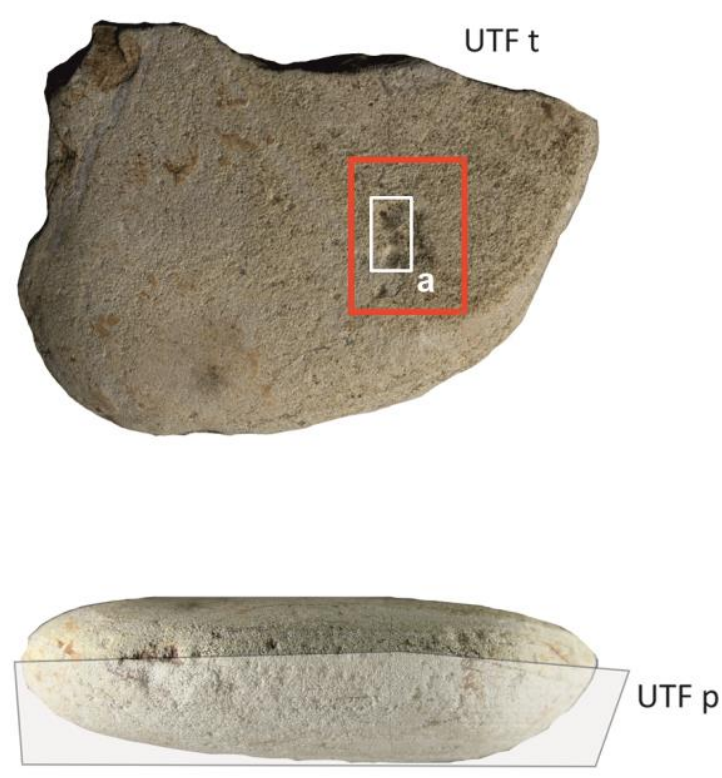

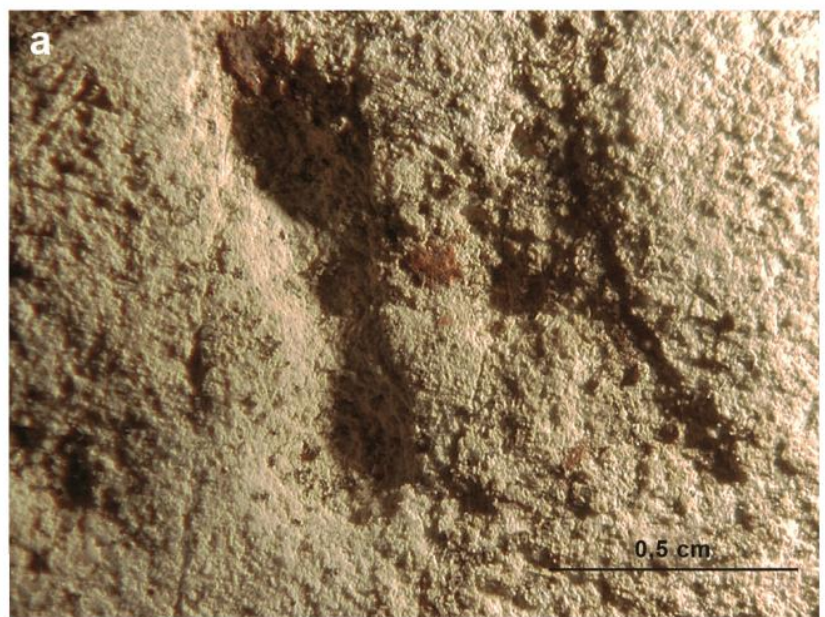

Anvil

UTF $\mathbf{t}$

localisation = lateral on the upper surface surface aspect $=$ flat

UTF $p$

localisation $=$ opposite to UTF $\mathrm{t}$

realisation $=$ natural shape of the blank; flat lower side of the blank

Fig. 19 CTC 17: Uluzzian flat anvil. To note: main features of the tool; description of techno-functional units (anvil); use-wear related to UTF t (anvil): a. linear hollow and linear impact 


\section{CTC 18}

Raw Material: Micritic limestone

Blank: Discoid broken fragment

Function: Anvil, Tool with working edges

Techno-complex: Uluzzian

Techno-type 1
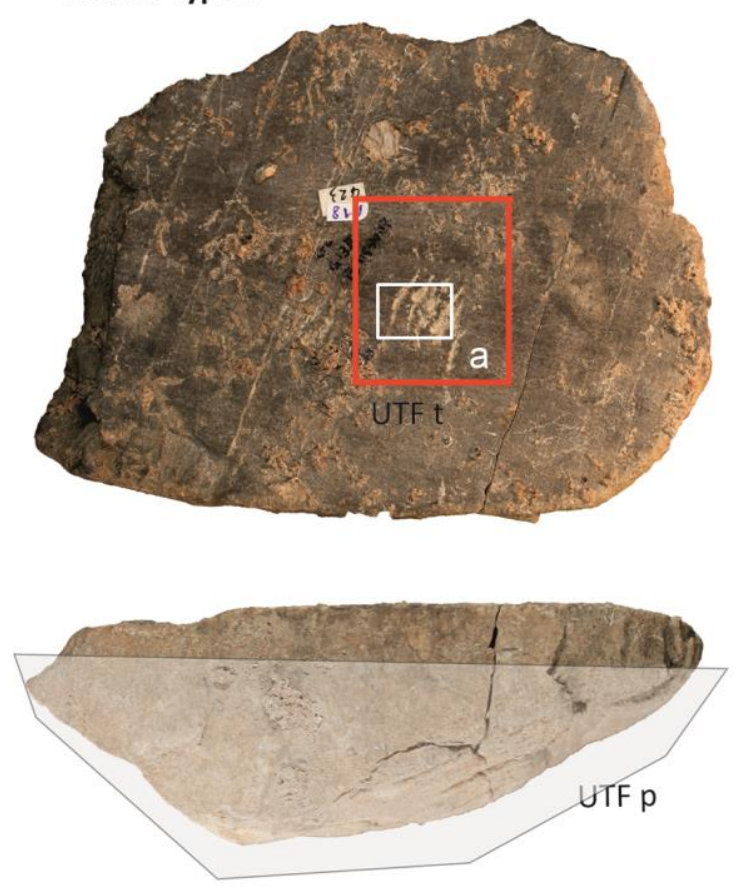
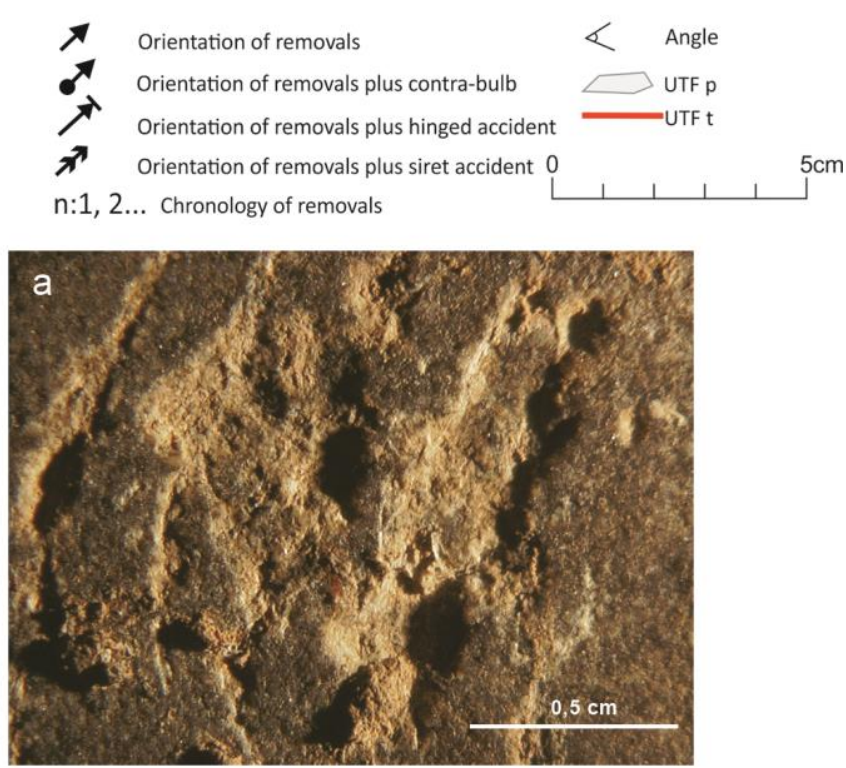

Anvil

UTF $\mathbf{t}$

localisation $=$ central

surface aspect $=$ flat

UTF $p$

localisation = opposite to UTF t3

realisation $=$ use of the cortical side of the blank where the removals 1, 2, 3', 5 created an angular side

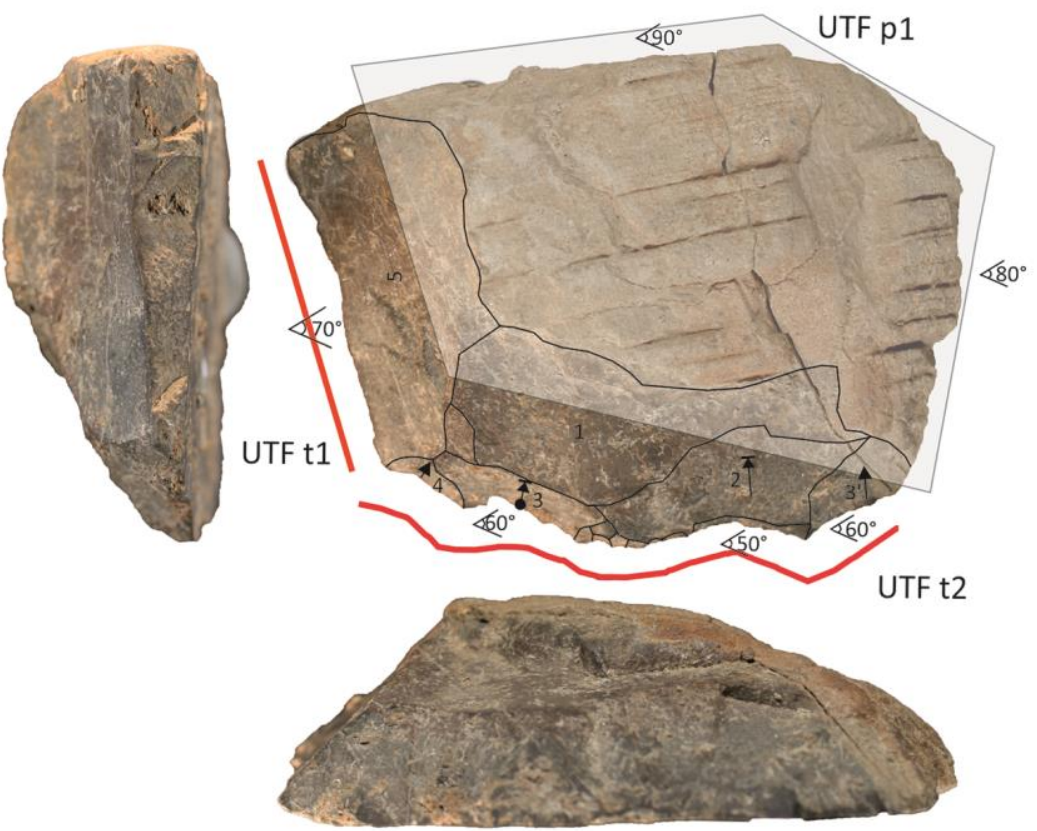

Tool with working edges

\section{UTF t1}

localisation $=$ transversal

delineation $=$ rectilinear

surfaces relation $=$ flat $\backslash$ flat

angles $=70^{\circ}$

profile $=$ rectilinear

\section{UTF t2}

localisation $=$ lateral left

delineation $=$ denticulates

surfaces relation $=$ flat $\backslash$ convex

angles $=60^{\circ}-50^{\circ}$

profile $=$ rectilinear

\section{UTF $\mathrm{p} 1$}

localisation = lateral right - proximal realisation $=$ use of natural cortical backed side of the gravel

Fig. 20 CTC 18: Uluzzian anvil with working edges. To note: main features of the tool; description of techno-functional units (anvil and working edges); use-wear related to UTF t (anvil): a. Linear impacts arranged in sequence. 


\section{CTC 02}

Raw Material: Fine grained sandstone

Blank: Discoid broken pebble

Function: Hammerstone-retoucher

Techno-complex: Uluzzian

Techno-type 3
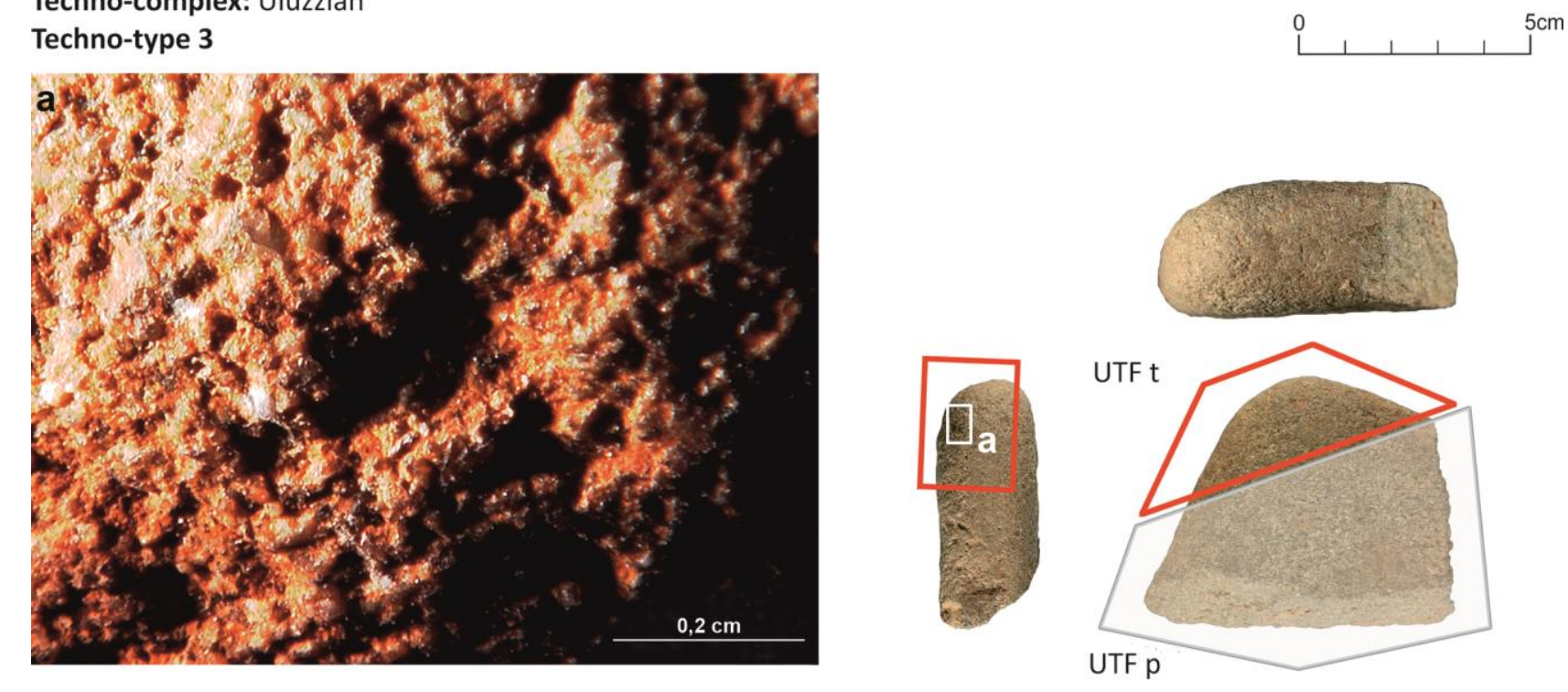

\section{Hammerstone}

UTF $\mathbf{t}$

localisation $=$ shorter side of the blank

surface aspect $=$ convex

\section{UTF $p$}

localisation = opposite to the UTF $t$

realisation $=$ use of natural surfaces of the blank

Fig 21 CTC 02: Uluzzian thin hammerstone. To note: main features of the tool; description of techno-functional units; use-wear related to UTF t: a. Battered zone at the extremity of the tool 
Anvil

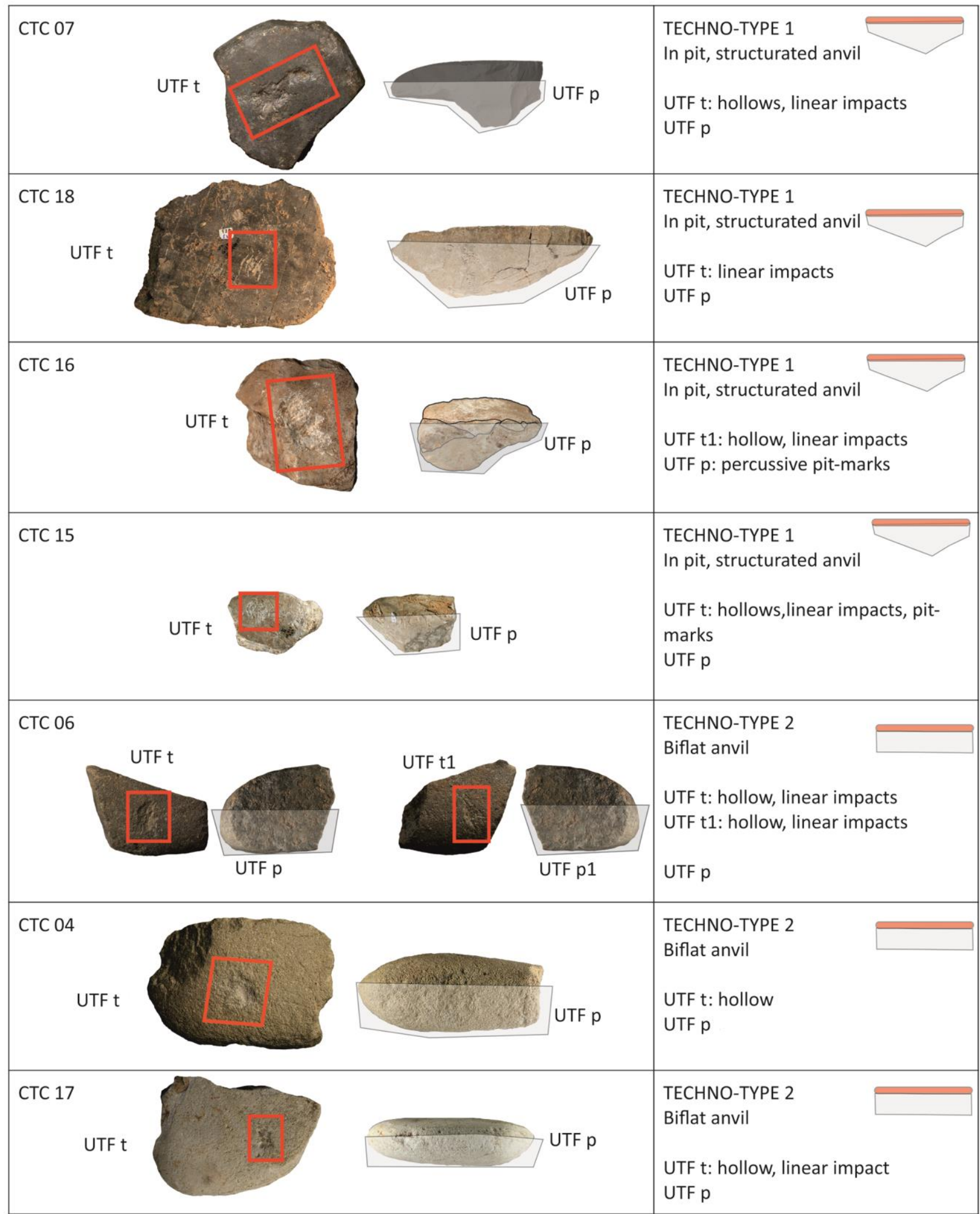

Fig 22: Anvils techno-type and use wear traces 


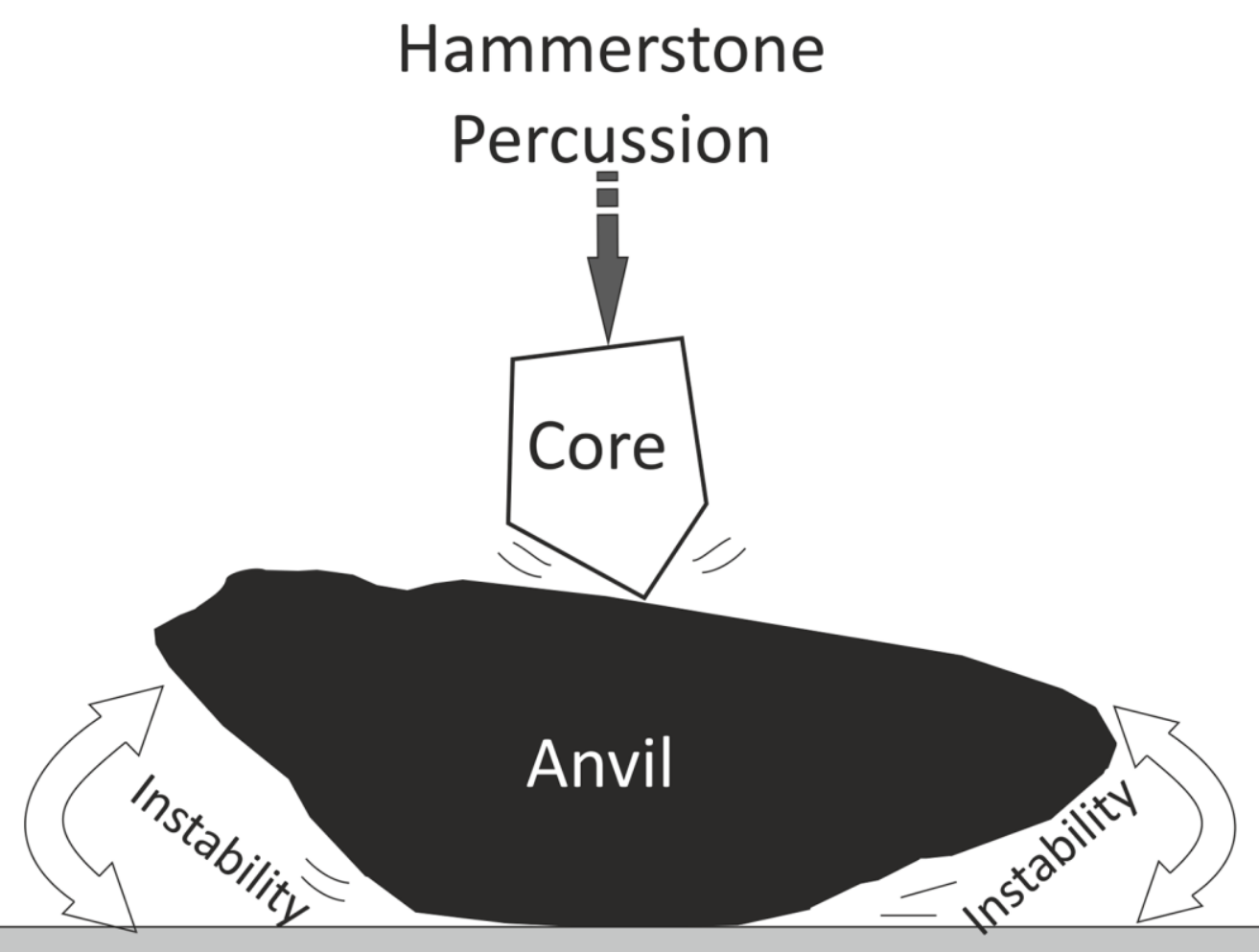

Flat surface

Hammerstone Percussion

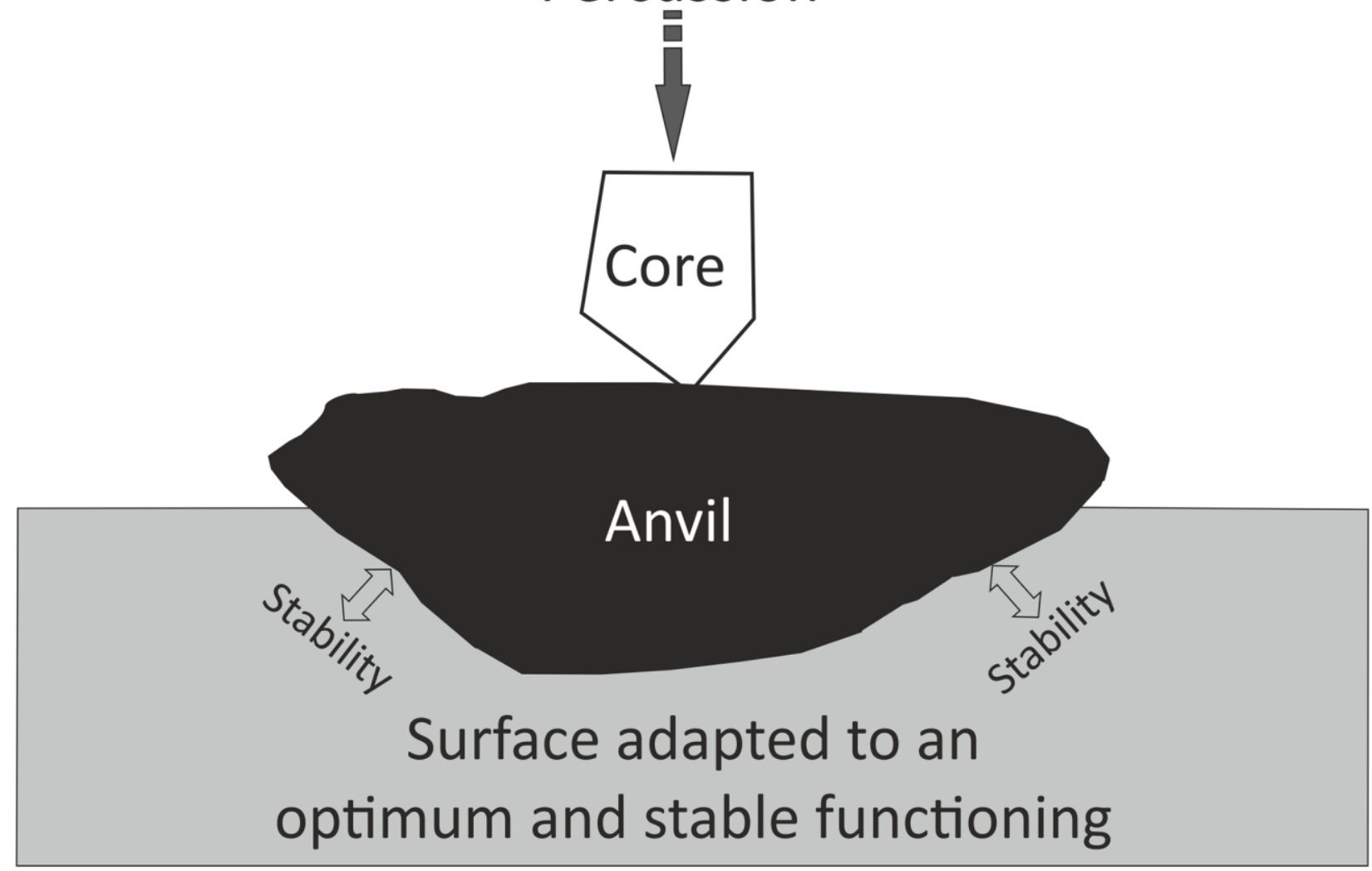


Fig 23 Hypothesize of stabilizing an angular anvil (techno-type 1) 


\section{Hammerstone}

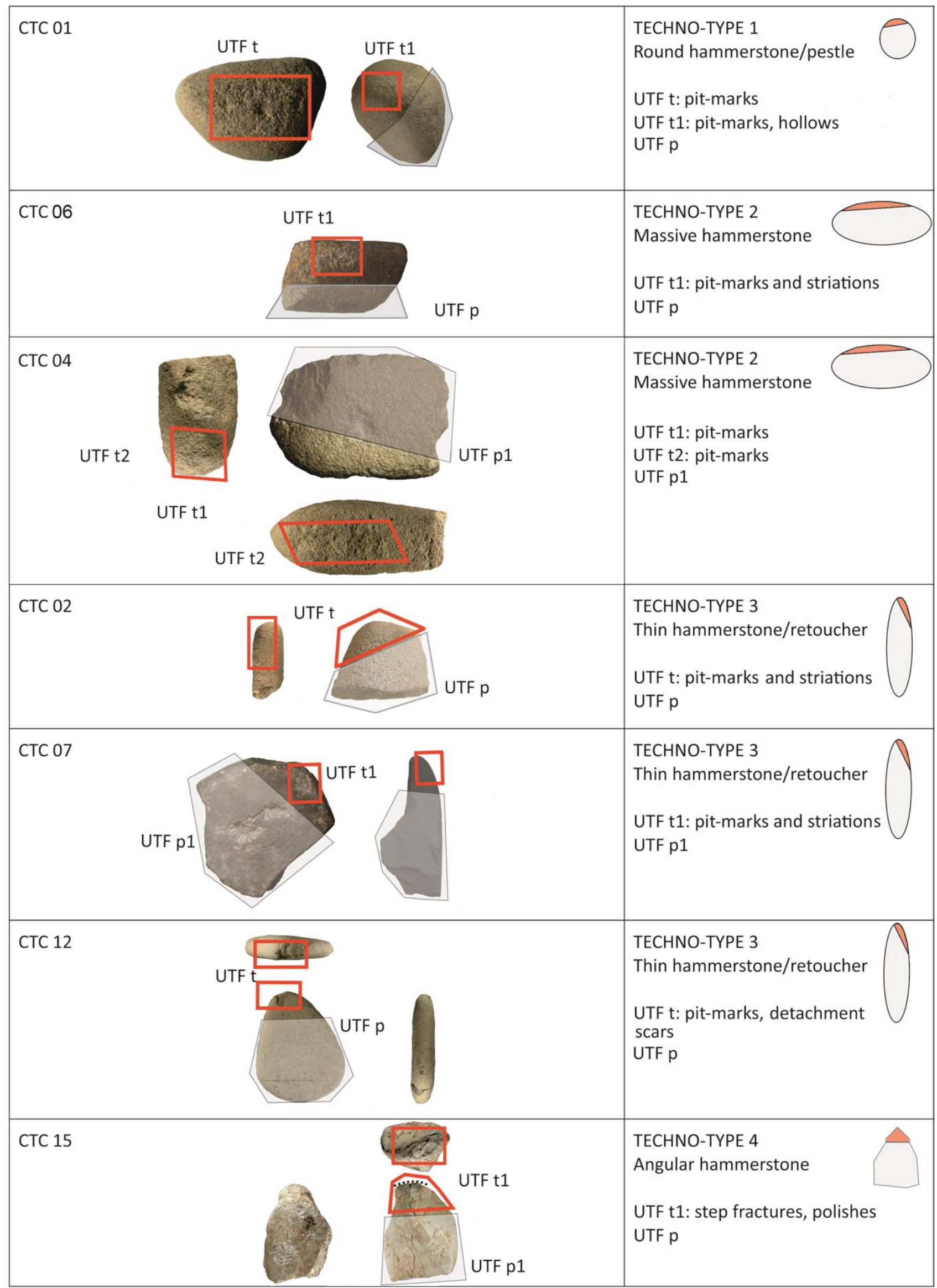

Fig 24 Hammerstone techno-type and use wear traces 


\section{Tool with working edges}

\begin{tabular}{|l|l|}
\hline CTC 16 & $\begin{array}{l}\text { Transversal working edge } \\
\text { UTF t1: edge rounding, } \\
\text { polishes } \\
\text { UTF } \mathrm{p} 1\end{array}$ \\
\hline CTC 18 & UTF $\mathrm{p} 1$ \\
\hline
\end{tabular}

Fig 25 Tool with working edges techno-type and use wear traces 